Florida International University FIU Digital Commons

2-10-2012

\title{
AC/DC Smart Control and Power Sharing of DC Distribution Systems
}

Mohamed A. Elshaer

Florida International University, melsh001@gmail.com

DOI: $10.25148 /$ etd.FI12041108

Follow this and additional works at: https://digitalcommons.fiu.edu/etd

\section{Recommended Citation}

Elshaer, Mohamed A., "AC/DC Smart Control and Power Sharing of DC Distribution Systems" (2012). FIU Electronic Theses and Dissertations. 556.

https://digitalcommons.fiu.edu/etd/556 


\section{FLORIDA INTERNATIONAL UNIVERSITY}

Miami, Florida

AC/DC SMART CONTROL AND POWER SHARING OF DC DISTRIBUTION SYSTEMS

Thesis submitted in partial requirement for the degree of MASTER OF SCIENCE in

ELECTRICAL ENGINEERING

by

Mohamed Anwar Elshaer 
To: Dean Amir Mirmiran

College of Engineering and Computing

This thesis, written by Mohamed Anwar Elshaer, and entitled AC/DC Smart Control and Power Sharing of DC Distribution Systems, having been approved in respect to style and intellectual content, is referred to you for judgment.

We have read this thesis and recommend that it be approved.

\section{Armando Barreto}

Jean H. Andrian

Osama A. Mohammed, Major Professor

Date of Defense: February 10, 2012

The thesis of Mohamed Anwar Elshaer is approved.

Dean Amir Mirmiran
College of Engineering and Computing

Florida International University, 2012 
(C) Copyright 2011 by Mohamed Anwar Elshaer All rights reserved. 


\section{DEDICATION}

I dedicate this thesis to my parents. Without their patience, understanding, support, and most of all love, the completion of this work would not be possible. 


\section{ACKNOWLEDGMENTS}

I feel immense pleasure and privilege in expressing my deep sense of gratitude, indebtedness, and thankfulness toward my advisor, Dr. Osama Mohammed, for his guidance, constant supervision, continuous inspiration, and support throughout the course of my work. His creativity, excellent critical thinking, professionalism, and long years of experience helped me successfully complete my degree. It also helped develop my confidence as a researcher and provided me encouragement to achieve a high quality of research. I also would like to acknowledge the support from the Office of Naval Research during my years of study at FIU.

I would like to express my sincere thanks to my MS thesis committee members, Dr. Armando Barreto and Dr. Jean H. Andrian for providing valuable suggestions, assistance and for serving on the committee.

I also would like to thank the entire Energy System Research Laboratory team for their excellent collaboration and help in completing the research projects. It is my sincere pleasure to be part of the group. 


\author{
ABSTRACT OF THE THESIS \\ AC/DC SMART CONTROL AND POWER SHARING OF DC \\ DISTRIBUTION SYSTEMS \\ by \\ Mohamed Anwar Elshaer \\ Florida International University, 2012 \\ Miami, Florida
}

Professor Osama Mohammed, Major Professor

The purpose of this research is to develop a grid connected DC distribution system to ensure efficient integration of different alternate sources to the power system. An investigation of different $\mathrm{AC}$ and $\mathrm{DC}$ converter topologies and their control is conducted. A new converter topology for sharing DC power was developed to enhance the efficiency and stability of the alternate sources connected to the DC Distribution System. Mathematical model and control system design of the developed converters were included in the thesis.

A novel smart-PID controller for optimal control of DC-DC converter was used as voltage controller in PV systems. This controller maximizes the stable operating range by using genetic algorithm (GA) to tune the PID parameters ultimately at various loading conditions. A fuzzy logic approach was then used to add a factor of intelligence to the controller such that it can move among different values of proportional gain, derivative gain, and integral gain based on the system conditions. This controller allows optimal control of boost converter at any loading condition with no need to retune the parameters or possibility of failure. Moreover, a novel technique to move between the PI and PID 
configurations of the controller such that the minimum overshoot and ripple are achieved. This increases the controller applicability for utilization of PV systems in supplying sensitive loads.

An effective algorithm for optimizing distribution system operation in a smart grid, from cost and system stability points of view, was developed. This algorithm mainly aims to control the power available from different sources so they satisfy the load demand with the least possible cost while giving the highest priority to renewable energy sources. Moreover, a smart battery charger was designed to control the batteries and allow them to discharge only when there is a small load predicted. During the period they become available, they act as a buffer for the predicted large load to increase the stability of the system and reduce voltage dips. 


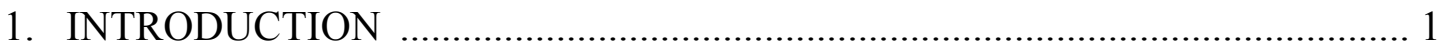

1.1 Project Motivation ........................................................................ 2

1.2 Problem Formulation and Thesis Contributions ................................... 3

2. HIGH-QUALITY INTEGRATION OF SUSTAIBALE ENERGY TO DC

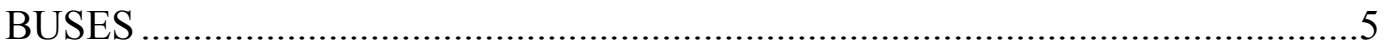

2.1 Introduction .................................................................................... 5

2.2 Conventional Boost Converter ....................................................... 8

2.3 The Developed topology for power sharing ..................................... 10

2.4 Simulation and Experimental Results .............................................. 13

2.4.1 Conventional Boost Converter.............................................. 14

2.4.2 Developed Topology ......................................................... 15

3. SMART CONTROL OF DC-DC BOOST CONVERTER IN PV SYSTEMS .... 19

3.1 Problem Statement ................................................................................ 19

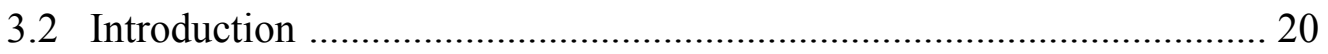

3.3 Characteristics of Solar Panels......................................................... 21

3.4 The Boost Converter ...................................................................... 22

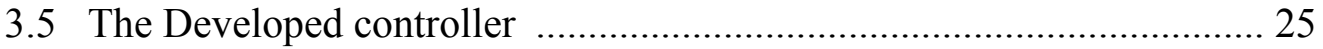

3.5.1 Online PID Gain Tuning for Maximizing the Operating Range.... 26

3.5.2 Fuzzy controller involvement for smart decision making ........... 27

3.5.3 Enhancing Transient and Steady State Response ...................... 32

3.6 Simulation Results ................................................................... 34

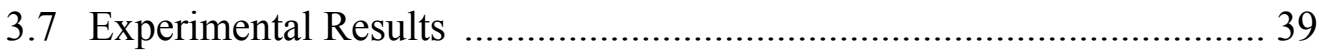

4. ENHANCING LOADING LIMITATIONS IN PV SYSTEMS ...................... 43

4.1 Systems Description ................................................................ 43

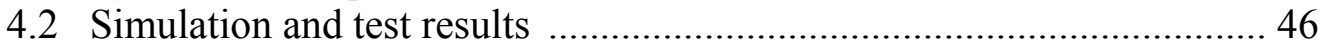

4.2.1 Steady state performance …................................................ 46

4.2.2 Dynamic Performance .......................................................... 48

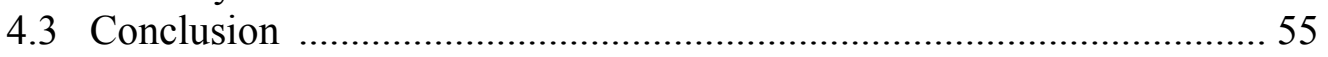

5. BI-DIRECTIONAL POWER TRANSFER CONTROL OF GRID-CONNECTED

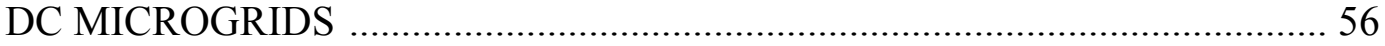

5.1 Connectivity to AC Grid ............................................................. 56

5.2 DC Bus Voltage Regulation .......................................................... 57

5.2.1 Converter Description and Mathematical Modeling ................... 58

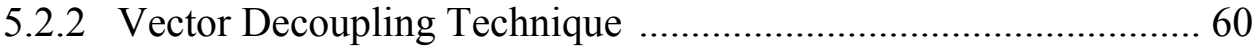

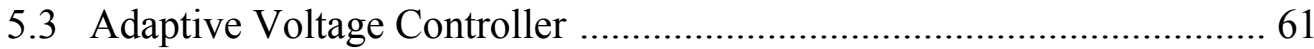

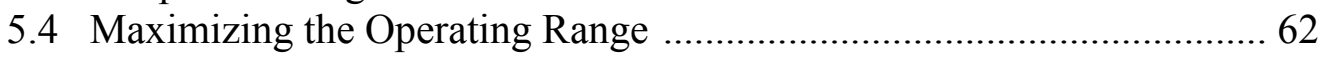




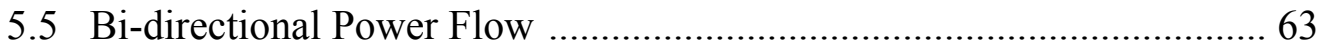

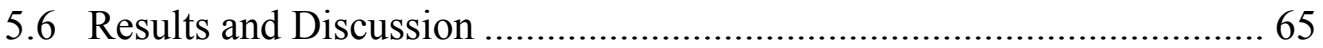

6. SMART DYNAMIC UNIT COMMITMENT SCHEME FOR AC DISTRIBUTION SYSTEMS INVOLVING HYBRID RENEWABLE ENERGY SOURCES ……................................................................................ 71

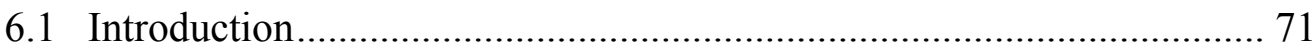

6.2 System and Problem Description ....................................................... 72

6.3 Data Forecasting ………………………………............................. 72

6.3.1 Data Collection ....................................................................... 73

6.3.2 Non-Linear Regression Modeling ……………………………..... 73

6.3.3 Model Evaluation Indices ......................................................... 74

6.3.4 Mathematical Modeling Results ................................................. 75

6.4 Unit Commitment Problem ……………………………………...... 78

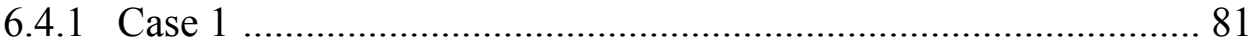

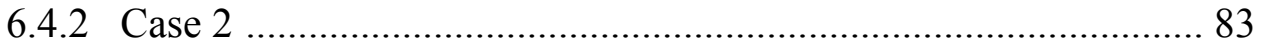

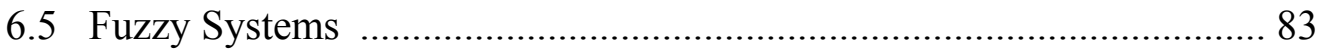

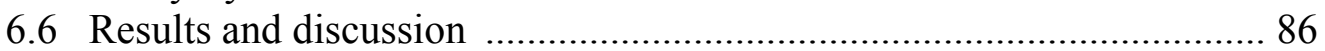

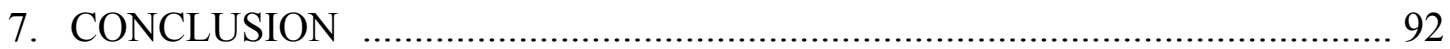

8. RECOMMENDATIONS FOR FUTURE WORK ……………………............... 94

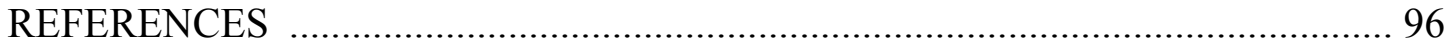

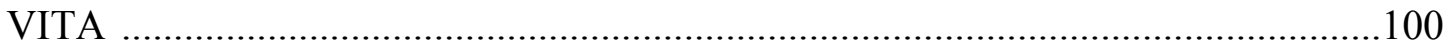




\section{LIST OF TABLES}

TABLE

PAGE

2.4.1. Parameters of different prototype systems used for simulation and

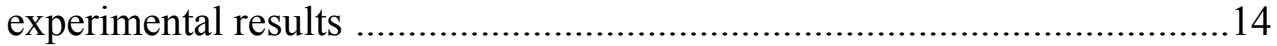

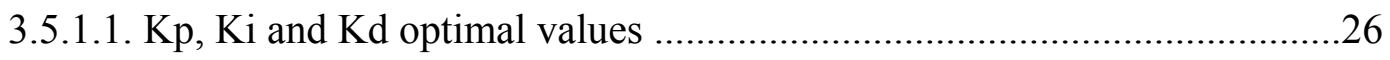

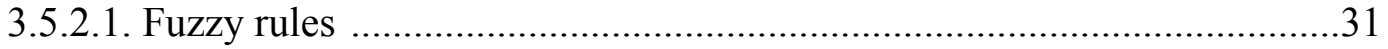

4.1.1. Specifications of PB 175 solar panels .................................................44

5.4.1. Kp, $\mathrm{Ki}$ and $\mathrm{Kd}$ optimal values at different loading conditions ..................63

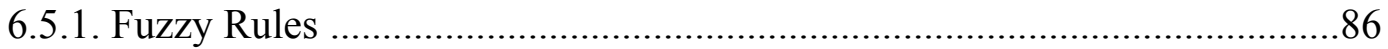




\section{LIST OF FIGURES}

FIGURE

PAGE

2.1.1. The DC ZEDS under study, (Type 1 converter) is the one under study in this paper whereas; (Type 2 converter) can be a conventional controlled DC-DC boost converter

2.2.1. Controlled boost converter for fuel cells integration into a DC ZEDS .8

2.2.2. Circuit configuration during different states of the power electronic switch.

(a) During turn ON state $\left(0>t \geq D T \_s\right)$, (b) During turn OFF state

(DT_s $>\mathrm{t} \geq \mathrm{T} \_\mathrm{s}$ )

2.3.1. The developed topology (Developed Topology 1) for fuel cells integration into a DC ZEDS

2.3.2. The $\mathrm{ON}$ and $\mathrm{OFF}$ states of the DC-DC converter with output LC filter described in section IV. (a) $0>t \geq D T \_s$ and (b) DT_s $>t \geq T \_s$

2.3.3. Block diagram of the controller

2.3.4. Bode plot for the open and closed loop responses for the developed topology

2.4.1. The application of the developed topology for power sharing among different sustainable energy sources connected to a common DC bus

2.4.1.1. Controlled conventional boost converter for fuel cells integration into a DC ZEDS. (a) simulation results, (b) experimental results .15

2.4.2.1. Results for the developed topology discussed in section 2.4. (a) simulation results, (b) experimental results

2.4.2.2. Power sharing response to a step change in the power reference, (a) simulation results, (b) experimental results

2.4.2.3. Power sharing response to a step change in the load, (a) simulation results, (b) experimental results

3.3.1. PV panel circuit model .22

3.3.2. Characteristics of PV panels. (a) V-I c/cs (b) P-I c/cs .23

3.4.1. Boost converter circuit 


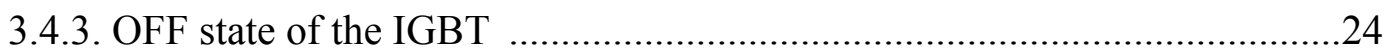

3.5.1. Block diagram of the developed controller .........................................25

3.5.1.1. Load step change voltage response for conventional PI controller .........27

3.5.1.2. Load step change voltage response for developed controller .................27

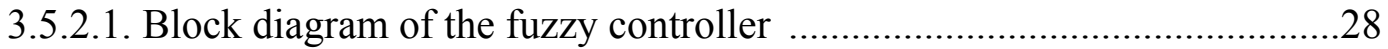

3.5.2.2. (a) Membership functions for the output current. (b) PV voltage ...........29

3.5.2.3. Membership functions for the Kp gain ..............................................29

3.5.2.4. Membership functions for the Ki gain ..................................................

3.5.2.5. Membership functions for the $\mathrm{Kd}$ gain .............................................. 30

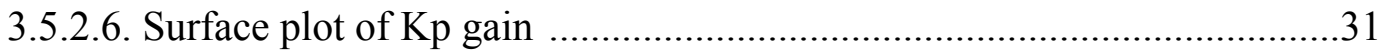

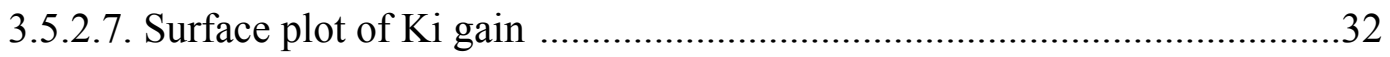

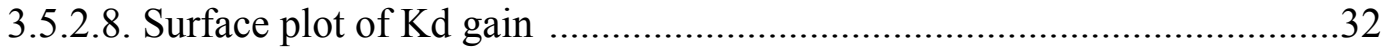

3.5.3.1. Load step change voltage response for conventional PID controller ......33

3.6.1. Smart Controller Load step change, $100 \mathrm{~W}-500 \mathrm{~W}$, response and controller

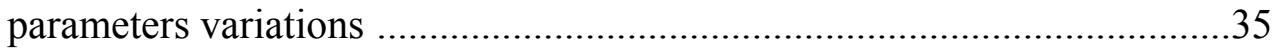

3.6.2. Smart Controller Load step change, $500 \mathrm{~W}-100 \mathrm{~W}$, response and controller

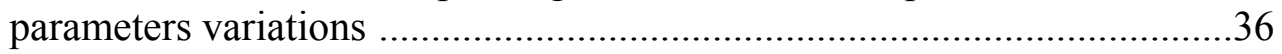

3.6.3. Traditional PI controller Load step change response (100W-500W) .........37

3.6.4. Traditional PI controller Load step change response (500W-100W) .........37

3.7.1. Smart optimal PID controller response for load step change from $220 \mathrm{~W}$ to $1 \mathrm{KW}$

3.7.2. Smart optimal PID controller response for load step change from $1 \mathrm{~kW}$ to $220 \mathrm{~W}$ 
3.7.3. Smart optimal PI controller (Kd is set to zero) response for load step change from $220 \mathrm{~W}$ to $1 \mathrm{KW}$

3.7.4. Smart optimal PI controller (Kd is set to zero) response for load step change from $1 \mathrm{KW}$ to $220 \mathrm{~W}$

3.7.5. PI controller response for load step change from $220 \mathrm{~W}$ to $1 \mathrm{KW}$ .42

3.7.6. Smart optimal PI controller response for load step change from $1 \mathrm{KW}$ to $220 \mathrm{~W}$

4.1.1. The block diagram of the PV system implemented in SIMULINK .43

4.1.2. Power and current characteristics of the PV panels versus voltage .44

4.2.1.1. Variations of $\mathrm{THD}$ versus $\mathrm{V}^{*} \mathrm{dc}$, optimum $\mathrm{V}^{*} \mathrm{dc}=210 \mathrm{~V}$ .47

4.2.1.2. Steady state stability of the system with respect to DC link voltage V ...48

4.2.2.1. Simulation results for voltage and current variations during .50

4.2.2.2. Experimental results for voltage and current variations during switching of a $220 \mathrm{~W}$ load for the fast controller

4.2.2.3. Simulation results for voltage and current variations during switching of a $220 \mathrm{~W}$ load for the slow controller

4.2.2.4. Experimental results for voltage and current variations during switching of a $265 \mathrm{~W}$ load for the slow controller .51

4.2.2.5. Simulation results for voltage and current variations during switching of a $265 \mathrm{~W}$ load for the fast controller

4.2.2.6. Experimental results voltage and current variations during switching of a $265 \mathrm{~W}$ load for the fast controller .53

4.2.2.7. Simulation results for voltage and current variations during switching of a $265 \mathrm{~W}$ load for the slow controller .53

4.2.2.8. Experimental results for Voltage and current variations during switching of a $265 \mathrm{~W}$ load for the slow controller ...................................................54

5.2.1. The three phase controlled rectifier used in the developed system .57

5.2.2.1. Vector decoupling control of the SPWM rectifier used in this paper .61 
5.5.1. The three phase bi-directional AC-DC/DC-AC used in the developed system

5.5.2. Vector decoupling control of the SPWM rectifier used in this paper .65

5.6.1. Controlled Bi-directional response to DC current reference change 1-3 Amps, (a) experimental results, (b) simulation results

5.6.2. Controlled Bi-directional response to DC current reference change 3-1 Amps, (a) (a) experimental results, (b) simulation results

5.6.3. Controlled Bi-directional response to DC current reference change (-3)-(-1) Amps, (a) experimental results, (b) simulation results .67

5.6.4. Controlled Bi-directional response to DC current reference change (-2)-(3) Amps, (a) simulation results, (b) experimental results .68

5.6.5. Controlled Bi-directional response to DC current reference change (3)-(-2) Amps, (a) simulation results, (b) experimental results .68

5.6.6. Harmonic analysis of the input current to the rectifier .68

6.3.4.1. PV actual versus modeling data for one year .77

6.3.4.2. Wind actual versus modeling data for one month .77

6.3.4.3. Load demand actual versus modeling data for one year .78

6.4.1.1. Battery power as a function of its $\mathrm{SOC}$ when there is an excess in power within the Off-peak period

6.4.1.2. Battery power as a function of its SOC when there is an excess in power within the peak period

6.4.1.3. Battery power as a function of its SOC when there is a deficiency in power within the peak period

6.5.1. Membership functions of different variables of the fuzzy controller. (a) and (b) show the membership functions of the two inputs to the Fuzzy system. Whereas, (c) shows the membership functions of the output variable ........85

6.5.2. A flow-chart of the developed energy management algorithm .87 
6.6.1. Case study 1, dynamic operation of the developed algorithm in a one-day period

6.6.2. Case study 2, dynamic operation of the developed algorithm in a one-day period 


\section{CHAPTER 1}

\section{INTRODUCTION}

Sustainable energy sources play a significant role in satisfying current as well as future energy demand. Renewable energy sources installed in homes supply their loads while having the capability of autonomously injecting their excess energy to the main grid. This leads to a reduction in the power flowing in connecting lines. Such a system will increase the grid security and decrease its power losses. However, renewable energy has some disadvantages due to its dependency on nature's conditions. For example, the amount of power that PV and wind provides at a specific time cannot be predicted. It is crucial to inject the maximum power generated by each renewable energy source at any instant of time to either the local loads or back to the main AC grid [32-34]. It is expected that distributed generation (DG) will play vital role in electric power systems. It allows residents and businesses the potential to generate electrical energy to sell surplus power to the grid. The variation of grid voltage due to power flow causes the power quality to decay. Consumers may suffer from the quality of power that is generated and transmitted via the $\mathrm{AC}$ grid. This reduction in power quality occurs due to poor switching operation in the network, voltage dips, interruptions in the grid, transients and network disturbances caused by loads. The use of on-site power generation equipment will provide consumers affordable power at high quality. The power control complexity for a micro-grid is substantially increased in the non-radial system configuration due to the presence of DG units and the "plug and play" feature is the key to insure that the installation of additional DG units will not change the control strategies of DG units already in the micro-grid [3536]. 
On the other hand, DC distribution system was suggested recently as a better method for electrical power delivery. This concept is inspired by the possibility of efficient integration of small distributed generation units which attract the attention of researchers all over the world. Moreover, there are other advantages to having electrical power transmitted through DC distribution systems such as a relatively higher efficiency, absence of reactive power component and the fact that many appliances operate using a DC voltage. The feasibility of using DC distribution systems instead of AC systems is being investigated by many researchers. Research has resulted in a number of publications in which certain aspects of the subject are developed [8-17]. Authors concluded that if DC distribution is used, the total system losses will decrease since the semiconductor losses due to switching in converter are reduced. The use of DC power systems to supply sensitive electronic loads will be studied in this thesis.

\subsection{Project Motivation}

This work investigates the importance of having DC micro-grids or DC distribution systems connected to the AC grid and the connectivity of DC systems to AC ones. Such connectivity should allow voltage regulation on the DC side. Furthermore, it should allow bi-directional power flow between AC and DC sides. Different studies were conducted to solve certain problems. For example, a fully controlled rectifier was used to tie the DC network to the $\mathrm{AC}$ grid while working at unity power factor and within acceptable limits of time harmonic distortion (THD) for the current drawn from the grid. This rectifier has a unidirectional power flow capability from the AC to DC grid and responsible for voltage regulation on the DC side. Hence, at least one of these rectifiers 
have to be connected to the DC system to maintain its voltage at a certain level otherwise, the system is working in island mode, therefore one of the DC-DC converters interfacing sustainable energy sources to the DC system has to take this responsibility. In order to increase the operating range of the rectifier, an adaptive controller that has the ability to dynamically change its parameters corresponding to the condition of the system is implemented. Then, a fully controlled bi-directional AC-DC/DC-AC converter was designed and implemented. This converter has the ability of controlling the amount of power flowing between the $\mathrm{AC}$ and $\mathrm{DC}$ grid in both directions. The amount of power flowing in either direction can be set to an established pre-set value while the controlled rectifier working as a voltage rectifier maintains the power balance as it is free to supply the power needed in the DC grid.

\subsection{Problem Formulation and contributions of the Thesis}

The Research problem is based on the design and control of converters and inverters connected in the system:

1. Evaluation of the performance of the DC-DC boost converter as an interface between alternate sources and DC bus.

2. Different techniques to control the power sharing among different sources and loads in the DC system was developed. In order to achieve that goal, a modified DC-DC converter topology was utilized. These techniques helped reduce the stress on the alternate source being utilized.

3. A smart controller that allows quite a stable wide range of loading is designed and implemented to replace conventional PI and other controllers. Simulation results 
followed by experimental results were taken to validate the concept for steady state and transient cases.

4. A Vector decoupling control sinusoidal pulse width modulation (SPWM) rectifier was designed to connect the $\mathrm{DC}$ system to the $\mathrm{AC}$ grid.

5. A Bi-Directional AC-DC/DC-AC converter was designed. Vector decoupling controlled (SPWM) technique was used to allow the designed converter to control the power transferred between the AC and DC sides in either direction. It also controls the active and reactive power drawn from the grid independently.

6. The controller ensured that the Bi-Directional AC-DC/DC-AC converter controls the active power transfer while operating at unity power factor.

7. Developed mathematical modeling and control system design of the converters were presented.

8. Simulation and experimental results of different topologies were included to validate the developed topologies and conduct a comparative study among different solutions to the problem of integrating variable $\mathrm{DC}$ power into the $\mathrm{AC}$ and DC grids. 


\section{CHAPTER 2}

\section{HIGH-QUALITY INTEGRATION OF SUSTAIBALE ENERGY TO DC BUSES}

\subsection{Introduction}

Integration of sustainable energy sources into electrical power systems is very important to make full use of these sources. Generally, sustainable energy sources are capable of operating in island mode. However, in most of the cases they are gridconnected and their output power is integrated to the main system. Most of these sustainable energy sources yield a variable DC voltage. Moreover, current shipboard and futuristic residential distribution systems have DC buses within them. In this paper, the integration of the output of sustainable energy sources into the DC bus of an electric power system is investigated.

Recently, the idea of applying DC distribution in shipboard power systems has acquired the attention of the U.S Navy as an alternative to conventional AC systems due to the vast increase of the load demand and the need to a high reliability high quality power supply to feed such loads [17]. The Navy investigates a form of DC distribution systems, which is called zonal DC electric distribution system [18-19]. In DC ZEDS, the system is divided into zones of DC and AC loads served through DC-DC and DC-AC converters as shown in

Figure 2.1.1 This system is beneficial from a protection point of view as the DCDC converters connecting different zones to the DC bus and the AC-DC rectifiers connecting the generators isolate both the loads and the generators from the rest of the system. 


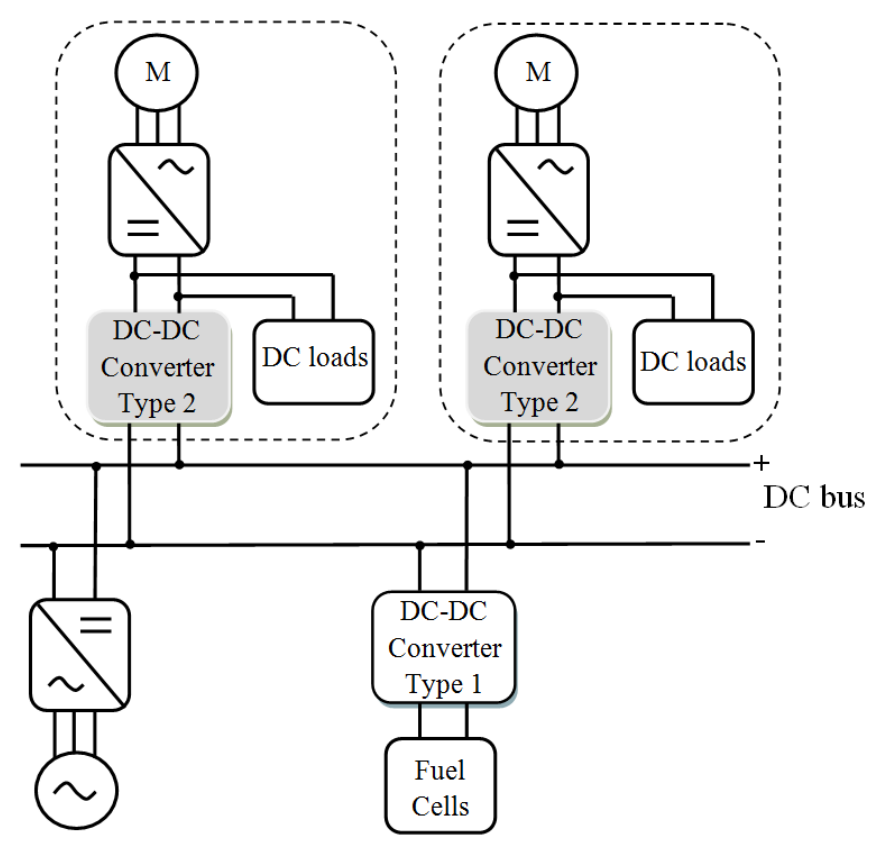

Figure 2.1.1: The DC ZEDS under study, (Type 1 converter) is the one under study in this paper whereas; (Type 2 converter) can be a conventional controlled DC-DC boost converter

On the other hand, great strides was taken toward the utilization of fuel cells on shipboard power systems, as fuel cells after exhaustive research, seem to be the most convenient sustainable energy sources onboard of a ship. There are different types of fuel cells like proton exchange membrane (PEMFC), Alkaline (AFC), Phosphoric Acid (PAFC), Molten Carbonate (MCFC), Solid Oxide (SOFC). Among these types of fuel cells, SOFC is gaining more interest as it has a relatively higher efficiency due to its thermal operating range. For instance, the Office of Naval Research (ONR) has started running a research project called 'Solid Oxide Fuel Cell Tactical Electric Power (TEP)'. This project aims at studying the challenges and opportunities associated with the development of a 10-15 kw SOFC TEP inspired by the fact that fuel cell systems offer high efficiency with extremely low pollution. In a typical DC zonal electric distribution 
system as shown in figure 2.1.1., the DC bus is the most suitable place to connect the output of fuel cells [19]. The DC bus voltage is regulated via a controlled rectifier which is connected to the AC side of the system [20]. The rectifier requires an output filter in order to maintain the bus voltage ripple within acceptable limits. Hence, we can model the two terminals of the DC bus as the terminals of a voltage source [20-22].

However, fuel cells yield variable DC voltage. In stand-alone systems, in order to be able to make full use of the generated power and to feed the loads, a controlled DCDC converter, which is designated as (Type 1 converter) in figure 2.1.1 is used as an interface between the fuel cells and the DC bus. The DC-DC converter controls the buck or boost converter, which receives variable input voltage from the fuel cells and outputs a constant voltage where DC loads, batteries, and machine drives can be connected. These converters have to be controlled in a closed-loop control system because the duty cycle has to change dynamically change to expected simultaneous variations of input voltage and/or output current. To control the output voltage under input voltage and output current variations, a voltage feedback signal is needed. Moreover, if current control or maximum power point tracking (MPPT) is applied, a current feedback signal has to be also considered.

In the grid connected fuel cell systems such as the DC ZEDS which is under study in this paper, DC-DC converters are used as interfaces to fuel cells and are not assigned the task of regulating the output voltage as they are supplying loads which are connected to a DC bus whose voltage has already been regulated. Instead, designers have to find the best way to inject the generated current as continuously and efficiently as possible to the DC bus. 
Type 2 converters as shown in figure 2.1.1 are easier to handle because they receive a constant input voltage to their input terminals. Type 2 converters also yield a constant output voltage. They work as an interface between the DC bus and the inverters in each zone.

DC-DC boost converters are mostly used as an interface between fuel cells and loads connected to them. However, if used in DC ZEDS, this creates a discontinuous output current. Performance of such converters will be investigated. Moreover, two new topologies are developed to enhance the performance of the simple DC-DC boost converter.

\subsection{Conventional Boost Converter}

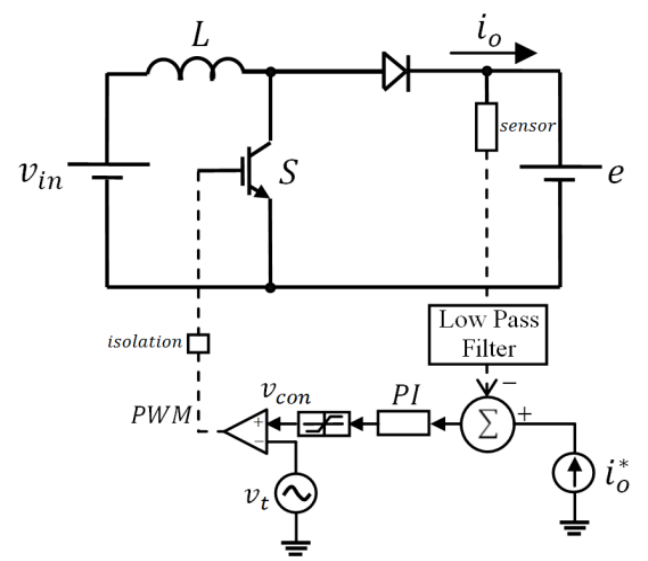

Figure 2.2.1: Controlled boost converter for fuel cells integration into a DC ZEDS

DC-DC boost converter is one of the most popular techniques to regulate the output voltage of the fuel cells and inject their power into the grid. A controlled DC-DC boost converter has the capability of regulating its output voltage even under input voltage or output current variations within a range. This operating range depends on the 
design of the control system and any stability issues related to the system itself and its loading conditions. DC-DC boost converter in its simplest circuit topology has a capacitive interface to the load. This assures a regulated output voltage and current. However, in the case of integrating fuel cells' energy into a DC ZEDS, because the DC bus is already connected to a regulating capacitor, there is no need for the output capacitor of the boost converter. The circuit takes the form shown in figure 2.2.1, and by controlling the duty cycle of the IGBT of the boost converter using the current controller corresponding to a certain reference value; we can control the average of the output current. However, the DC-DC converter in this form cannot support continuous current to the DC bus because it becomes completely disconnected from the DC bus during one of the switching states as shown in figure 2.2.2. Hence, its output current pulsates at the switching frequency.

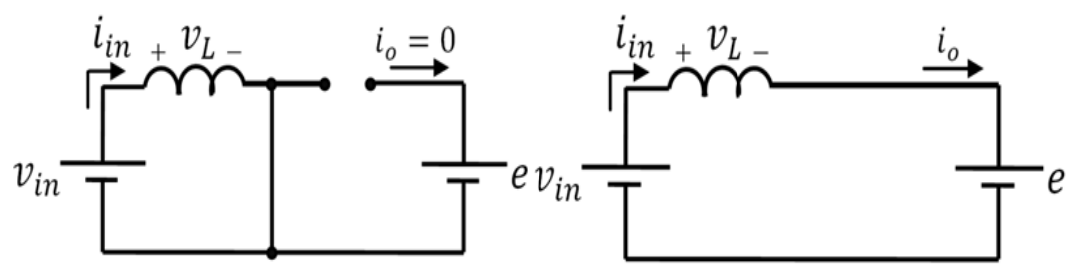

Figure 2.2.2: Circuit configuration during different states of the power electronic switch: (a) During turn ON state ( $0>t \geq D \mathrm{~T}_{\mathrm{s}}$ ), (b) During turn OFF state $\left(\mathrm{DT}_{\mathrm{s}}>t \geq \mathrm{T}_{\mathrm{s}}\right.$ )

If a DC-DC boost converter is used, the controller has to be designed based on the average, not the instantaneous value of the output current. This limits the capability of the fuel cells and the converter as well because the current is drawn instantaneously to satisfy an average output of current which may exceed the current limiting capability of the fuel cells. 


\subsection{Developed Topology for Power Sharing}

In order to solve the problem of discontinuity in the output current when using conventional boost converters, a modified DC-DC boost converter was developed by adding an L-filter to the output side of the converter as shown in Figure 2.3.1. The added inductance assures continuous conduction of the output current. The configuration of the circuit during the ON and OFF states of the switches are shown in Figure 2.3.2.

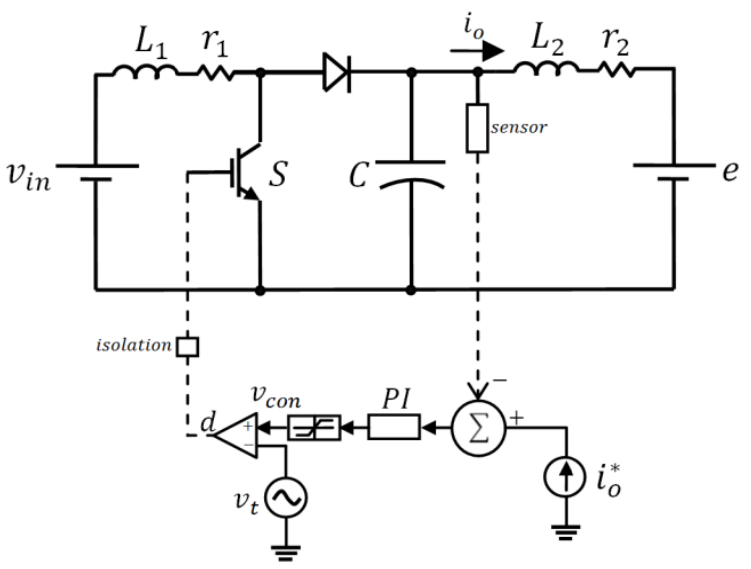

Figure 2.3.1: A developed topology (Developed Topology 1) for fuel cells integration into a DC ZEDS

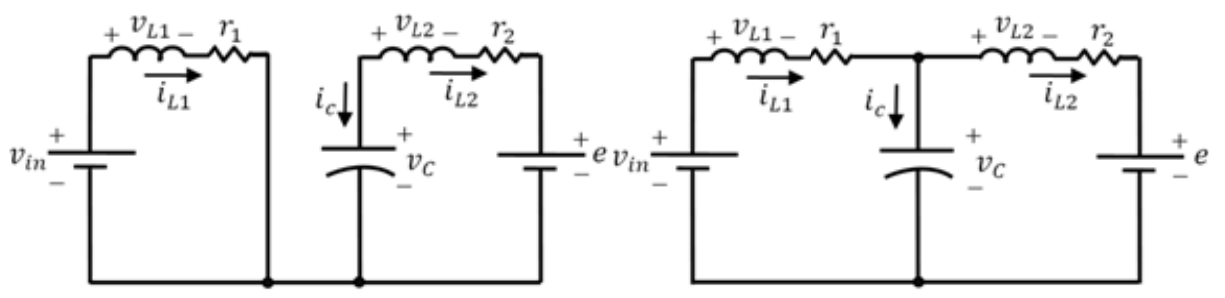

(a)

(b)

Figure 2.3.2: The ON and OFF states of the DC-DC converter with output LC filter described in section IV: (a) $0>t \geq D \mathrm{~T}_{\mathrm{s}}$ and (b) $\mathrm{DT}_{\mathrm{s}}>t \geq \mathrm{T}_{\mathrm{s}}$

The small-signal mathematical model of the developed converter was obtained using a state space averaging technique. 
The state space model during the interval $\left(0>t \geq D T \_s\right)$ is,

$\left[\begin{array}{l}i_{L 1}^{\bullet} \\ i_{L 2}^{\bullet} \\ v_{C}^{\bullet}\end{array}\right]=\left[\begin{array}{ccc}-\frac{r_{1}}{L_{1}} & 0 & -\frac{1}{L_{1}} \\ 0 & -\frac{r_{2}}{L_{2}} & \frac{1}{L_{2}} \\ 0 & -\frac{1}{C} & 0\end{array}\right]\left[\begin{array}{l}i_{L 1} \\ i_{L 2} \\ v_{C}\end{array}\right]+\left[\begin{array}{cc}\frac{1}{L_{1}} & 0 \\ 0 & -\frac{1}{L_{2}} \\ 0 & 0\end{array}\right]\left[\begin{array}{c}v_{i n} \\ e\end{array}\right]$

Whereas, the state space model during the interval $\left(D T_{s}>t \geq T_{s}\right)$ is

$\left[\begin{array}{c}i_{L 1}^{\bullet} \\ i_{L 2}^{\bullet} \\ v_{C}^{\bullet}\end{array}\right]=\left[\begin{array}{ccc}-\frac{r_{1}}{L_{1}} & 0 & 0 \\ 0 & -\frac{r_{2}}{L_{2}} & \frac{1}{L_{2}} \\ \frac{1}{C} & -\frac{1}{C} & 0\end{array}\right]\left[\begin{array}{l}i_{L 1} \\ i_{L 2} \\ v_{C}\end{array}\right]+\left[\begin{array}{cc}\frac{1}{L_{1}} & 0 \\ 0 & -\frac{1}{L_{2}} \\ 0 & 0\end{array}\right]\left[\begin{array}{c}v_{i n} \\ e\end{array}\right]$

$i_{o}=i_{L 2}$

Using the state space averaging technique,

$\left[\begin{array}{c}\left\langle i_{L 1}^{\bullet}\right\rangle \\ \left\langle i_{L 2}^{\bullet}\right\rangle \\ \left\langle V_{C}^{\bullet}\right\rangle\end{array}\right]=\left[\begin{array}{ccc}-\frac{r_{1}}{L_{1}} & 0 & -\frac{d}{L_{1}} \\ 0 & -\frac{r_{2}}{L_{2}} & \frac{1}{L_{2}} \\ \frac{(1-d)}{C} & -\frac{1}{C} & 0\end{array}\right]\left[\begin{array}{c}\left\langle i_{L 1}\right\rangle \\ \left\langle i_{L 2}\right\rangle \\ \left\langle v_{C}\right\rangle\end{array}\right]+\left[\begin{array}{cc}\frac{1}{L_{1}} & 0 \\ 0 & -\frac{1}{L_{2}} \\ 0 & 0\end{array}\right]\left[\begin{array}{c}\left\langle v_{\text {in }}\right\rangle \\ \langle e\rangle\end{array}\right]$

If we consider a small signal perturbation, the large signal state space equations will be,

$\left[\begin{array}{l}0 \\ 0 \\ 0\end{array}\right]=\left[\begin{array}{ccc}-\frac{r_{1}}{L_{1}} & 0 & -\frac{d}{L_{1}} \\ 0 & -\frac{r_{2}}{L_{2}} & \frac{1}{L_{2}} \\ \frac{(1-d)}{C} & -\frac{1}{C} & 0\end{array}\right]\left[\begin{array}{l}\left\langle I_{L 1}\right\rangle \\ \left\langle I_{L 2}\right\rangle \\ \left\langle V_{C}\right\rangle\end{array}\right]+\left[\begin{array}{cc}\frac{1}{L_{1}} & 0 \\ 0 & -\frac{1}{L_{2}} \\ 0 & 0\end{array}\right]\left[\begin{array}{c}\left\langle V_{\text {in }}\right\rangle \\ \langle E\rangle\end{array}\right]$ 
Whereas, the small signal state space set of equations will be,

$$
\left[\begin{array}{c}
\hat{i_{L 1}} \\
\hat{i_{L 2}^{\bullet}} \\
\hat{v_{C}^{\bullet}}
\end{array}\right]=\left[\begin{array}{ccc}
-\frac{r_{1}}{L_{1}} & 0 & -\frac{D}{L_{1}} \\
0 & -\frac{r_{2}}{L_{2}} & \frac{1}{L_{2}} \\
\frac{(1-D)}{C} & -\frac{1}{C} & 0
\end{array}\right]\left[\begin{array}{c}
\hat{i_{L 1}} \\
\hat{i_{L 2}} \\
\hat{v_{C}}
\end{array}\right]+\left[\begin{array}{cc}
\frac{1}{L_{1}} & \frac{v_{C}}{L_{1}} \\
0 & 0 \\
0 & -\frac{I_{L 1}}{C}
\end{array}\right]\left[\begin{array}{c}
\hat{v} \\
\hat{v_{i n}} \\
\hat{d}
\end{array}\right]
$$

Where,

$i_{L 1}=I_{L 1}+\hat{i}_{L 1}, i_{L 2}=I_{L 2}+\hat{i}_{L 2}, v_{c}=V_{c}+\hat{v}_{c}, v_{i n}=V_{\text {in }}+\hat{v}_{\text {in }}, e=E+\hat{e}$ and $d=D+\hat{d}$.

Using the above set of equations (2-6) after transforming them into Laplace domain, we obtain the small signal output current to duty cycle transfer function that will be used for controller design as given by (2-7)

$$
G_{1}(S)=\frac{\hat{i_{L 2}}}{d \hat{(S)}}=\frac{-E\left[r_{1} /(1-D)\right]}{\left(\mathrm{S}+\frac{\mathrm{r}_{2}}{L_{2}}\right)\left[\mathrm{L}_{1} \mathrm{CS}^{2}+\mathrm{S}\left(1 / \mathrm{r}_{1}+\mathrm{Cr}_{1}\right)+1\right]}
$$

This converter topology is also applicable for integrating different sustainable energy sources into a common DC bus, which is one of the most important reasons why researchers have started thinking about replacing the AC distribution system with a DC one.

A block diagram of the controller designed for the developed topology is shown in figure 2.3.3 Moreover, bode plots of the open loop and closed loop response for it is given in figure 2.3.4. 


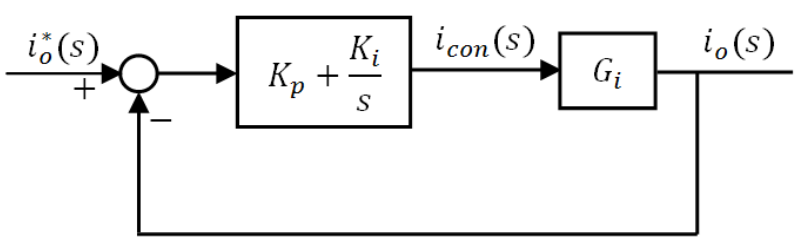

Figure 2.3.3: Block diagram of the controller
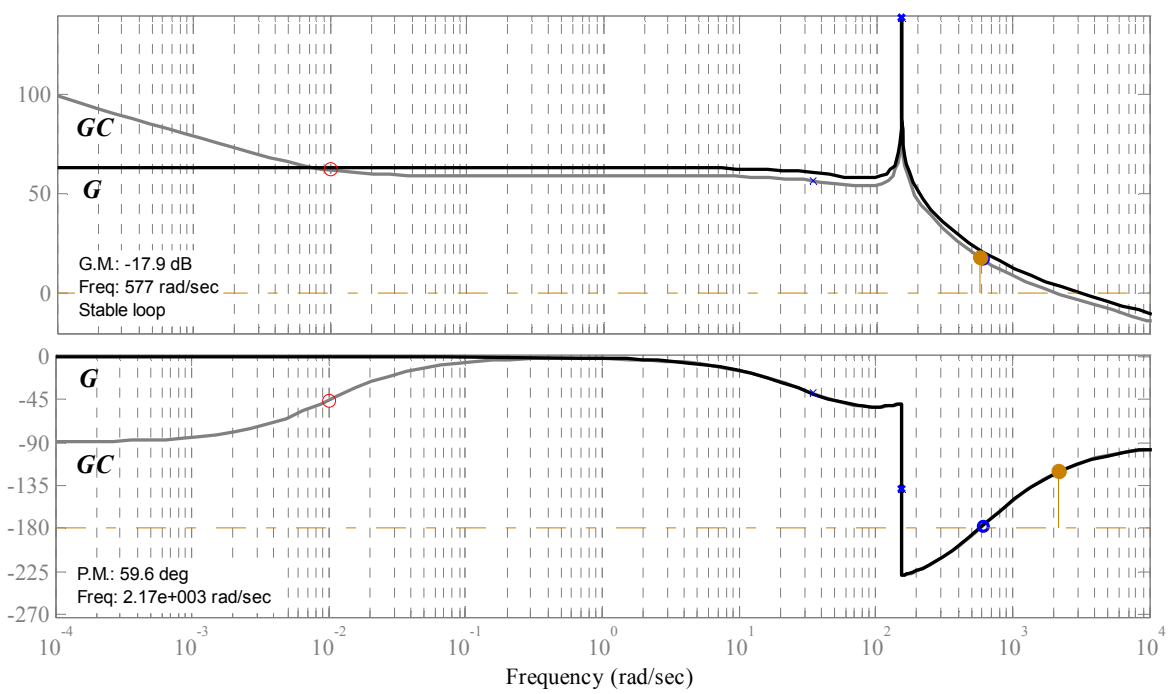

Figure 2.3.4: Bode plot for the open and closed loop responses for the developed topology

\subsection{Simulation and Experimental Results}

A prototype system was designed and implemented in hardware in order to examine the performance of the developed solutions. A scaled down DC voltage of $200 \mathrm{~V}$ is assumed for the DC bus. For control purposes, the digital signal processing board D Space 1104 is used. The switching frequency for all the converters is $5 \mathrm{kHz}$. Parameters designed for each of the three converters under study in this paper are given in Table 2.4.1. 


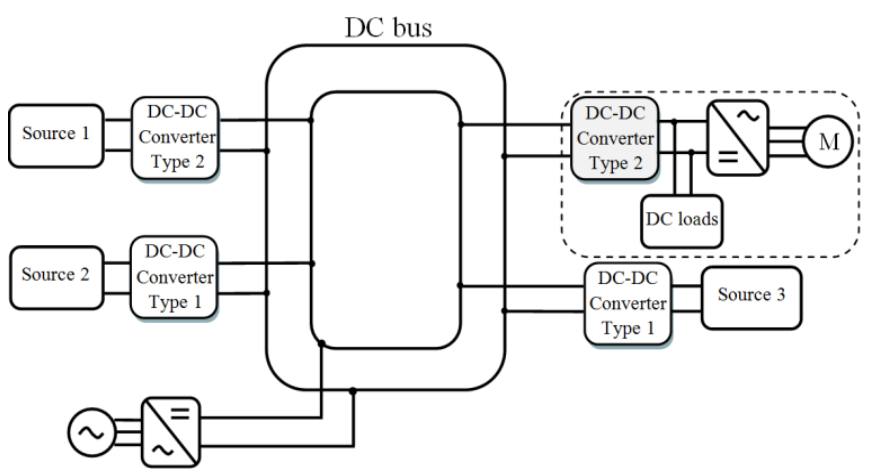

Figure 2.4.1: The application of the developed topology for power sharing among different sustainable energy sources connected to a common DC bus.

Table 2.4.1: Parameters of different prototype systems used for simulation and experimental results.

A. Conventional Boost Converter

\begin{tabular}{cl|l}
\hline \multicolumn{2}{c|}{ Element } & \multicolumn{1}{c}{ Value } \\
\hline$L$ & \multicolumn{1}{c}{$3 \mathrm{mH}$} \\
\hline \multicolumn{2}{c|}{ B. Proposed Topology } \\
\hline \multicolumn{2}{c|}{ Element } & \multicolumn{1}{c}{ Value } \\
\hline$L_{1}$ & & $2.2 \mathrm{mH}$ \\
$L_{2}$ & & $24 \mathrm{mH}$ \\
$r_{1}$ & & $0.06 \mathrm{ohm}$ \\
$r_{2}$ & & $0.84 \mathrm{ohm}$ \\
$C$ & & $4800 \mu \mathrm{f}$ \\
\hline
\end{tabular}

\subsubsection{Conventional Boost Converter}

Results for the conventional boost converter are shown in figure 2.4.1.1. The average value of the output current tracks its reference. However, the instantaneous value of the current is pulsating, which means poor power quality injected to the grid and more stress on the source and the power electronic switch. 

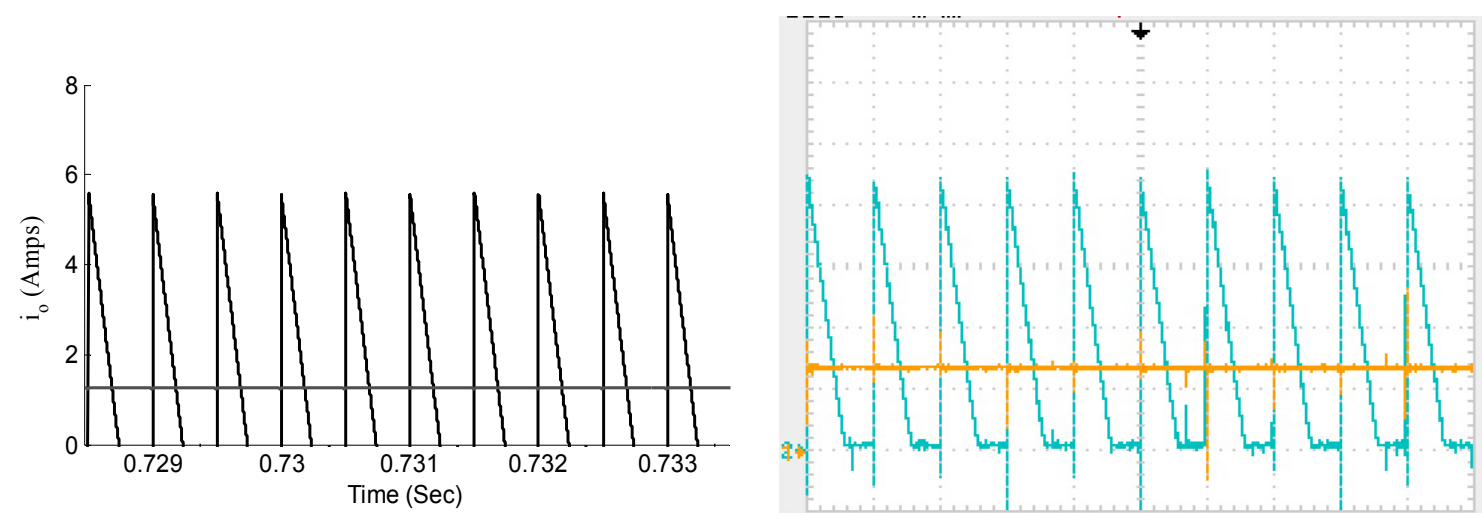

Figure 2.4.1.1: Controlled conventional boost converter for fuel cells integration into a DC ZEDS: (a) simulation results, (b) experimental results.

\subsubsection{Developed Topology}

Results for the developed topology, discussed in section 2.3, are shown in figure 2.4.2.1. The output current is continuous and the ripple is as small as $2 \%$ which means high power quality injected to the grid.

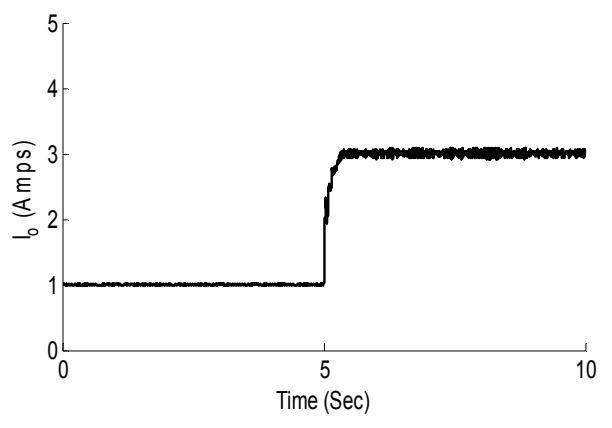

(a)

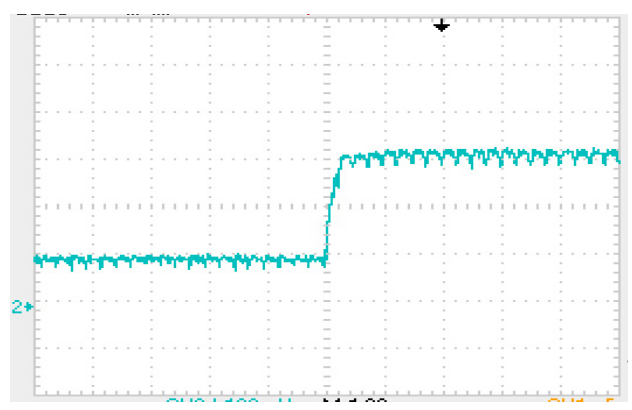

(b)

Figure 2.4.2.1: Results for the developed topology discussed in section 2.4: (a) simulation results, (b) experimental results.

Furthermore, another study was conducted to validate the applicability of this topology to integrate multiple sources into a common DC bus. Hence, the system described in figure 2.4.1 consisting of three DC-DC converters integrating three 
sustainable energy sources into a common DC bus was examined. One of the three DCDC converters is a DC-DC boost converter (Type 2) which is used to regulate the voltage on the DC bus and is free to supply the power required in the network. Hence, it maintains the power balance in the network. However, the other two converters are of the topology (Type 1). They have the ability to control the power injected to the DC network. Results of such system are shown in figure 2.4.2.2 and figure 2.4.2.3 shows the response of output power from each source and the bus voltage. In this case, the input voltages to the $\mathrm{DC} / \mathrm{DC}$ converters connected to bus 1 , bus 2 and bus 3 are $100 \mathrm{~V}, 100 \mathrm{~V}$ and $120 \mathrm{~V}$, respectively. A load of $800 \mathrm{~W}$ is applied to the DC Grid.

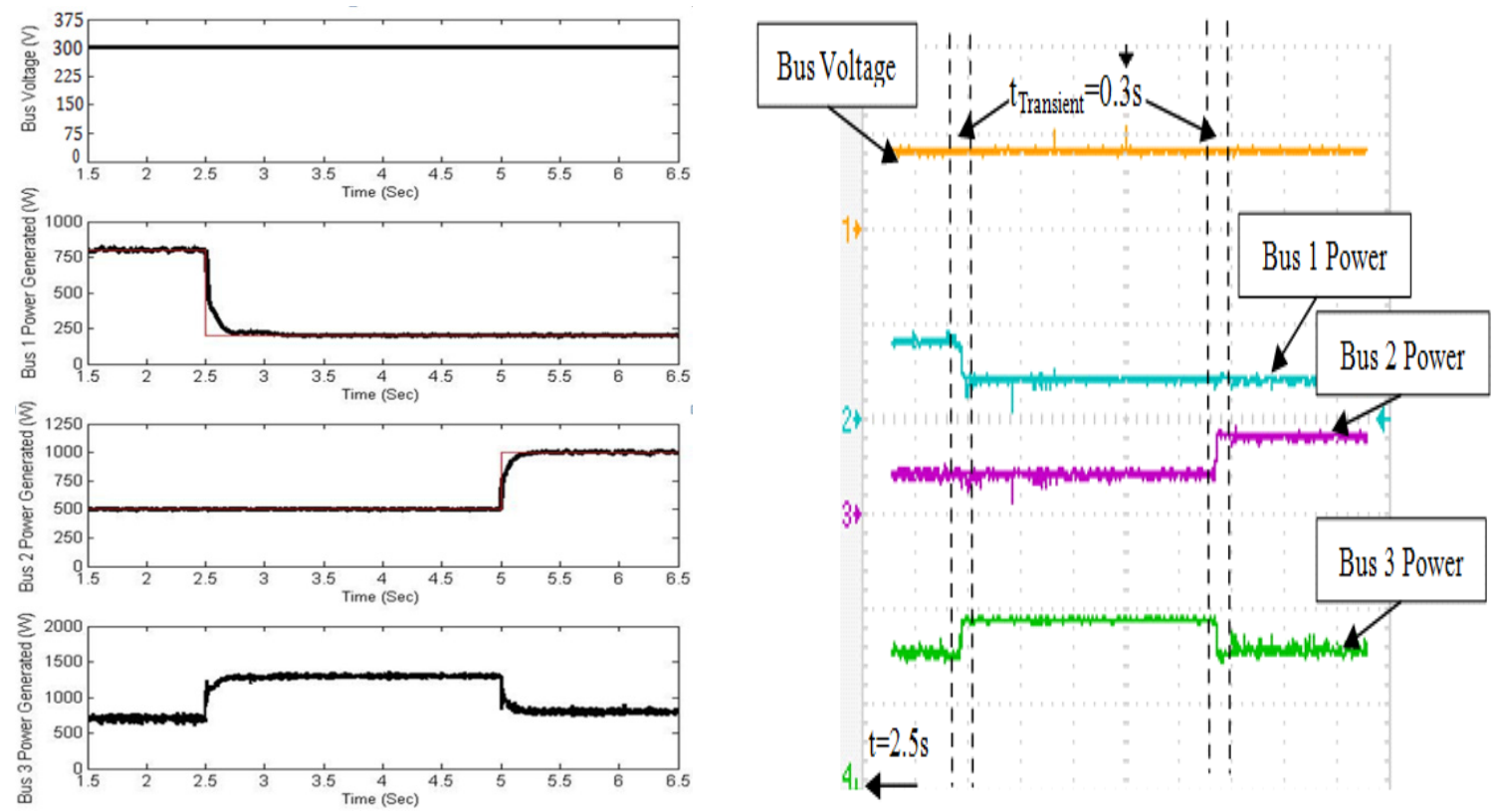

Figure 2.4.2.2: Power sharing response to a step change in the power reference, (a) Simulation results, (b) Experimental results. 
The DC-DC boost converter is responsible for regulating and boosting the voltage to $200 \mathrm{~V}$. The output of the three converters is connected directly to the bus. A transient of less than 0.3 seconds occurs immediately when changing the power reference of any of the buses available in the network. A change from $200 \mathrm{~W}$ to $100 \mathrm{~W}$ is applied to bus 1 and is applied after 5.4 seconds. The controller was able to track the reference in a reasonable time (1 second transient). The bus voltage maintains a maximum of $4 \mathrm{~V}$ ripple during transient operation and $1.5 \mathrm{~V}$ ripple at steady state operation. Bus 3 is free to generate the rest of the load power.
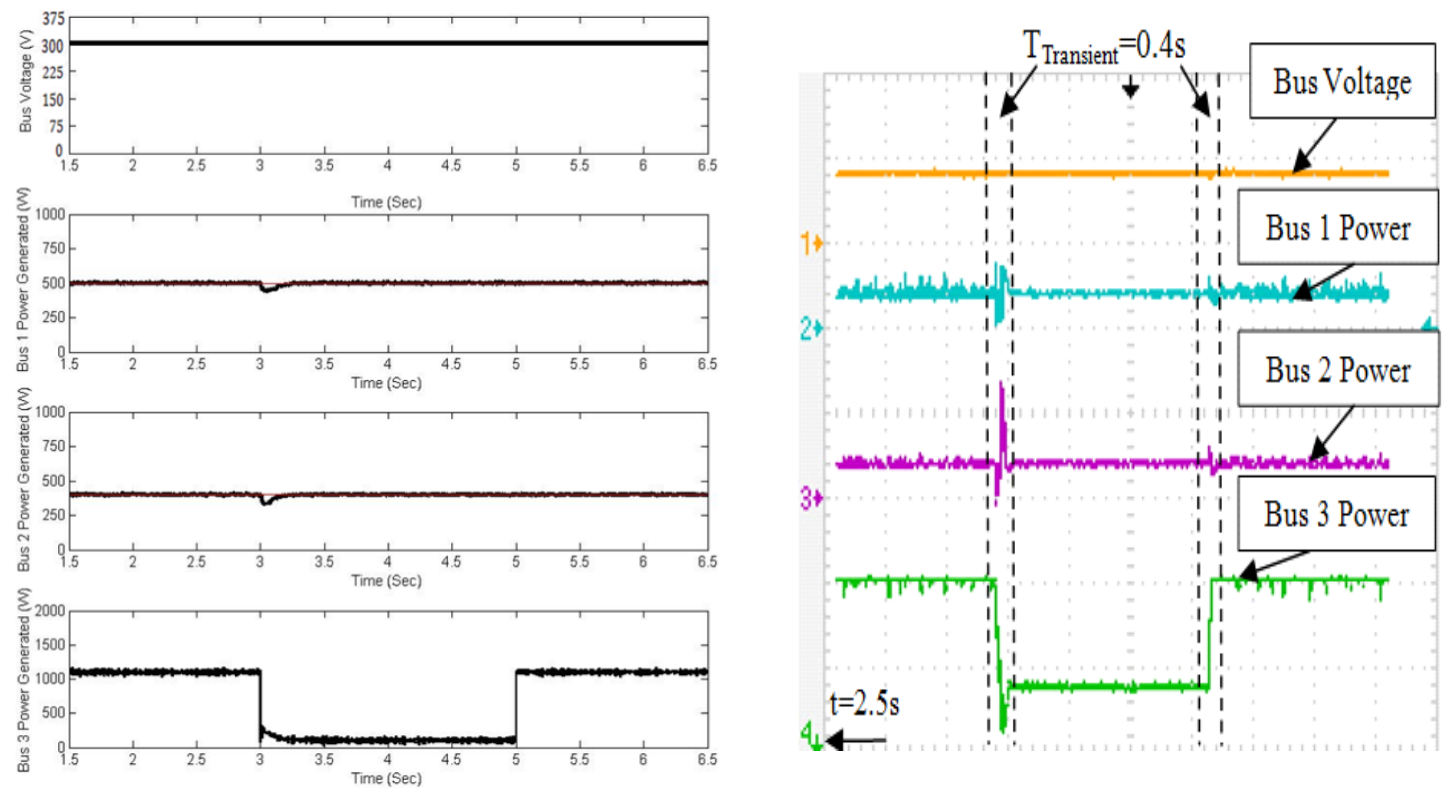

Figure 2.4.2.3: Power sharing response to a step change in the load, (a) Simulation results, (b) Experimental results.

In figure 2.4.2.3, a load step change is applied to the DC grid. The load connected is doubled from $107.143 \mathrm{~W}$ to $214.3 \mathrm{~W}$. The bus voltage was not affected. As can be seen, the controller for each DC-DC converter is able to recover load step changes in a very fast time. There are some distortions during the transient time in the injected power out of 
sources 1 and 2 due to the load increase. However, each bus maintains its referenced power after recovering from the transient interval. Since the converter connected to source 1 is commanded to inject $100 \mathrm{~W}$ only at any time and converter at source 2 is also commanded to inject only $100 \mathrm{~W}$ at any time, converter 3 must inject the remaining 186.7W needed for the load. As seen in figure 10, the system could tolerate the sudden change in the load. 


\section{CHAPTER 3}

\section{SMART CONTROL OF DC-DC BOOST CONVERTER IN PV SYSTEMS}

\subsection{Problem Statement}

Proportional integral derivative (PID) controllers are usually used to control DCDC boost converters in_photovoltaic (PV) systems. However, they have to be tuned based on certain defined operating range using averaged mathematical models. Loading conditions have great effect on PI controllers; PI controllers are subjected to failure under dramatic load changes. This limits the PI controller's operating range. Moreover, transient and steady state response both get affected by changing the operating range.

This chapter presents a novel smart-PID-Fuzzy based controller for optimal control of DC-DC boost converter used as voltage controller in PV systems. This developed controller maximizes the stable operating range by using genetic algorithms (GA) to tune the PID parameters ultimately at various loading conditions. Then, a fuzzy logic approach is used to add a factor of intelligence to the controller such that it can move among different values of proportional gain $(\mathrm{Kp})$, derivative gain $(\mathrm{Kd})$ and integral gain $(\mathrm{Ki})$ based on the system conditions. This controller allows optimal control of boost converter at any loading condition with no need to retune parameters or possibility of failure. Moreover, the chapter presents a novel technique to move between the PI and PID configurations of the controller such that the minimum overshoot and ripple are obtained, which makes the controller very applicable for PV systems supplying sensitive loads. The controlled boost converter is used as an interface between (PV) panels and the loads connected to them. It converts any input voltage within its operating range into a 
constant output voltage that is suitable for load feeding. The developed smart controller adapts the duty cycle of the boost converter based on input voltage and loading conditions which creates constant output voltage. A prototype system will be developed to verify the applicability of the developed controller.

\subsection{Introduction}

Photovoltaic systems have become globally accepted as a practical and feasible tool to generated power. Researcher's efforts for facilitating PV systems utilization and their integration to currently available systems was inspired by the national goal of having renewable and clean energy sources. Those research efforts have successfully solved many of the problems that are attached to PV systems [19]. However, one of the major problems of $\mathrm{PV}$ systems is that the output voltage of $\mathrm{PV}$ panels is highly dependent on solar irradiance and ambient temperature. Hence, loads cannot be directly connected to the output of PV panels.

A DC-DC converter is required to operate as an interface between PV panels and loads [20]. The DC-DC boost converter fixes the output voltage of the PV system. It receives variable input voltage, which is the output of PV panels, and yields constant output voltage across its output capacitors where the loads can be connected. Normally, a DC-DC boost converter operates at a certain duty cycle. In this case, the output voltage corresponds to that duty cycle. If the input voltage is changed while the duty cycle is kept constant, the output voltage will vary. However, in the controlled boost converter utilized in this research, the duty cycle is controlled based on the input voltage and loading 
conditions such that the output voltage is constant. Duty cycle is varied using a pulse width modulation (PWM) technique.

PID controllers are commonly used as controllers for boost converters in PV systems. However, these controllers have to be tuned according to certain operating range and loading conditions. This limits the operating range of the controller. In this paper, the operating range of the controller is maximized by tuning the PID controller parameters; $\mathrm{Kp}, \mathrm{Kd}$ and $\mathrm{Ki}$ at different operating points using genetic algorithms. A fuzzy controller [21-22] is then used to set the optimal values of the controller parameters based on the measured output current. The controller will be utilized in this paper to output a proper modulation index for pulse width modulation.

\subsection{Characteristics of Solar Panels}

Solar panels consist of different solar cells connected in series and/or are parallel in order to achieve desired voltage and current levels. Solar panels consist of semiconductor materials that have the ability to convert solar irradiation into DC current. This is called the PV effect. The characteristic equation of solar arrays is given by (3-1) [22],

$$
I=I_{L G}-I_{O S}\left\{\exp \left[\frac{q}{A K T}\left(V+I R_{S}\right)\right]-1\right\}-\frac{V+I R_{S}}{R_{s h}}
$$

Where:

$$
\begin{array}{ll}
I_{L G} & \text { Light generated current } \\
I_{O S} & \text { Reverse saturation current } \\
Q & \text { Electronic charge } \\
A & \text { Dimensionless factor }
\end{array}
$$




$$
\begin{array}{ll}
K & \text { Boltzmann's constant } \\
R_{S} & \text { Series resistance of the cell } \\
R_{s h} & \text { Shunt resistance of the cell }
\end{array}
$$

The equivalent circuit of the PV panel is given in figure 3.3.1.

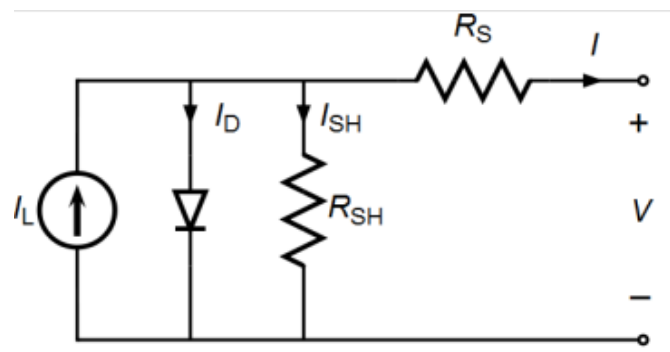

Figure 3.3.1: PV panel circuit model

Inspecting the characteristic equation of PV panels given in (3-1), we can see that the relation between output voltage and current of PV panels is not linear. Therefore, output voltage of PV panels is dependent on the amount of power drawn out of them as shown in Fig. 3.3.2. Moreover, the output voltage of PV panels is dependent on solar irradiation and ambient temperature, which are naturally variable. However, a constant voltage level is needed for connecting loads to PV panels which is imperative for the interface between PV panels and loads similar to the developed boost converter.

\subsection{The Boost Converter}

The boost converter is a DC-DC converter that steps up its input voltage based on the formula given in (3-2)

$$
V_{\text {out }}=\frac{1}{1-D} V_{\text {in }}
$$

Where $\mathrm{V}_{\text {out }}$ is the output voltage of the boost converter, $\mathrm{V}_{\text {in }}$ is the input voltage and $\mathrm{D}$ is the duty cycle which is the ratio between the time ON of the IGBT and the Period of the 
switching frequency. The circuit diagram of the boost converter is shown in figure 3.4.1. It consists of an inductor, an IGBT switch, a fast switching diode and a capacitor. The configurations of the boost converter circuit during switching ON and OFF intervals are shown in figure 3.4.2 and figure 3.4.3, respectively. When the IGBT is switched ON ( $\left.0 \leq \mathrm{t}>\mathrm{t}_{\text {on }}\right)$, the inductor is directly connected to the input voltage source. In this case, the inductor current rises therefore charging it and the inductor is storing energy while the diode is reverse biased and disconnects the load $(\mathrm{R})$ and output capacitor $(\mathrm{C})$ from the voltage source. During this interval, the pre-charged capacitor assures constant voltage across the load terminals.
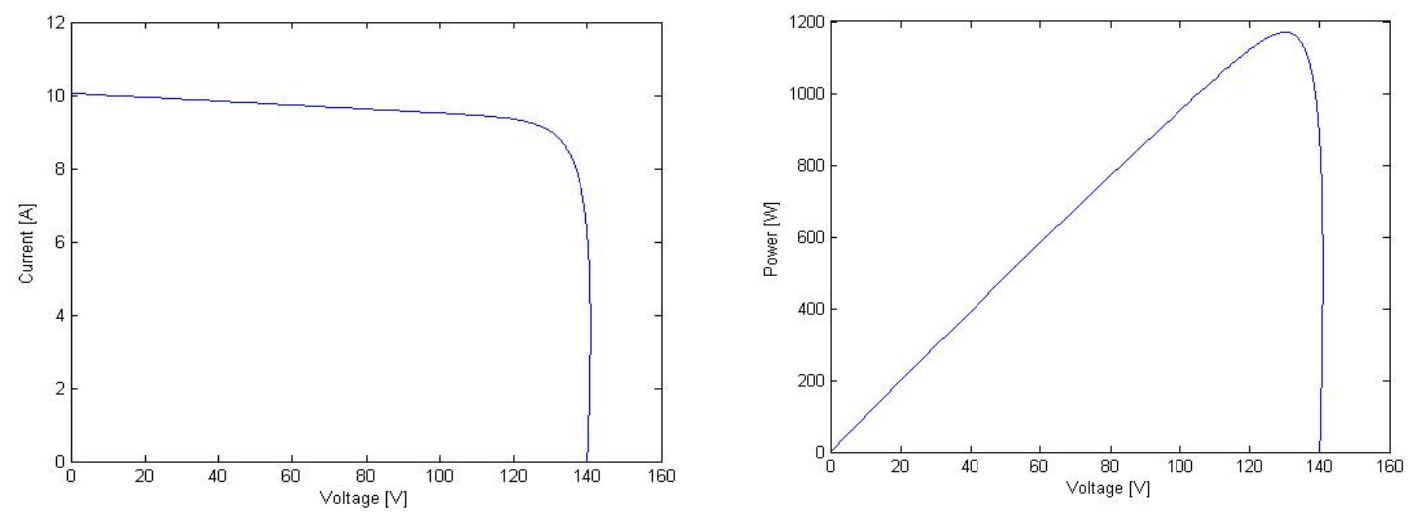

Figure 3.3.2: Characteristics of PV panels: (a) V-I c/cs (b) P-I c/cs

When the IGBT is switched OFF ( $\mathrm{t}_{\text {on }} \leq \mathrm{t}>\mathrm{T}_{\mathrm{s}}$ ) where $\underline{\mathrm{Ts}}$ is the switching period, the diode is forward biased and both the source and the charged inductor are connected to the load. The inductor releases the energy stored in it. This energy is then transferred to the load in the form of voltage which adds to the source voltage. Hence, the converter boosts the input voltage. 


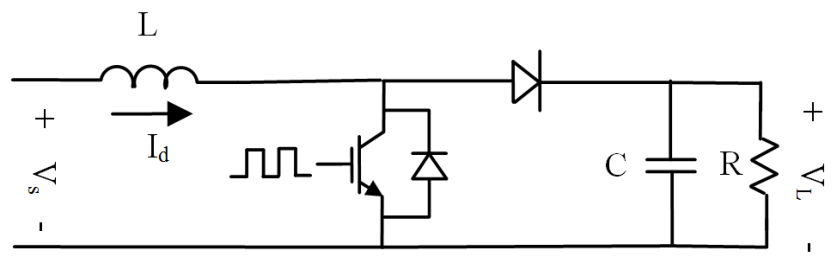

Figure 3.4.1: Boost converter circuit

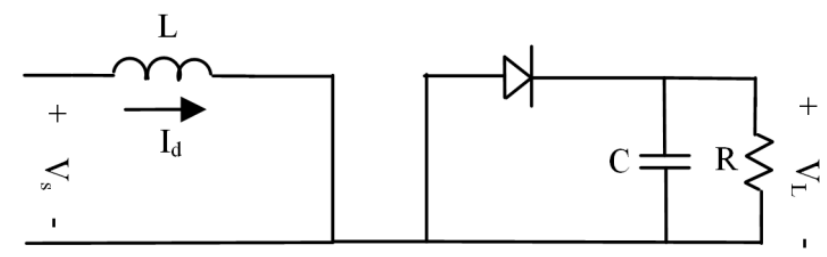

Figure 3.4.2: ON state of the IGBT

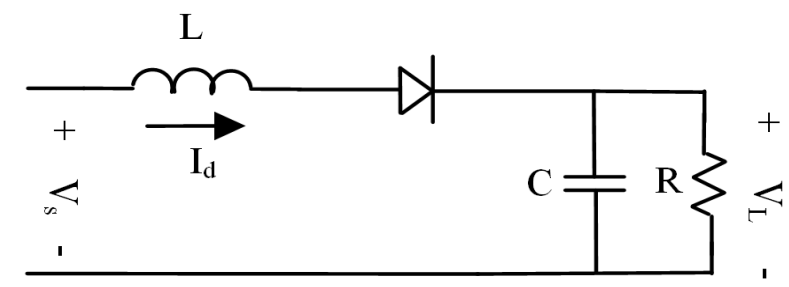

Figure 3.4.3: OFF state of the IGBT

The boost is designed to operate in the continuous conduction modes (CCM) which means that the inductor current is always higher than zero. The inductance value is designed to be higher than the minimum inductance required for operation in CCM given by $(3-3)[23]$

$$
L_{\min }=\frac{(1-D)^{2} D R_{L}}{2 F_{S}}
$$

Where $\mathrm{L}_{\min }$ is the minimum inductance, $\mathrm{D}$ is the duty cycle, $\mathrm{RL}$ is load resistance, and fs is the switching frequency of the IGBT. 
The capacitance is designed such that the output voltage ripple is within the desired boundary. The minimum capacitance required for certain output voltage ripple is given by (3-4)

The duty cycle governs how much boosting of the input voltage will be achieved during boost converter operation. In other words, by controlling the duty cycle we can output constant output voltage even in the case of input voltage or loading variation. A Fuzzy-based controller that adapts the duty cycle based on the input voltage and loading conditions is used to regulate the output voltage.

$C_{\min }=\frac{D}{R F_{S} V_{r}}$

Where, $\mathrm{D}$ is duty cycle, $\mathrm{R}$ is load resistance, $\mathrm{F}_{\mathrm{s}}$ is switching frequency and $\mathrm{V}_{\mathrm{r}}$ is voltage ripple.

\subsection{The Developed controller}

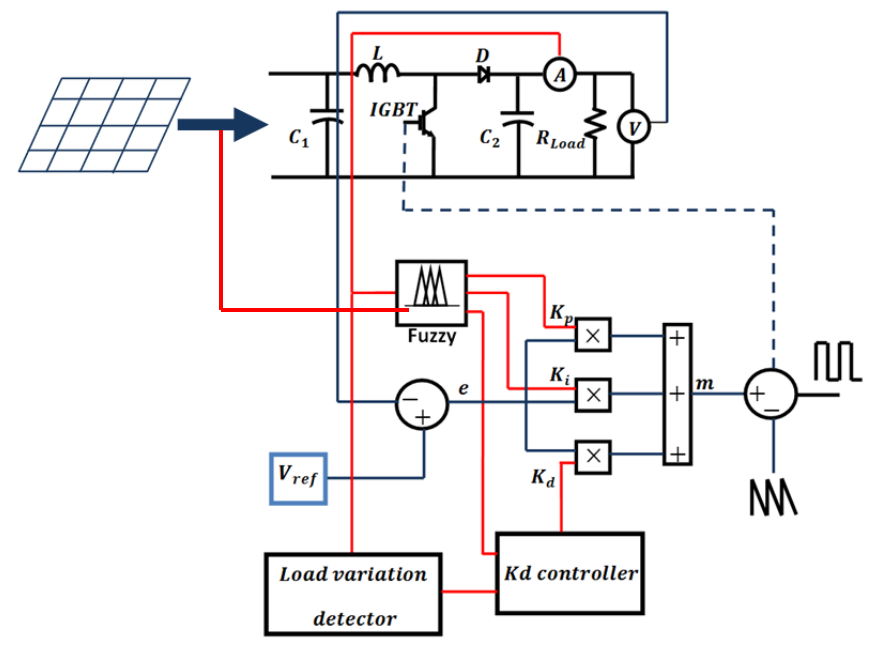

Figure 3.5.1: Block diagram of the developed controller 


\subsubsection{Online PID Gain Tuning for Maximizing the Operating Range}

In order to maximize the operating range of the control system and make the controller capable of handling wide range of output currents, the genetic algorithm [23] is used to tune the parameters of the PID controller. The optimization problem aims at minimizing rise time, settling time, ripple and steady state error of the output voltage of the boost converter corresponding to step changes in input voltage and load. The optimization process yields values of $\mathrm{Kp}, \mathrm{Ki}, \mathrm{Kd}$ that are optimal for different output current ranges and input voltage ranges. Results of the tuning process at different loading conditions at a fixed voltage range are given in Table 3.5.1.1.

\begin{tabular}{|c|c|c|c|}
\hline Current range & Kp & Ki & Kd \\
\hline $0.00-0.80$ & 0.00200 & 0.2000 & 0.000000 \\
\hline $0.80-1.36$ & 0.00940 & 0.6216 & $1.1765 \mathrm{e}-4$ \\
\hline $1.36-1.76$ & 0.00830 & 0.6216 & $1.1913 \mathrm{e}-4$ \\
\hline $1.76-2.24$ & 0.00320 & 0.6214 & $7.0000 \mathrm{e}-4$ \\
\hline $2.24-3.00$ & 0.00270 & 0.5300 & $2.7420 \mathrm{e}-5$ \\
\hline $3.00-5.0$ & 0.00128 & 0.4042 & $1.4527 e-4$ \\
\hline
\end{tabular}

Figure 3.5.1.1 and figure 3.5.1.2 show the response of the PID controller to a step change in the loading condition using two different techniques; firstly in figure 3.5.1.1 when the PID controller has the same parameters values before and after the change in loading condition. Secondly, Figure 3.5.1.2 shows the response for the controller when the parameters vary corresponding to Table 3.5.1.1 such that a matching set of $(\mathrm{Kp}, \mathrm{Ki}$ and $\mathrm{Kd}$ ) constants are used after the step change is applied. We can see that the response in figure 3.5.1.2 is better in terms of much less overshoot of $12.5 \%$ and less ripple. 


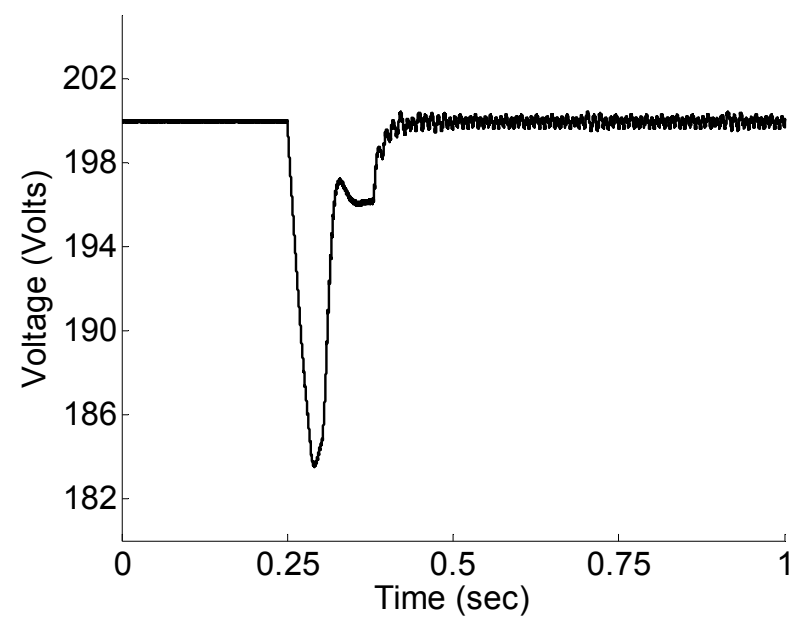

Figure 3.5.1.1: Load step change voltage response for conventional PI controller

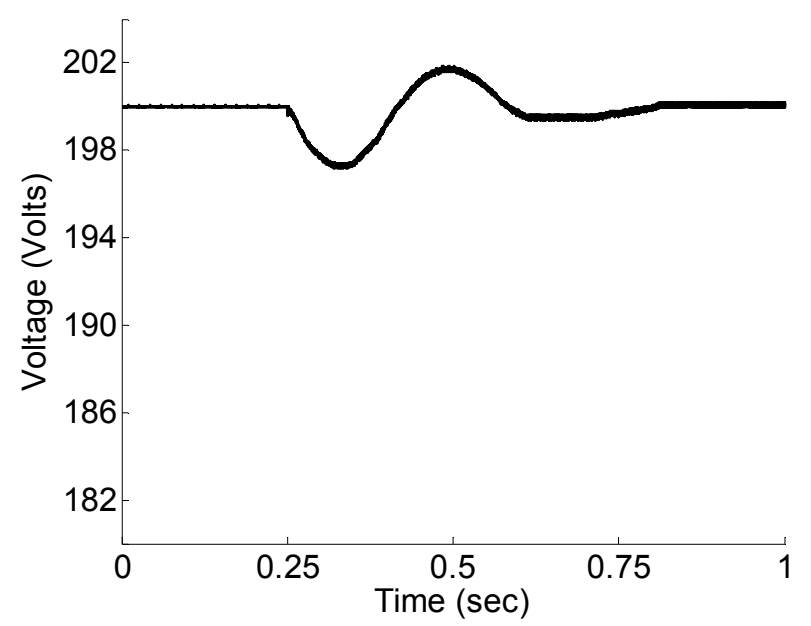

Figure 3.5.1.2: Load step change voltage response for developed controller

\subsubsection{Fuzzy controller involvement for smart decision making}

Fuzzy control is a powerful control method that can be applied to different systems. It is based on the experience of the user about the system behavior rather than modeling the system under control mathematically such as in the linear control theory. This makes fuzzy control a powerful control technique especially with non-linear systems which are more difficult to derive an accurate approximated mathematical model of the 
system and expect its behavior. Fuzzy control is a rule-based control technique that is approached by linguistic fuzzy rules, which describe the output desired out of the system under different operating conditions. Fuzzy rules are in the form of if and then rules, therefore the proficient should be designed in such a manner that expected conditions the system will endure are covered.

Designing a fuzzy logic controller is achieved through three basic steps; fuzzification, inference mechanism, and defuzzification as shown in figure 3.5.2.1 The Mamdani type fuzzy system was used.

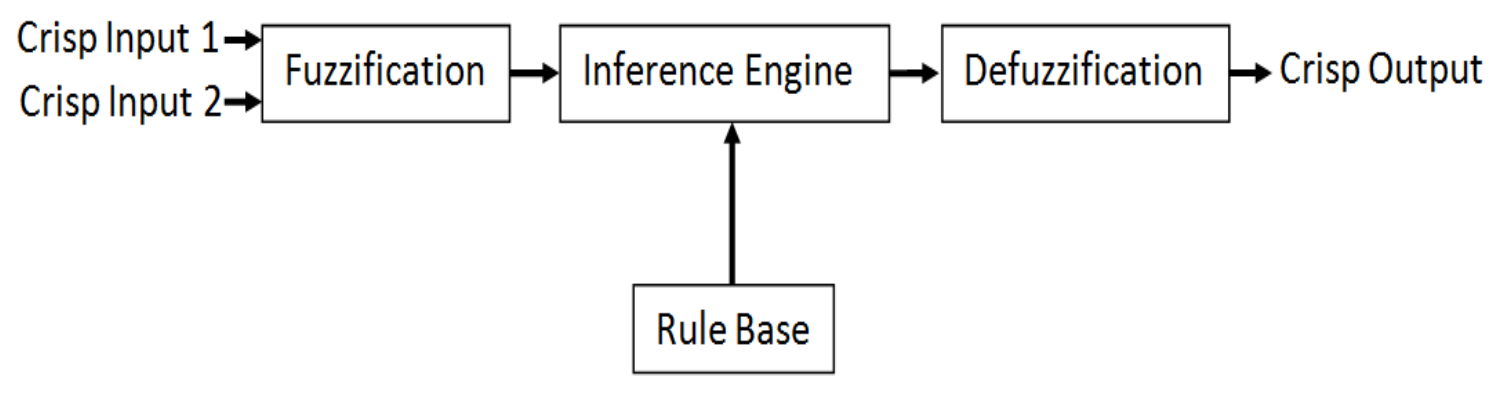

Figure 3.5.2.1: Block diagram of the fuzzy controller

In fuzzification, the output current which is the input to the control system is mapped into a certain linguistic value. Six fuzzy subsets were used. The membership functions are numbered from 1 to 6 . Number 1 represents the smallest current and number 6 represents the largest current. The membership functions for the input variable are shown in figure 3.5.2.2. These membership functions are used to map the input variables, which is the output current and the PV voltage in the fuzzy set. Operation of the membership functions on the input variable yields the extent to which that variable is a member of a particular rule. The process of converting control variables into linguistics rules is called fuzzification. 
The fuzzy controller has three outputs which are $\mathrm{Kp}, \mathrm{Ki}$ and $\mathrm{Kd}$. Each is fuzzified into membership function and mapped into a certain linguistic values. In case for the $\mathrm{Kp}$, it is divided into 6 membership functions named 3t15, 0t0.8, 2.24t3, 2.24t3, 1.36t1.76 and 0.8t1.36. These numbers are named to indicate the range of current of which each membership function is tuned for. The membership functions for the Kp gains are shown in figure 3.5.2.3. Same thing is done for $\mathrm{Ki}$ and $\mathrm{Kd}$. Figure 3.5.2.4 and figure 3.5.2.5 show the Ki gain membership function and the kd membership function respectively.

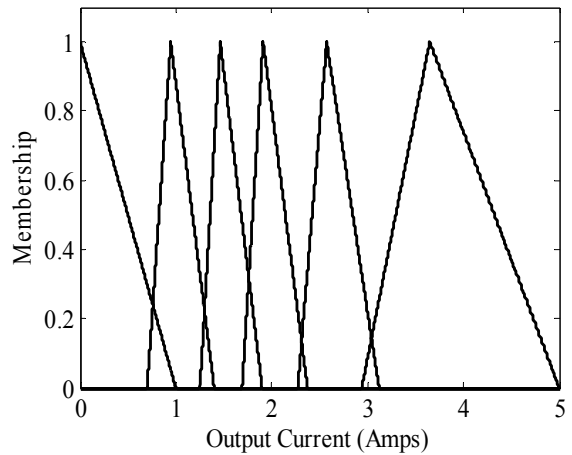

(a)

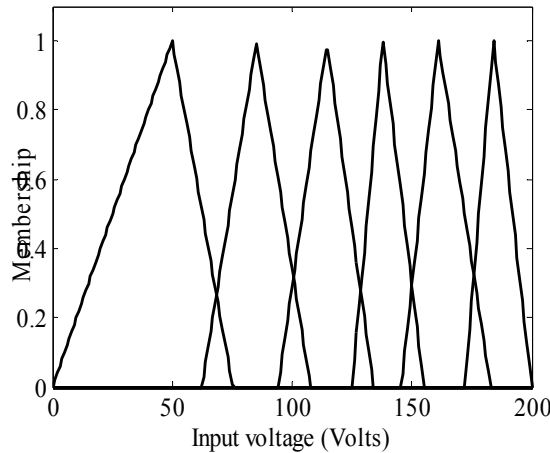

(b)

Figure 3.5.2.2: (a) Membership functions for the output current. (b) PV voltage

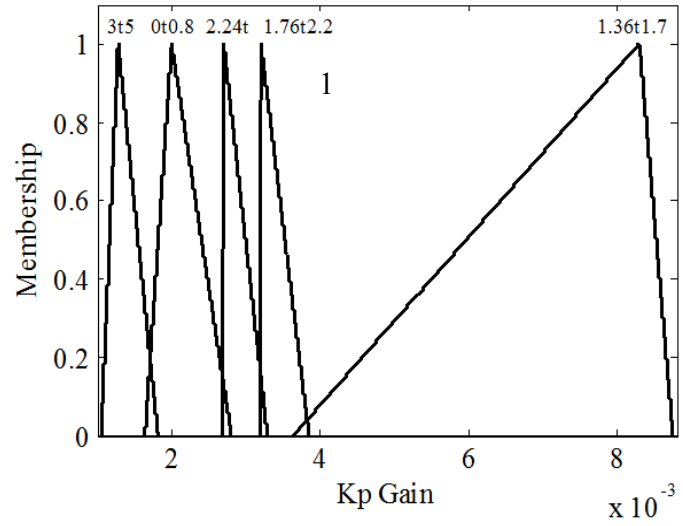

Figure 3.5.2.3: Membership functions for the Kp gain 


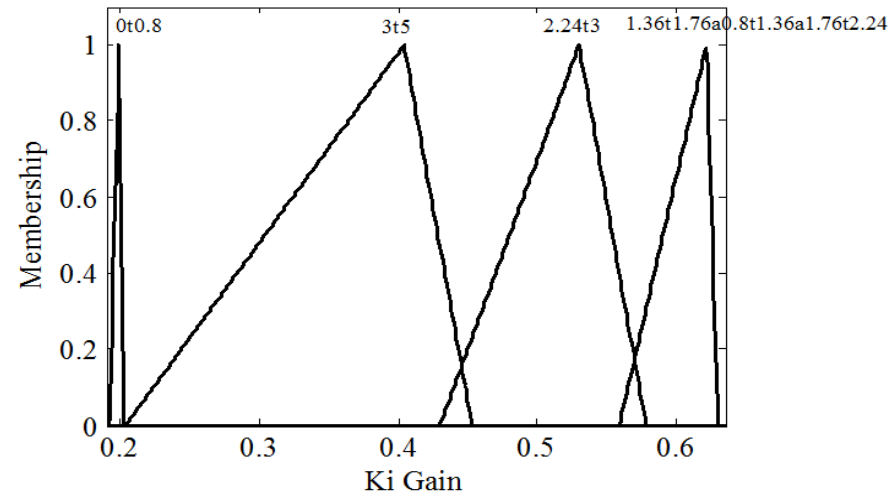

Figure 3.5.2.4: Membership functions for the Ki gain

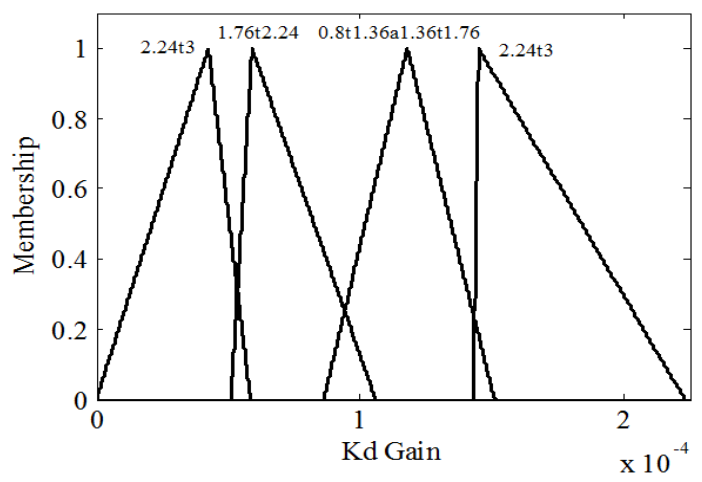

Figure 3.5.2.5: Membership functions for the Kd gain

However, in inference Engine and Rule base step, the output of fuzzy controller is managed through the use of certain linguistic rules. Those rules are shown in Table 3.5.2.1. The control rules are constructed and based on given conditions (inputs) such that the fuzzy controller decides the proper control action. The control action here means that the controller outputs a suitable Kp gain, Ki gain and Kd gain such that the PID controller parameters are those which give the optimal performance at every operating range. The rules are designed such that the controller gives the values of the PID parameters suitable for the current loading condition. 
Finally, in defuzzification, as the output of the fuzzy controller is in the form of fuzzy set and it has to be transformed from linguistic form into a number that can be used to control the system. Many defuuzification methods like weighted average (wtaver) or weighted summation (wtsum) methods were developed. The wtaver method was utilized [22]. The value of $\mathrm{Kp}, \mathrm{Ki}$ and $\mathrm{Kd}$ is based on the output current of the converter and the PV voltage, which in this case is the input to the fuzzy controller. Figure 3.5.2.6, Figure 3.5.2.7 and figure 3.5.2.8 show the output of the fuzzy controller as function of the output current and input voltage.

Table 3.5.2.1: Fuzzy rules

\begin{tabular}{|c|c|c|c|c|}
\hline Vin & Io & $\mathbf{K p}$ & $\mathbf{K i}$ & $\mathbf{K d}$ \\
\hline S & $\mathbf{1}$ & $0 \mathrm{t} 0.8$ & $0-0.9$ & $3 \mathrm{t} 5 \mathrm{a} 0 \mathrm{t} 0.8$ \\
\hline SB & $\mathbf{2}$ & $0.8 \mathrm{t} 1.36$ & $1.36 \mathrm{t} 1.76 \mathrm{a} 0.8 \mathrm{t} 1.36 \mathrm{a} 1.76 \mathrm{t} 2.24$ & $0.8 \mathrm{t} 1.38$ \\
\hline M & $\mathbf{3}$ & $1.36 \mathrm{t} 1.76$ & $1.36 \mathrm{t} 1.76 \mathrm{a} 0.8 \mathrm{t} 1.36 \mathrm{a} 1.76 \mathrm{t} 2.24$ & $0.8 \mathrm{t} 1.36 \mathrm{a} 1.36 \mathrm{t} 1.76$ \\
\hline MB & $\mathbf{4}$ & $1.76 \mathrm{t} 2.24$ & $1.36 \mathrm{t} 1.76 \mathrm{a} 0.8 \mathrm{t} 1.36 \mathrm{a} 1.76 \mathrm{t} 2.24$ & $1.76 \mathrm{t} 2.24$ \\
\hline B & $\mathbf{5}$ & $2.24 \mathrm{t} 3$ & $2.24 \mathrm{t} 3$ & $2.24 \mathrm{t} 3$ \\
\hline BB & $\mathbf{6}$ & $3 \mathrm{t} 5$ & $3 \mathrm{t} 5$ & $3 \mathrm{t} 5 \mathrm{a} 0 \mathrm{t} 0.8$ \\
\hline
\end{tabular}

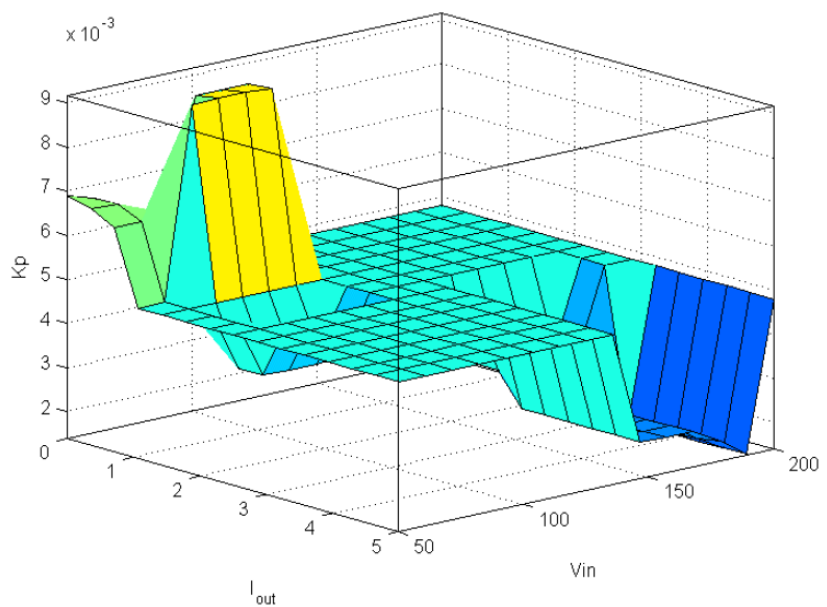

Figure 3.5.2.6: Surface plot of Kp gain 


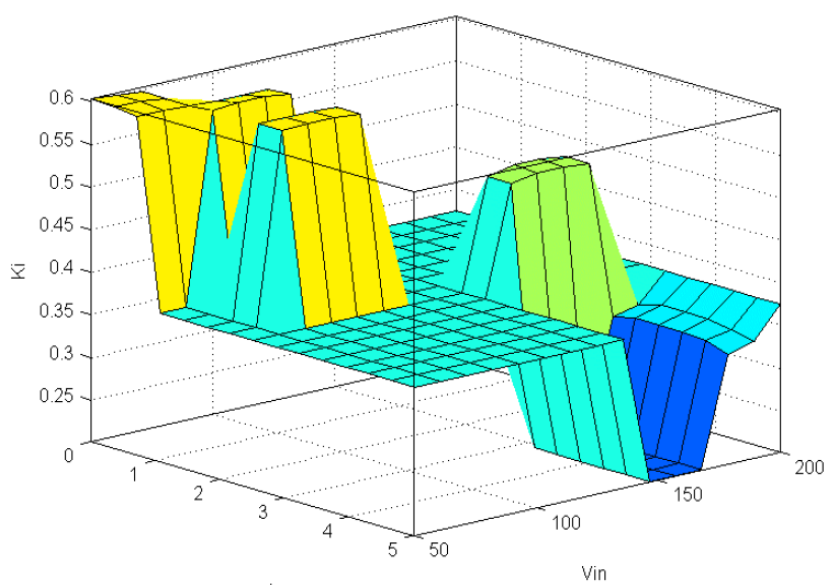

Iout

Figure 3.5.2.7: Surface plot of Ki gain

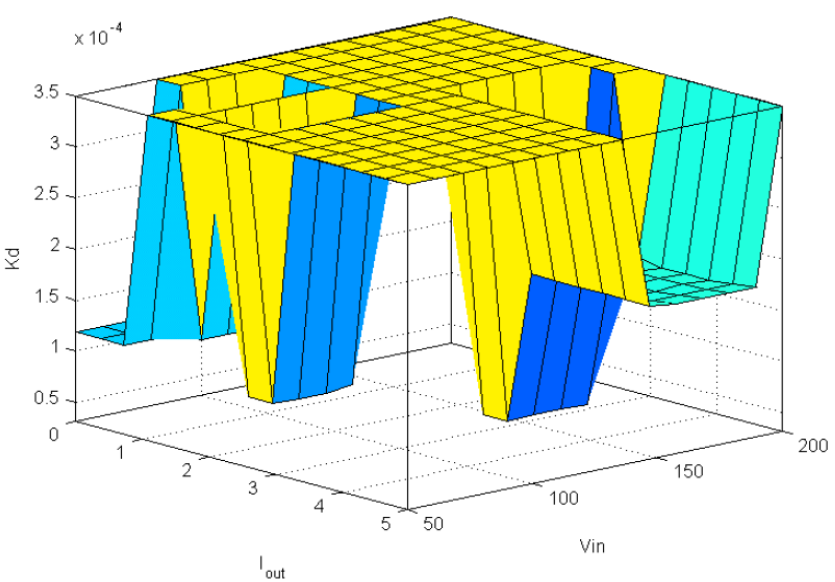

Figure 3.5.2.8: Surface plot of Kd gain

\subsubsection{Enhancing Transient and Steady State Response}

PI controller is the most commonly used controller in the industry. It is simply a PID controller in which the derivative gain value is set to zero. Generally, the proportional integral (PI) controller is able to control a DC-DC boost converter. On the other hand, the derivative part of the PID controller has the characteristic of anticipating the future behavior of the error as it deals with the derivative of the error. Hence, it is very helpful in mitigating sudden and step changes that the system may be subjected to. 
However, it causes ripple in the output voltage waveform. Figure 3.5.3.1 shows the response of the PID controller for the same case study given in figure 3.5.1.1. As can be seen in the figure, adding the derivative component (PID controller) decreases the voltage dip caused by the step change of the load. However, the ripple increases in this case more than in the case of the PI controller after.

This work introduces a technique to benefit from help of the derivative part only when it is useful to have it as a part of the controller and eliminate its effect gradually until we obtain a PI controller with minimum ripple.

As explained previously, the developed controller is made of a PID controller that utilizes fuzzy control to design the optimum values of the proportional gain, the integral gain and the derivative gain of the PID controller. When designing a PID controller, the PID parameters are tuned only once in order to be operated for a wide operating range.

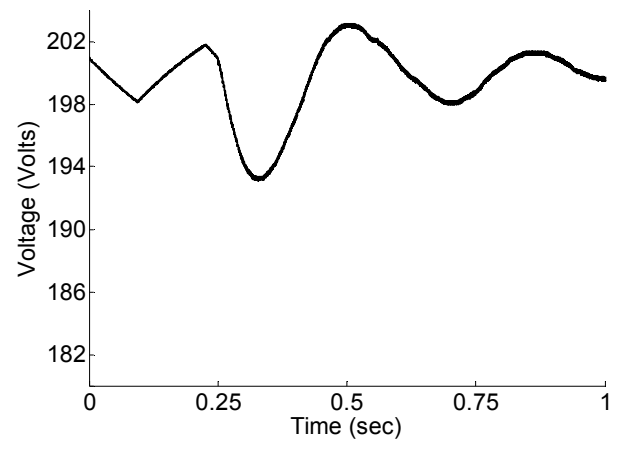

Figure 3.5.3.1: Load step change voltage response for conventional PID controller 


\subsection{Simulation Results}

In case of the $\mathrm{DC} / \mathrm{DC}$ boost converter, the load connected to the output of the boost converter plays a significant role in affecting the output voltage response of the DC/DC converter. This situation occurs when the parameters of the PID are tuned for fixed values. The boost converter circuit is based on three main components that perform the voltage boosting functionality. An inductor is placed in a series with the power supply, an IGBT switch is connected parallel to the output point of the inductor and the power supply and a capacitor connected to the output terminals of the converter; Resistive loads are connected in parallel to the capacitor. Therefore, when the switch is closed the inductor charges and when the switch opens the inductor discharges to supply the load. From this operation we can conclude that the switch time ON contributes to the voltage level of the capacitor which is connected in parallel to the resistive load. Understanding this operation is a requirement for designing the optimal values of the PID gains. The resistor is connected in parallel to the capacitor, then increases the resistance value which leads to a slower voltage response and vice versa.

The converter is operated with switching frequency of $3 \mathrm{KHz}$ and sampling time of $0.3 \mathrm{~ms}$ which allow the controller to detect the variations of loading and respond to it very fast before the capacitor voltage can be affected by the load changes. This fast control operation eliminates the transient which occurs when a pulse load is applied to the converter. The load current then gives feedback about the capacitor time constant. Therefore, using the voltage and current as a feed back to the controller, the optimal parameter values of the PID gains can be estimated for each operating loading point. Figure 3.6.1 shows the voltage, current and PID gains responses to a load step change 
from $100 \mathrm{~W}$ to $500 \mathrm{~W}$. Load current is an input for the fuzzy controller and based on its value, the PID parameters are estimated. As seen the $\mathrm{Kp}$ and $\mathrm{Ki}$ gains changed instantaneously with the load step change with an extremely small delay of $0.3 \mathrm{~m}$ seconds. It can be observed that the $\mathrm{Kd}$ value is continuously changing with time and eliminates voltage undershoot or overshoot when loading is applied or unplugged from the converter.
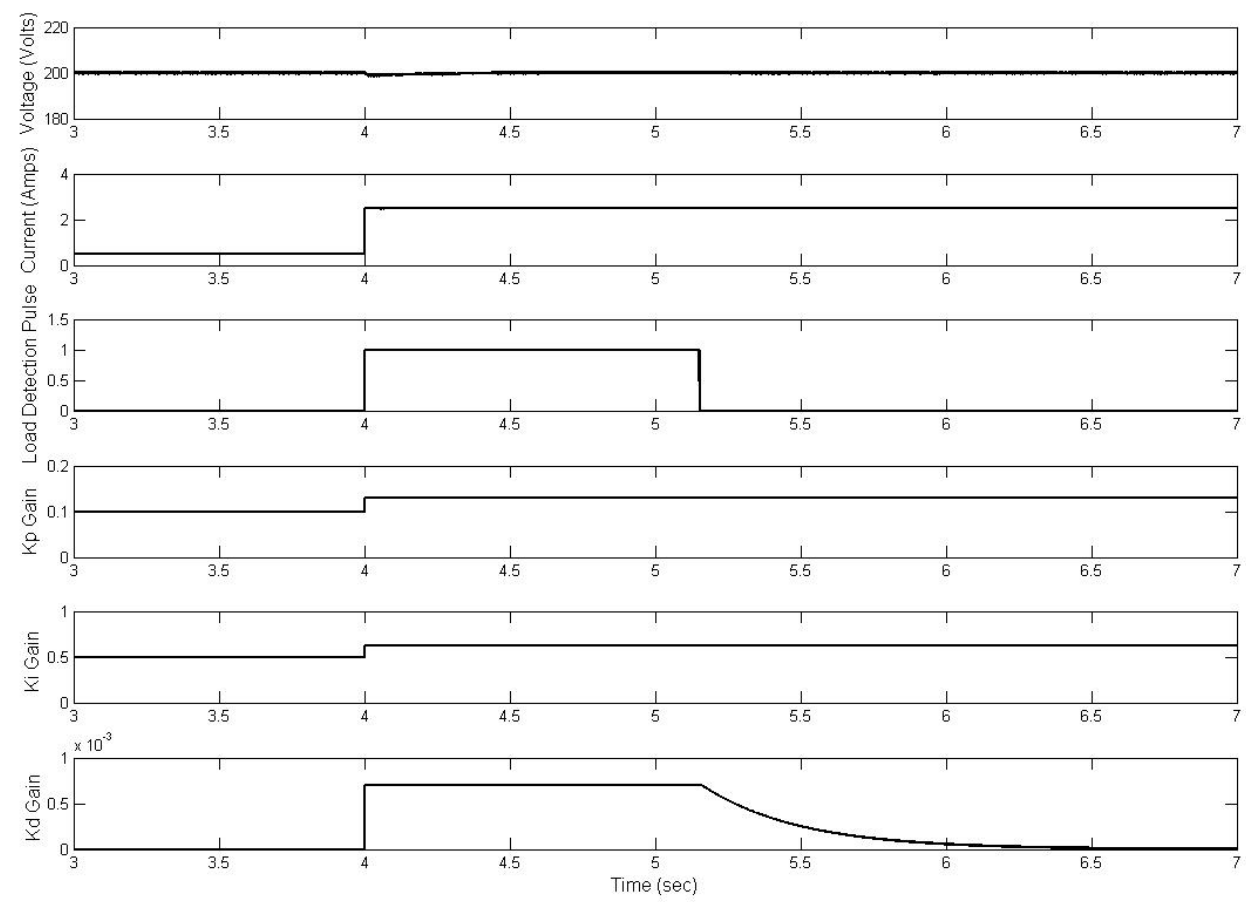

Figure 3.6.1: Smart Controller Load step change, 100W-500W response and controller parameters variations

It can be seen in figure 3.6.1 that a pulse is generated with a period function of capacitor time constant to detect any loading to the DC/DC converter. At steady state operation the gain $\mathrm{Kd}$ in this case causes the capacitor to have a slow charge/discharge operation. However, this is undesired in this case. One of the advantages of having a fast 
controller is its ability to enhance the ripple of the output voltage. Therefore, the $\mathrm{Kd}$ gain is zero at steady state operation. However, at any loading change it is applied to a tuned value that is function of the load current. This value is chosen by the fuzzy logic controller.
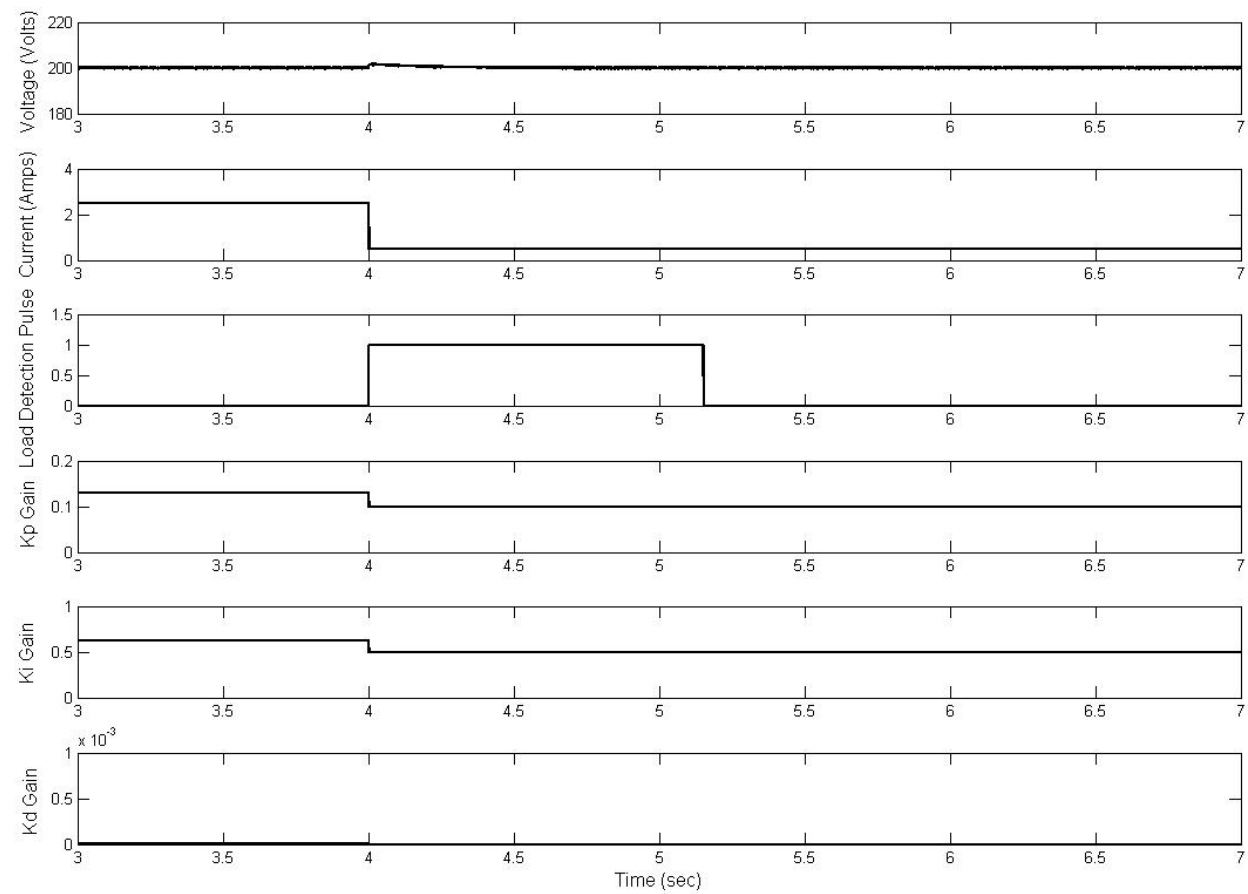

Figure 3.6.2: Smart Controller Load step change, 500W-100W, response and controller parameters variations

It can be observed from Figure 3.6.1 that the $\mathrm{Kd}$ gain has a fixed value of 0.7e-3 during the load detection pulse ON period. Once the load detection pulse is turned off, an exponential damping factor is applied to the $\mathrm{Kd}$ value to give a $\mathrm{Kd}$ of zero and enhance the ripple of the device at a steady state of operation. However, the $\mathrm{Kp}$ and $\mathrm{Ki}$ values are fixed. When in the steady state of operation the $\mathrm{Kp}$ and $\mathrm{Ki}$ values are chosen to create a quick response in order to achieve full control of the charging and discharging operation of the capacitor at steady state; which leads to reducing the ripple, then changing the $\mathrm{Kd}$ 
gain instantaneously which will then create an undesired voltage transient response. Therefore, it is reduced slowly to zero so it does not affect the voltage waveform and does not harm the load with a voltage overshoot or undershoot. Figure 3.6.2 shows the smart controller response when a load of $500 \mathrm{~W}$ is decreased to $100 \mathrm{~W}$. As it can be observed that the voltage did not get affected by the loading variations. A very small voltage overshoot of $\underline{1 \mathrm{~V}}$ is observed due to the load step change. This is considered an excellent response for a $200 \mathrm{~V}$ bus.
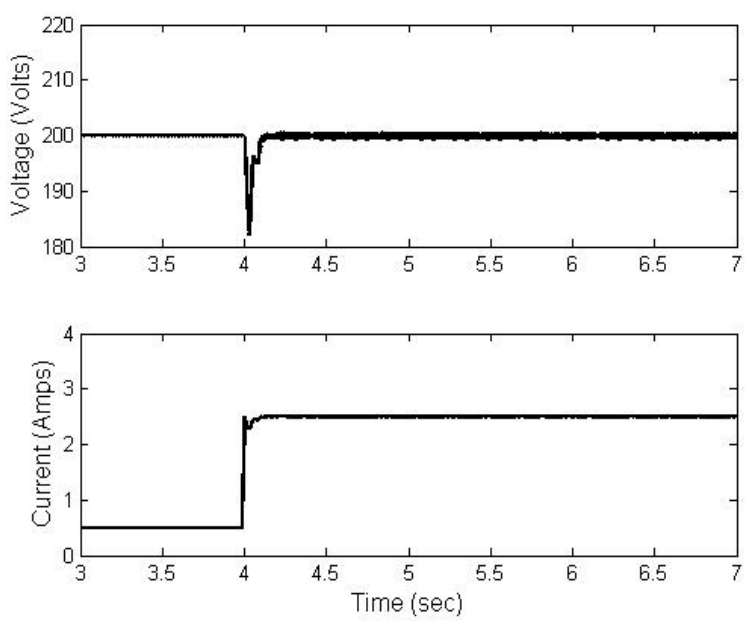

Figure 3.6.3: Traditional PI controller Load step change response (100W-500W)
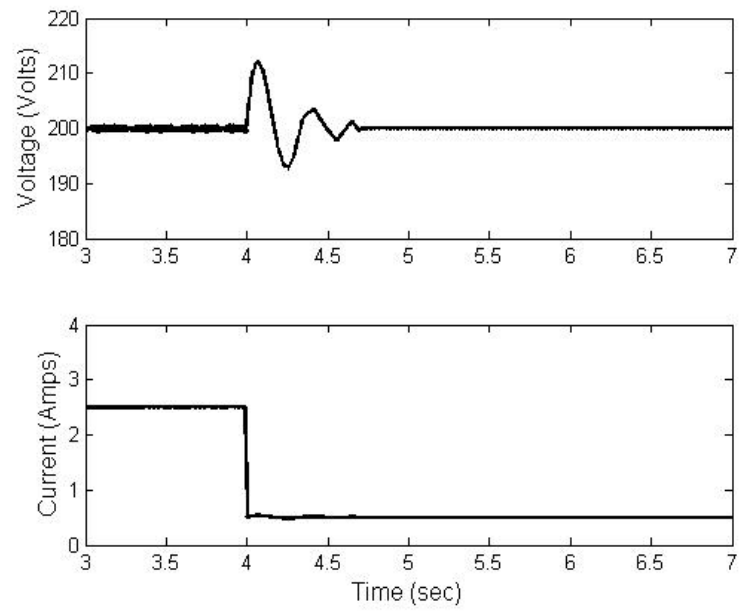

Figure 3.6.4: Traditional PI controller Load step change response (500W-100W) 
A PI controller is used in comparison with the developed smart controller to highlight its advantages. Figure 3.6.3 shows the voltage and current response to a load step change of $100 \mathrm{~W}$ to $500 \mathrm{~W}$. The same load step change is applied previously to the smart controller illustrated in figure 3.6.1. The axis level for the voltage and current in figure 3.6.1 and figure 3.6.2 are exactly the same, so the significant difference in the transient response corresponding to that load change can be clearly observed. In case of the traditional PI controller, a 19V voltage dip occurred due to the load step change. As you can see that the controller still recovers and maintains itself. However, you can observe that the ripple in voltage in figure 3.6 .3 is much higher in the high load instant then the lower load region. In the other hand, the smart controller in figure 3.6.1 maintains a small ripple in both cases. Figure 3.6.4 shows the voltage and current response for the traditional PI controller as the load is changed from $500 \mathrm{~W}$ to $100 \mathrm{~W}$, which is the same case for the smart controller illustrated in figure 3.6.2. Almost 20 volts ripple occur during the transient time. As explained in the beginning of the discussion, the controller does not take the derivative of the error into account which leads to higher overshoot and undershoot during transient operation. Also, when the load is reduced from 500W to $100 \mathrm{~W}$, the $\mathrm{Kp}$ and $\mathrm{Ki}$ gains are not tuned for that wide range. The $\mathrm{Ki}$ and $\mathrm{Kd}$ gains in case of the traditional controller do not change when the load changes. Therefore, the error of the voltage is based through fixed gains, which causes a longer time to converge to the retrace voltage. 


\subsection{Experimental Results}

Experimental results were taken to insure the validity of the developed control strategy. The Fuzzy controller was used to decide the values of the PID controller based on the current passing through the load. While using this controller to control the duty cycle of the IGBT switch, a load step change was applied to the output of the DC/DC boost converter. The load is changed from $220 \mathrm{~W}$ to $1 \mathrm{KW}$. As seen in figure 3.7.1, a transient of $0.05 \mathrm{sec}$ has occurred and almost no voltage dip can be observed. Another test was conducted to test the controller. A load step change from $1 \mathrm{KW}$ to $220 \mathrm{~W}$ was applied to the DC/DC converter. Due to that step change, a transient of 0.05 seconds occurred. In addition, voltage ripple is observed to reach $1 \mathrm{~V}$ during the transient case. Figure 3.7.2 shows the voltage and current response for a load step change from $1 \mathrm{KW}$ to 220W.

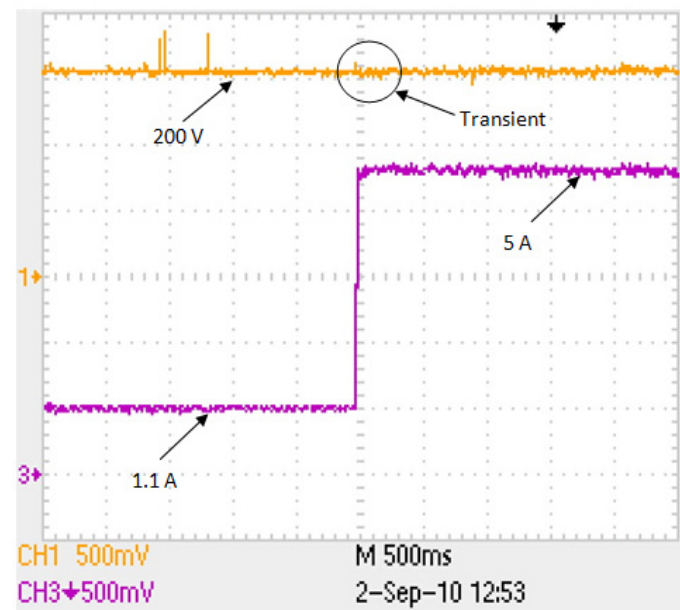

Figure 3.7.1: smart optimal PID controller response for load step change from $220 \mathrm{~W}$ to $1 \mathrm{KW}$ 


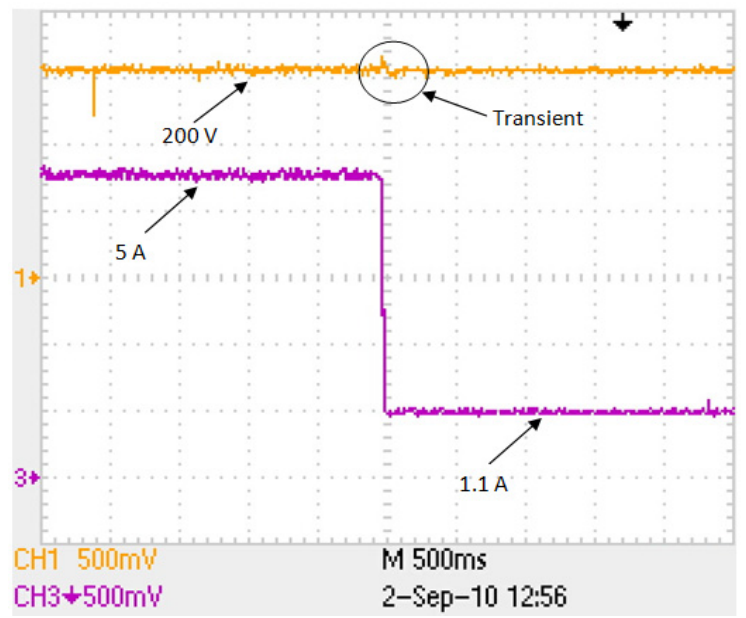

Figure 3.7.2: smart optimal PID controller response for load step change from 1 KW to $220 \mathrm{~W}$

To illustrate the effect of having the derivative gain in the controller, Figure 3.7.3 shows the voltage and current transient response for a load step change of $1 \mathrm{KW}$ to 220 W. This is the same exact case in figure 3.7.1. The response was taken while the fuzzy controller is choosing only the PI parameters. Whereas, the derivative gain value was set to zero at all loading conditions. It can be observed that a voltage dip of approximately 10 V occurred when the load was switched and took 0.35 seconds to stabilize. Also another test was conducted for a load step change from $1 \mathrm{KW}$ to $220 \mathrm{~W}$. Figure 3.7.4 shows an overshoot of $8 \mathrm{~V}$ which occurred over a $0.3 \mathrm{sec}$ period of time. These experimental results indicate that when adding the derivative gain component in the PID during the instant loading, a better transient response is achieved. Another experiment is implemented to compare the traditional PI controller to the developed controller. 


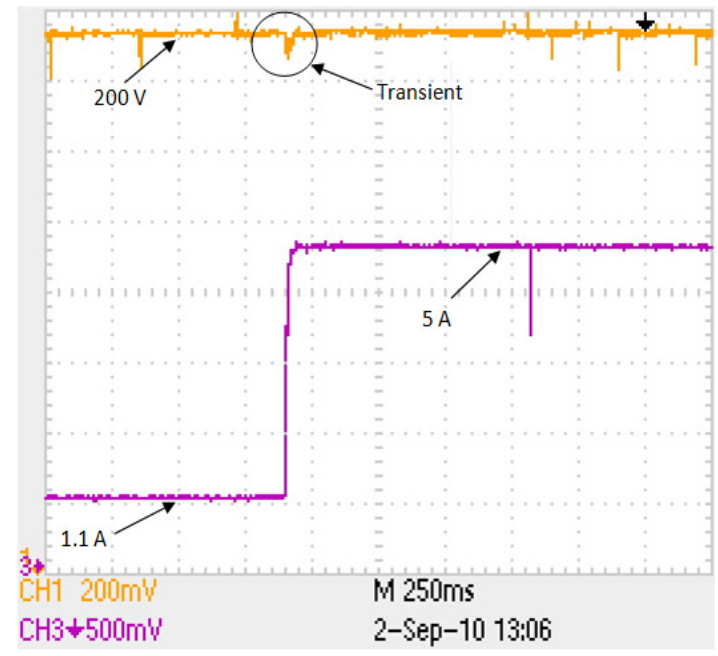

Figure 3.7.3: smart optimal PI controller ( $\mathrm{Kd}$ is set to zero) response for load step change from $220 \mathrm{~W}$ to $1 \mathrm{KW}$

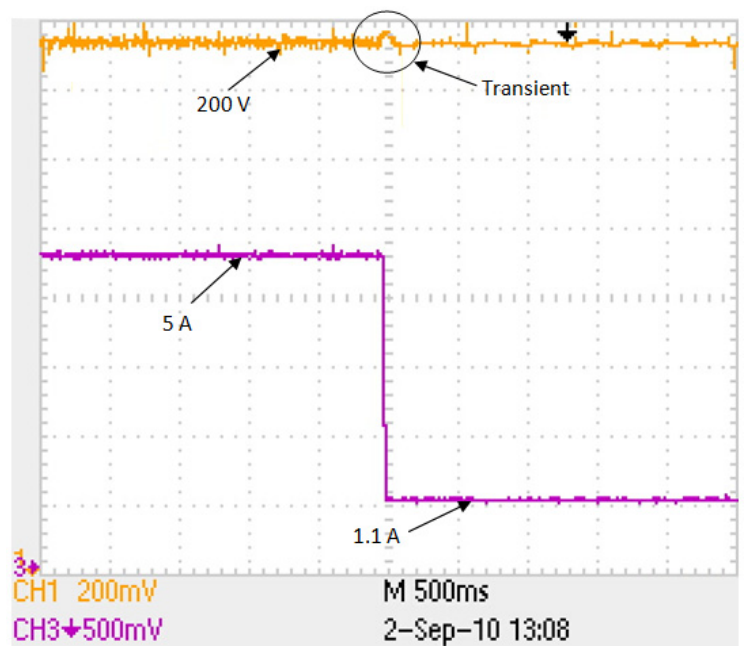

Figure 3.7.4: smart optimal PI controller ( $\mathrm{Kd}$ is set to zero) response for load step change from $1 \mathrm{KW}$ to $220 \mathrm{~W}$ 


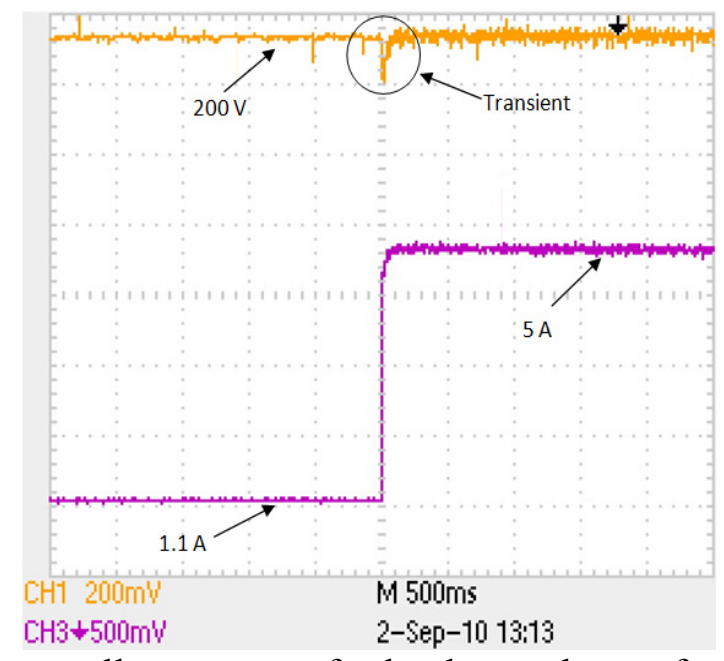

Figure 3.7.5: PI controller response for load step change from $220 \mathrm{~W}$ to $1 \mathrm{KW}$

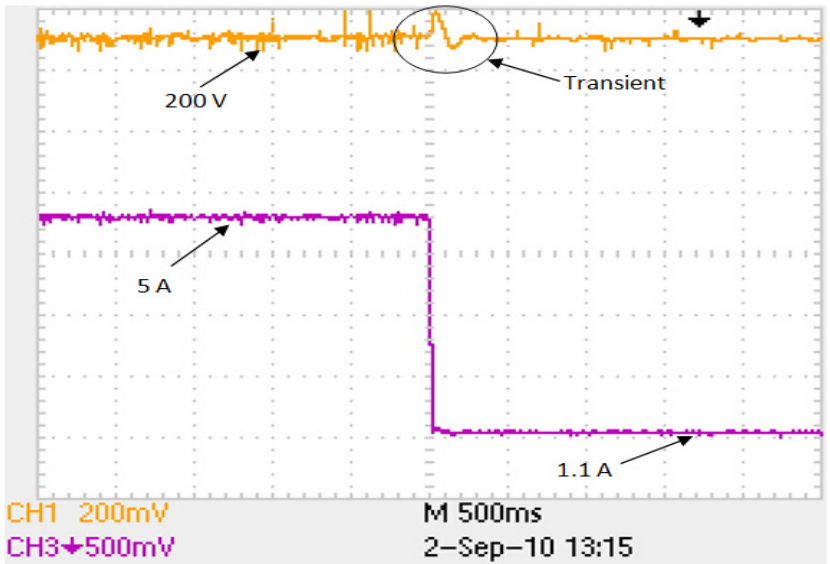

Figure 3.7.6: smart optimal PI controller response for load step change from 1 KW to $220 \mathrm{~W}$

Figure 3.7.5 and figure 3.7.6 show the voltage and current transient response for the same loads presented for the other two cases. The PI controller gives the worst voltage response because it has an under damped voltage of 18 Volts and higher when the $1 \mathrm{KW}$ load is applied. This indicates that the PI is not as efficient or as staple for wide range of load variations. 


\section{CHAPTER 4}

\section{ENHANCING LOADING LIMITATIONS IN PV SYSTEMS}

\subsection{Systems Description}

This chapter discusses the loading limitations in PV systems resulting from switching the power electronic interfaces and transients associated with large loads. These conditions de-rate the power generation capability of the PV system. A method for enhancing the loadability of these systems under both steady state and dynamic operations is discussed. A PV system for home application purposes, with a rated power of $280 \mathrm{~W}$ was designed and built.

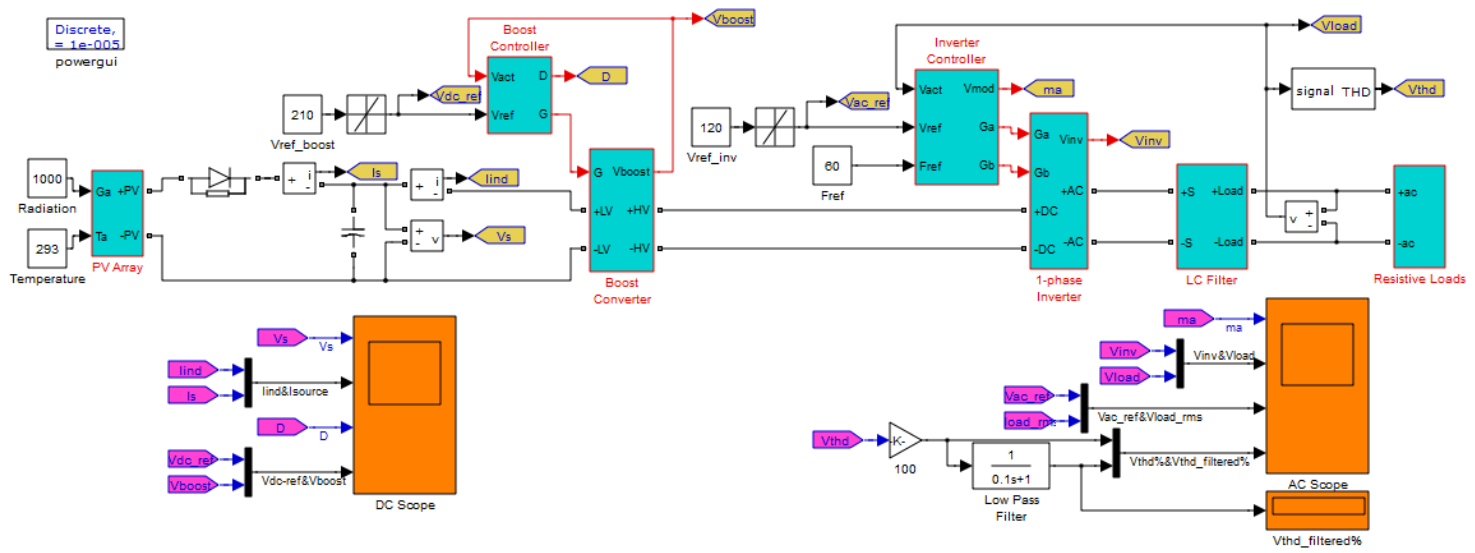

Figure 4.1.1: The block diagram of the PV system implemented in SIMULINK

Figure 4.1.1 depicts the block diagram of the PV system, built in MATLAB/SIMULINK. The system consists of a PV array containing two $P B 175 B$ panels connected in series and each panel has the following specifications at the standard test conditions $\left(\mathrm{STD}\right.$, temperature $=25^{\circ} \mathrm{C}$ and solar irradiance $\left.=1 \mathrm{~kW} / \mathrm{m}^{2}\right)$ : 
Table 4.1.1: specifications of PB 175 solar panels

\begin{tabular}{|c|c|c|c|c|}
\hline $\mathrm{P}_{\max }$ & $\mathrm{V}_{\max }$ & $\mathrm{I}_{\max }$ & $\mathrm{V}_{\text {oc }}$ & $\mathrm{I}_{\text {sc }}$ \\
\hline $175 \mathrm{~W}$ & $35.7 \mathrm{~V}$ & $4.9 \mathrm{~A}$ & $44.5 \mathrm{~V}$ & $5.4 \mathrm{~A}$ \\
\hline
\end{tabular}

Figure 4.1.2 shows the electric characteristics of the PV panels. Fluctuations in the output current $(\Delta \mathrm{I})$, result in fluctuations in the output voltage $(\Delta \mathrm{V})$, which leads to fluctuations in the output power $(\Delta \mathrm{P})$. The figure indicates that any power fluctuations around the Maximum Power Point (MPPT) de-rate the average power coming from the panel.

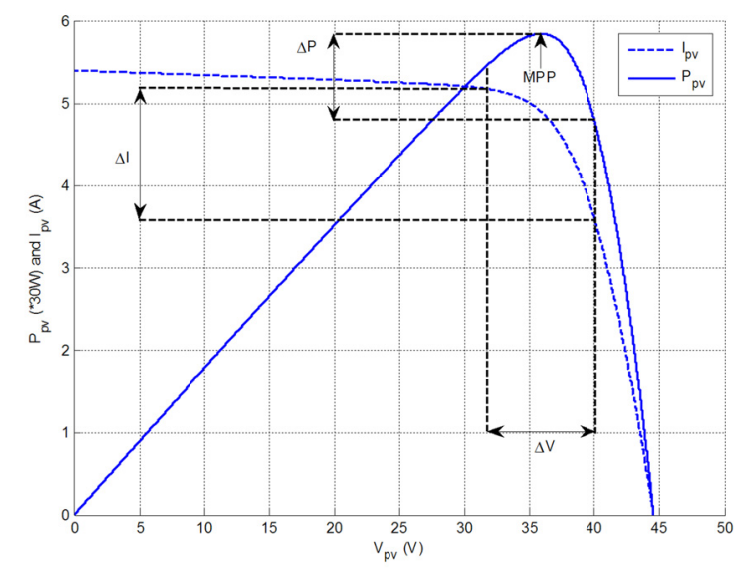

Figure 4.1.2: Power and current characteristics of the PV panels versus voltage

The PV array is connected to a boost converter. As a result, the current input to the boost converter will oscillate around its DC value, those oscillations result in current fluctuations at the PV's side which de-rate the array's power. As a consequence, the loadability of the array decreases, which is not desired.

In order to reduce the fluctuations at the PV array side, and increase the system loadability ${ }_{2}$ one may use a capacitor to smooth the output current and voltage profile of the array $($ Here $\mathrm{C}=1200 \mu \mathrm{F})$. 
In the stable operating conditions the output voltage of the PV array, depending on the load, varies between $70 \mathrm{~V}$ to $90 \mathrm{~V}$, which is not a proper level for converting to 120 VAC. As a result, a boost converter steps up and repairs the array output voltage (Here, $\mathrm{L}=2.7 \mathrm{mH}+0.59 \Omega$, and $\mathrm{C}=1200 \mu \mathrm{F}$, and $\mathrm{fs}=2 \mathrm{kHz}$ ).

An anti-windup PI controller controls the boost converter by means of adjusting the duty cycle which leads it to produce the proper PWM pulses for triggering the IGBT switch. The anti-windup block prevents the integrator from accumulating the error, when the controller output goes to saturation region, i.e. duty cycle greater than 1 or less than 0 . In our experiments, the duty cycle is limited between 0 and 0.9 . This approach helps the controller to quickly recover from the saturation region, after observing a change in the sign of error signal [24].

A full bridge single-phase IGBT inverter converts the DC link voltage to 120 VAC at $60 \mathrm{~Hz}$, which is suitable for home applications. The IGBT gates are fired by PWM signals which are provided by the inverter controller. In general, a sinusoidal PWM operates in the non-linear range when its amplitude modulation ratio (ma) exceeds 1 (over-modulation), and saturates when ma reaches 3.24 [25]. Hence, in the same manner as the boost controller, the PI should be augmented with an anti-windup block for fast recovery from the saturation region.

An LC filter refines the square wave output voltage of the inverter. This filter reduces the harmonic content of the $\mathrm{AC}$ voltage before injecting it to the load. The filter parameters are: $\mathrm{L}=12 \mathrm{mH}+2.23 \Omega$, and $\mathrm{C}=49 \mu \mathrm{F}$. We use Total Harmonic Distortion (THD) as a measure of the quality of the load voltage. In this study, the DC link reference voltage, i.e. boost reference voltage, and the frequency modulation ratio (mf) [26-30] for 
the inverter are set such that the minimum THD is achieved over the operating range of the system.

\subsection{Simulation and test results}

This study investigates two different aspects of the system which are steady state and dynamic performance. In the steady state analysis, the load voltage quality, in particular THD, and the steady state loadbility are taken into consideration. In addition, w the dynamic analysis of the systems stability, speed, and accuracy are considered with specifically concerned about load switching effects on the system stability.

To verify the obtained results from the simulations, the described system is implemented in the laboratory. We used d SPACE 1104 for interfacing SIMULINK and hardware. Also, we utilized a DC programmable power supply instead of actual PV arrays. All the inductors and capacitor sizes used in the simulations were based on the actual parts available in the lab.

\subsubsection{Steady state performance}

Figure 4.2.1.1 shows the variations of the load voltage THD versus, the DC link reference voltage for $\mathrm{mf}=38$. Figure 4.2.1.2 shows the same graph for a smaller range of load power, i.e. Pload $=[270,292 \mathrm{~W}]$. In addition to THD profile, these figures are helpful in investigating the loadability or steady state stability of the system. The dark red regions on the right sides of the figures with higher THD indicate the loadability margin of the system. It can be observed that, increasing Vdc from $160 \mathrm{~V}$ to $240 \mathrm{~V}$ deteriorates the system loadability. On the other hand, for small Vdcs the THD may exceed 5\% which is 
beyond the distortion limits for general low voltage systems [30]. From this figure, $\mathrm{V}^{*} \mathrm{dc}=210 \mathrm{~V}$ offers a tradeoff between THD profile and loadability over a wide range of the operation specifically around the rated power. For the given set point, the system can run up to $286 \mathrm{~W}$ which is about $82 \%$ of the rated capacity of two panels. This de-ration_is a result of the fluctuations in the array side as well as the losses caused by the boost and inverter switching and the heat dissipated in the system resistors such as the boost and LC filter.

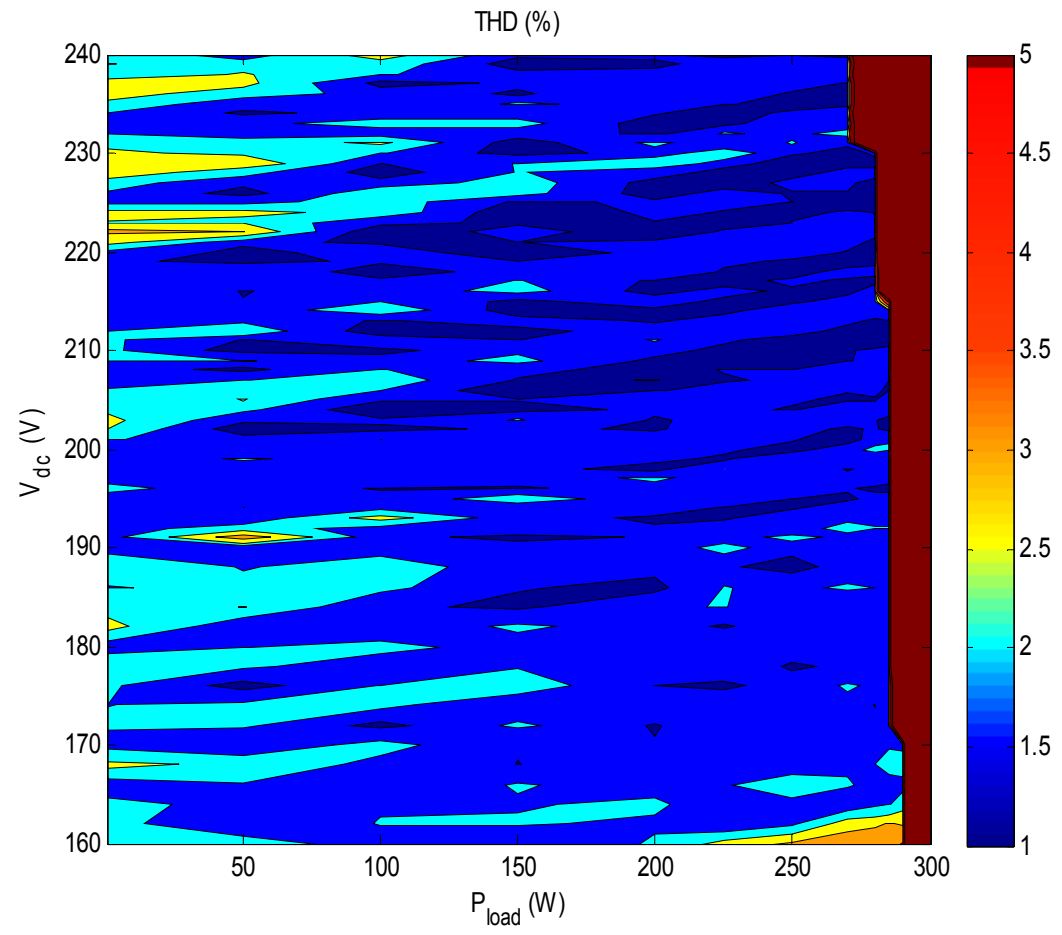

Figure 4.2.1.1: Variations of THD versus $\mathrm{V}^{*}{ }_{\mathrm{dc}}$, optimum $\mathrm{V}^{*}{ }_{\mathrm{dc}}=210 \mathrm{~V}$ 


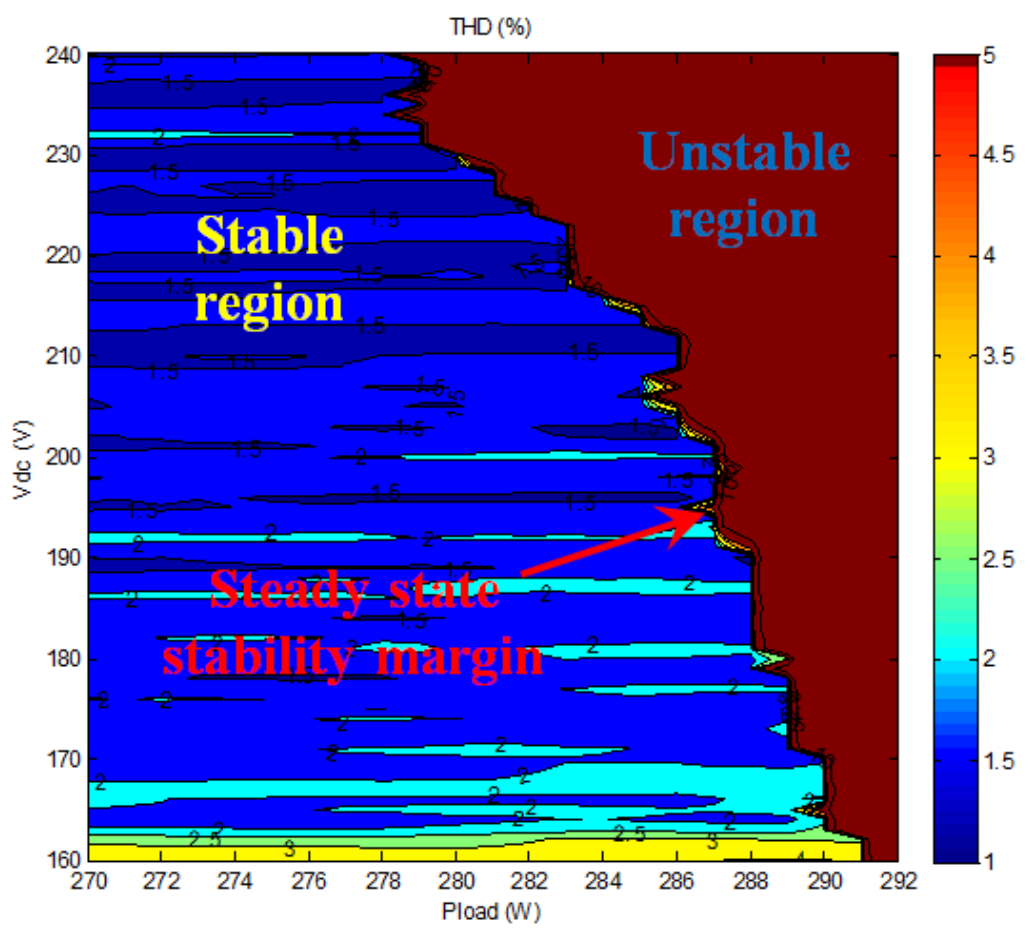

Figure 4.2.1.2: Steady state stability of the system with respect to DC link voltage

\subsubsection{Dynamic Performance}

As discussed in section 4.1, the power capability of a PV panel is very sensitive to its operation point. If under any condition, one draws large current, its voltage and consequently its power collapse. We faced this problem during the charging periods of the boost converter and the inverter. This means that the array could not afford the large currents during the start up or voltage build up process of the boost converter and the inverter. To solve this problem, instead of applying step inputs, the reference voltages of both of these components, should gradually increase from zero to their final value. There were two rate limiters were employed, one for the boost controller $(200 / \mathrm{sec})$ and another one for the inverter controller $(400 / \mathrm{sec})$. It should be noted that, although these rate limiters slow down the system and start up process, since the system usually starts only 
once and serve the load for a long period, this delay is not considered as a big issue in load connectivity.

In addition to the start up, load switching is a major aspect that must be investigated. Actually, all the regular loads, such as home appliances are just plugged and ran, instantaneously. Therefore, we cannot deal with them in a similar manner to the boost converter and the inverter. This means that soft start is not applicable. The goal is to set the controllers on such a way that the largest possible load can be switched and then served with a satisfactory quality. Our experiments show that a slow PI controller for the boost converter can reduce the effects of switching large loads at the array side. In fact, it does not matter if DC link voltage drops or increases for a few seconds and stabilizes with some delays. This is because it is not connected to any load or any other voltage sensitive device. Hence, we employ a slow controller for the boost converter which somehow isolates the PV array from instantaneous fluctuations in the load side and use a fast PI controller for the inverter which fixes the load voltage at its desired value within a fraction of second and with a small over shoot. In this study, we set proportional gains $(\mathrm{kP})$ of the boost and inverter controllers at 0.004 and 0.002 , and the integrator gains $(\mathrm{kI})$ are 0.02 and 1 , respectively.

This system can successfully respond to switching $265 \mathrm{~W}$ load, while in the case of a fast boost controller with $\mathrm{kP}=0.004$ and $\mathrm{kI}=2$ the system can maintain the service for switching loads no larger than $220 \mathrm{~W}$. However, it is pretty stable, fast, and accurate under switching of loads smaller than 220W. Figure 4.2.2.1, Figure 4.2.2.2, Figure 4.2.2.3 and figure 4.2.2.4 shows the simulation and experiment voltage and current 
variations at the $\mathrm{DC}$ (PV array and boost) and $\mathrm{AC}$ sides, during start up and switching of a 220W loads for the fast and slow controllers, respectively.
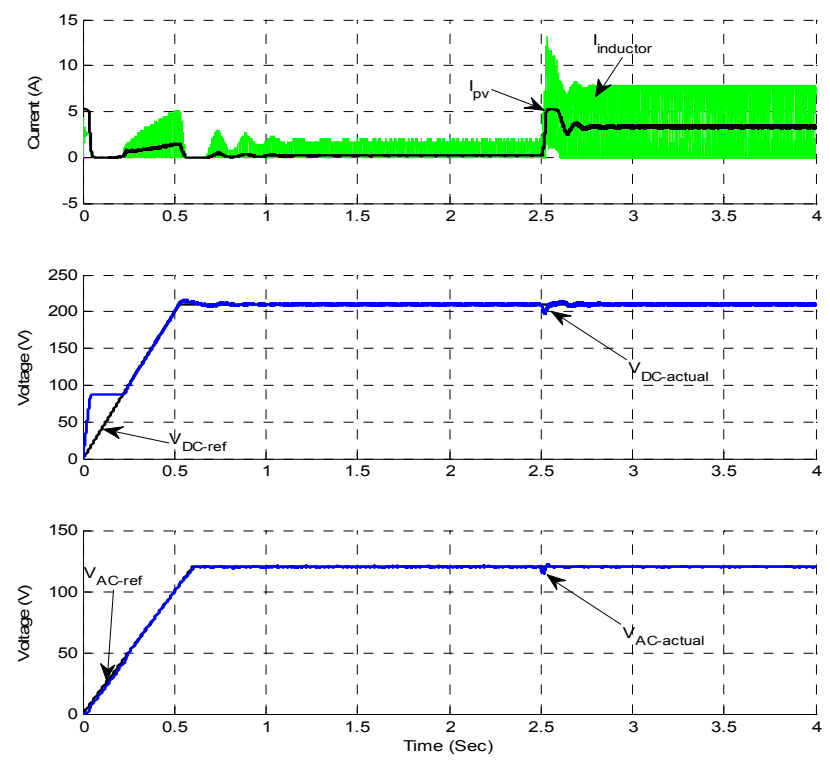

Figure 4.2.2.1: Simulation results for voltage and current variations during

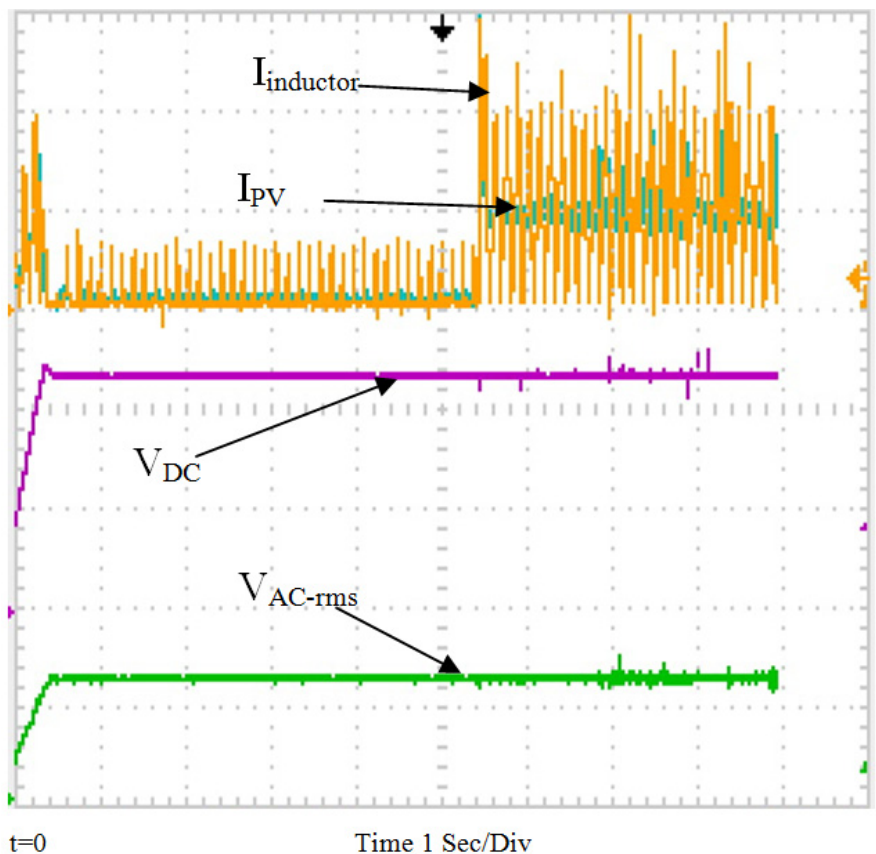

Figure 4.2.2.2: Experimental results for voltage and current variations during switching of a $220 \mathrm{~W}$ load for the fast controller 

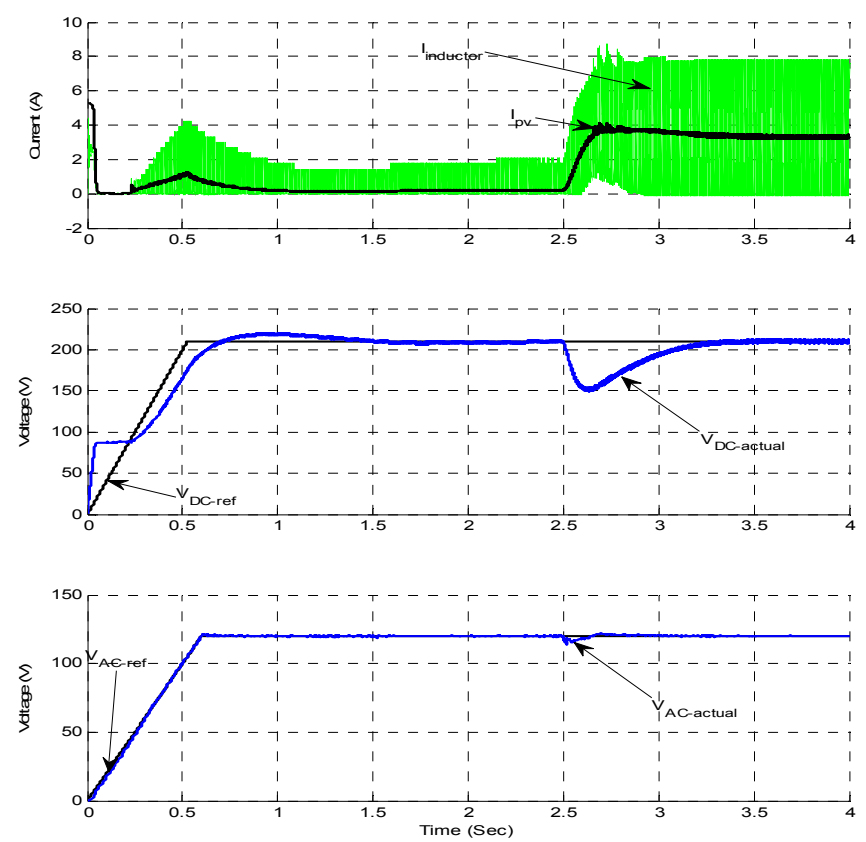

Figure 4.2.2.3: Simulation results for voltage and current variations during switching of a $220 \mathrm{~W}$ load for the slow controller

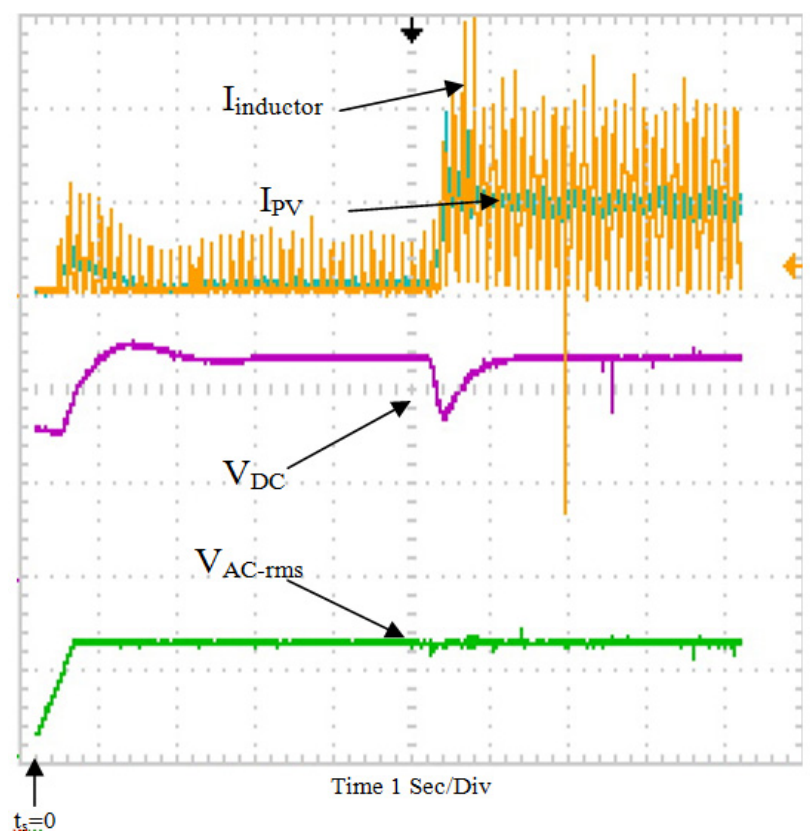

Figure 4.2.2.4: Experimental results for voltage and current variations during switching of a $265 \mathrm{~W}$ load for the slow controller 
It can be observed that the experimental results are consistent with the experimental results, which verifies the validity of the simulation model. When these figures are compared results indicate that for a $220 \mathrm{~W}$ load the fast controller has much better transient performance (in terms of speed and overshoot) than the slower one. Moreover, the top figures show the effectiveness of using a capacitor between the PV array and the boost converter in reducing the current, and as a consequence voltage, fluctuations of the array and enhancing its loadability.
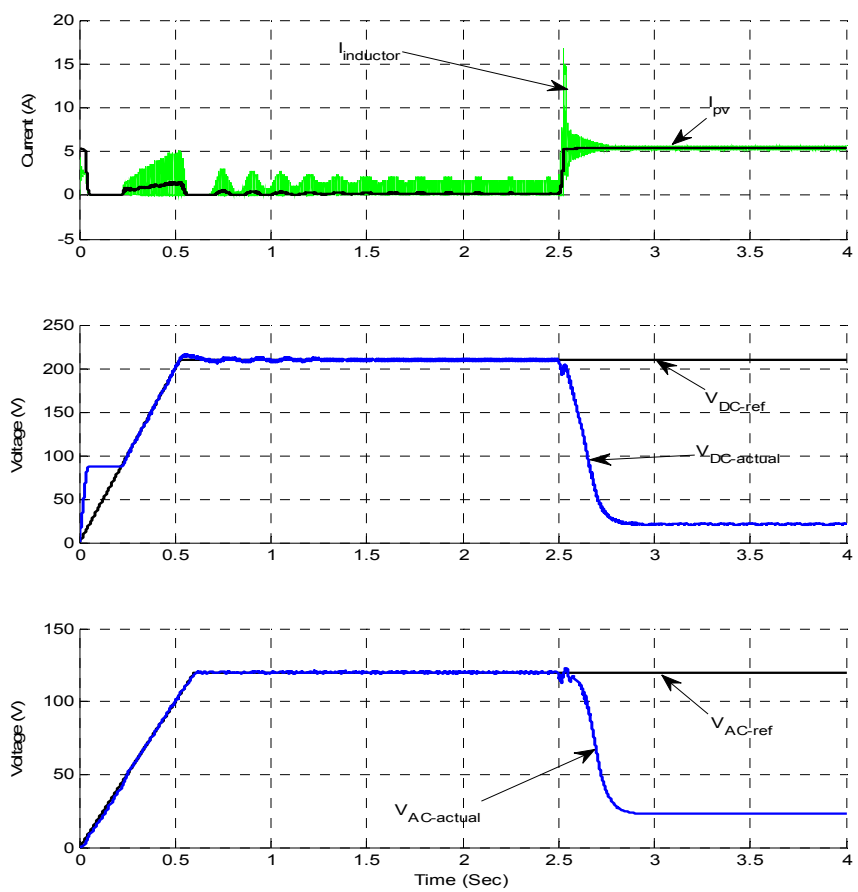

Figure 4.2.2.5: Simulation results for voltage and current variations during switching of a $265 \mathrm{~W}$ load for the fast controller 


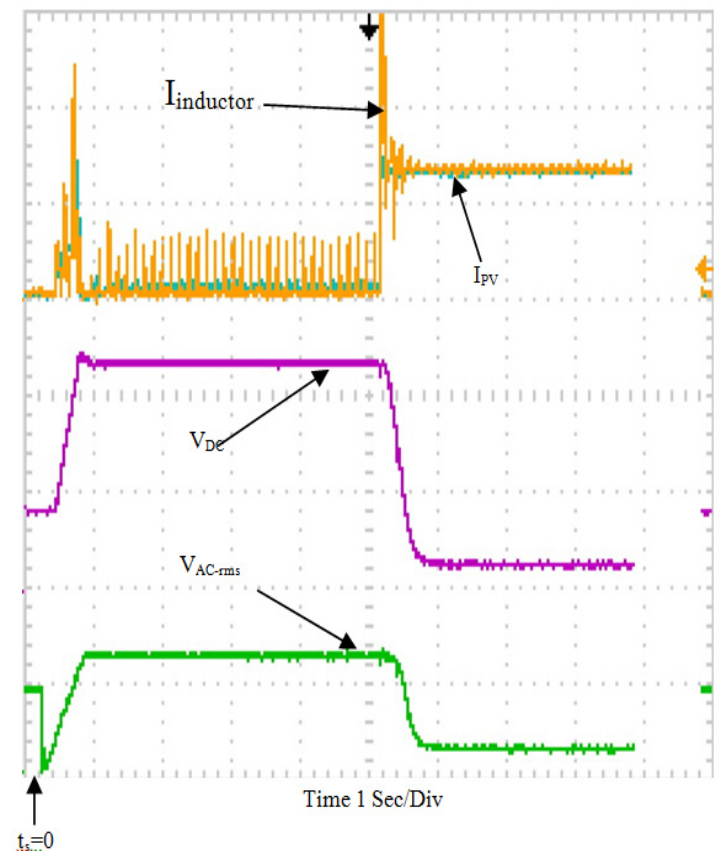

Figure 4.2.2.6: Experimental results voltage and current variations during switching of a $265 \mathrm{~W}$ load for the fast controller
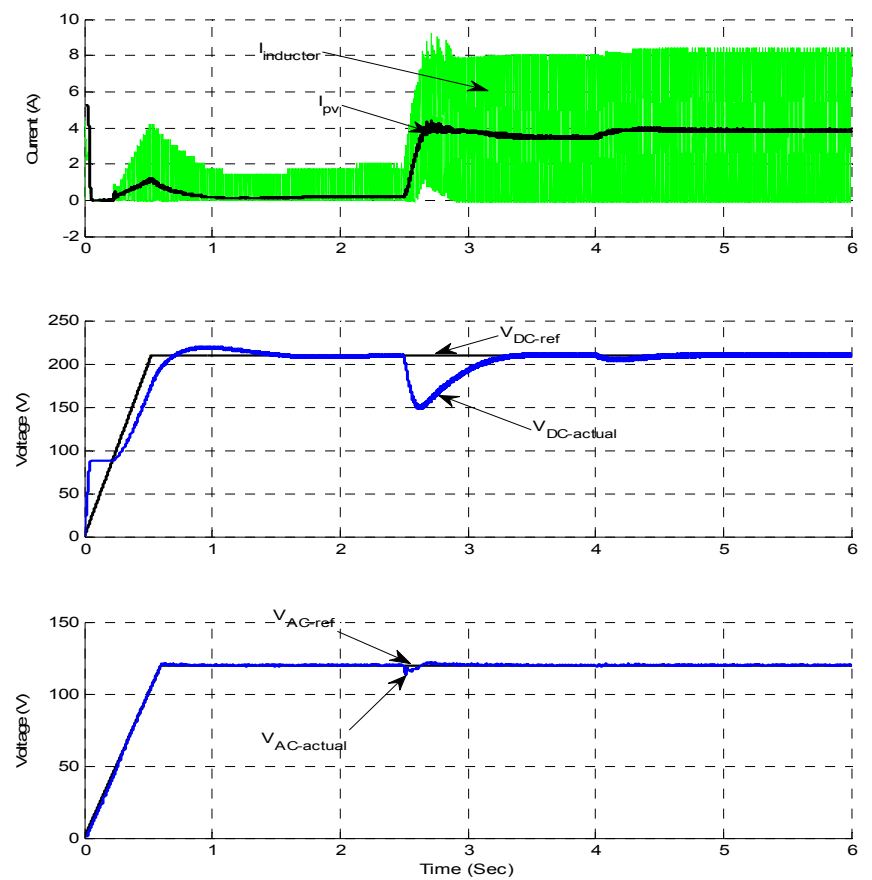

Figure 4.2.2.7: Simulation results for voltage and current variations during switching of a $265 \mathrm{~W}$ load for the slow controller 


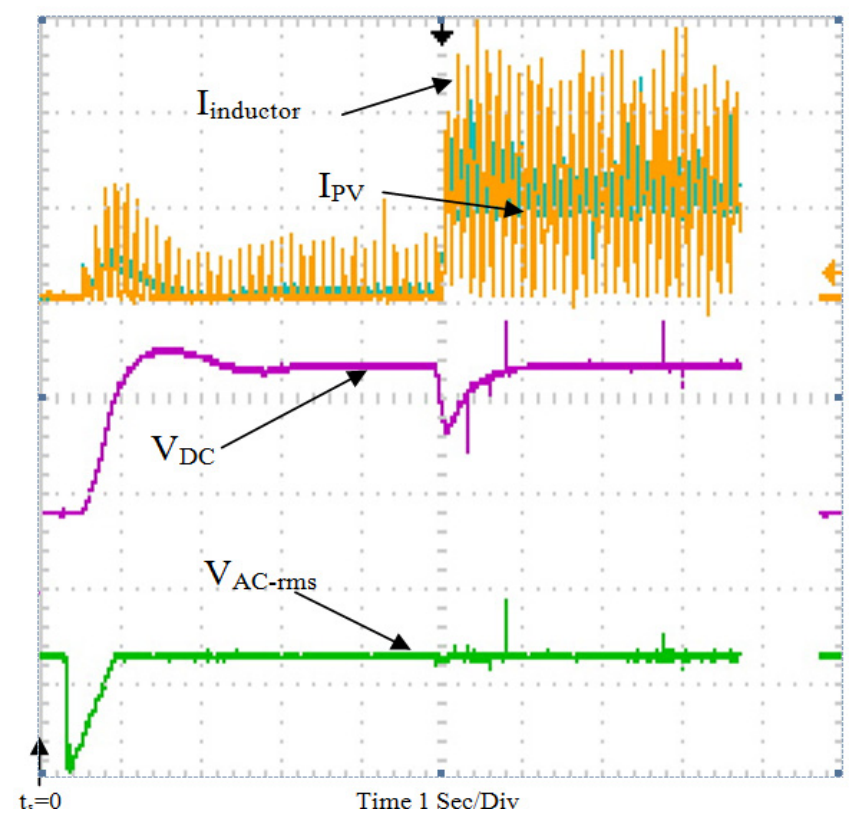

Figure 4.2.2.8: Experimental results for Voltage and current variations during switching of a $265 \mathrm{~W}$ load for the slow controller

Figure 4.2.2.5 and figure 4.2.2.6 present the same waveforms for switching a $\underline{265}$ W load in the fast system. It can be seen that the system with the fast boost controller fails to respond the load switching. On the other hand, Figure 4.2.2.7 and figure 4.2.2.8 shows that the slow system can fulfill the load demand during both the transient and steady states. A $265 \mathrm{~W}$ load at $\mathrm{t}=2.5 \mathrm{sec}$ and $20 \mathrm{~W}$ at $\mathrm{t}=4 \mathrm{sec}$ are switched (totally $285 \mathrm{~W}$ in two switches, out of $286 \mathrm{~W}$ possible capacity). The right figure shows the same waveforms for switching about a $265 \mathrm{~W}$ load. 


\subsection{Conclusion}

This chapter discusses the loadability of PV systems under both steady state and dynamic operations. An enhancement to the steady state performance of the system is achieved by inserting a capacitor at the array output and by the proper adjusting of the DC link reference voltage. Also, the developed slower controller for the boost converter increased the stability and loadability of the system during large loads switches. Actually, the DC link can act as a buffer which reduces the effects of the transients at the AC side on the arrays. Experimental results verify the effectiveness of the developed approaches. 


\section{CHAPTER 5}

\section{BI-DIRECTIONAL POWER TRANSFER CONTROL OF GRID-CONNECTED DC MICROGRIDS}

\subsection{Connectivity to AC Grid}

In this chapter some of the aspects related to the connectivity of DC micro-grids to the main grid are investigated. A prototype system was designed and implemented to address these aspects. The described system is dependent on sustainable energy sources. Hence, special care was given to dealing with the sources while designing different components of the system. Certain features had to be maintained in the system in order to assure efficient integration of different sources such as, efficient and reliable load-feeding capability and full controllability of voltage and power flow among various buses in the system. Two different converters were investigated; firstly, a fully controlled rectifier was designed to tie the $\mathrm{DC}$ grid with the $\mathrm{AC}$ one. A vector decoupling controlled sinusoidal pulse width modulation (SPWM) technique was used to allow the designed rectifier to maintain a constant output voltage while being able to control the active and reactive power drawn from the grid independently. Hence, this controlled rectifier acts as a voltage regulator for the DC micro-grid and has a unidirectional power flow capability from the AC grid to the DC micro-grid. Moreover, in order to allow bi-directional power flow, a bi-directional AC-DC/DC-AC converter was designed. Vector decoupling controlled sinusoidal pulse width modulation technique has also been used to allow the designed converter to control the power transferred between the AC and DC sides in either direction while being able to control the active and reactive power drawn from the 
grid independently. Hence, the Bi-directional AC-DC/DC-AC converter controls the active power transfer while operating at unity power factor. Both simulation and experimental results verify the validity of the developed converter.

\subsection{Bus Voltage Regulation}

The DC distribution system under study is shown in figure 5.2.1. It consists of a DC micro-grid that is tied to the AC grid through a controlled rectifier. The first issue that has to be considered while designing such system is having a constant output voltage on the DC network. This facilitates the integration of different sustainable energy sources. The fully controlled rectifier used in this paper is responsible for fixing the DC voltage in the system in case it is grid-connected. Otherwise, at least one of the DC-DC converters connected to sustainable energy sources has to be assigned the responsibility of regulating the DC micro-grid voltage and maintaining the power balance in the system. In this paper, the system grid-connectivity in the grid-connected mode is investigated.

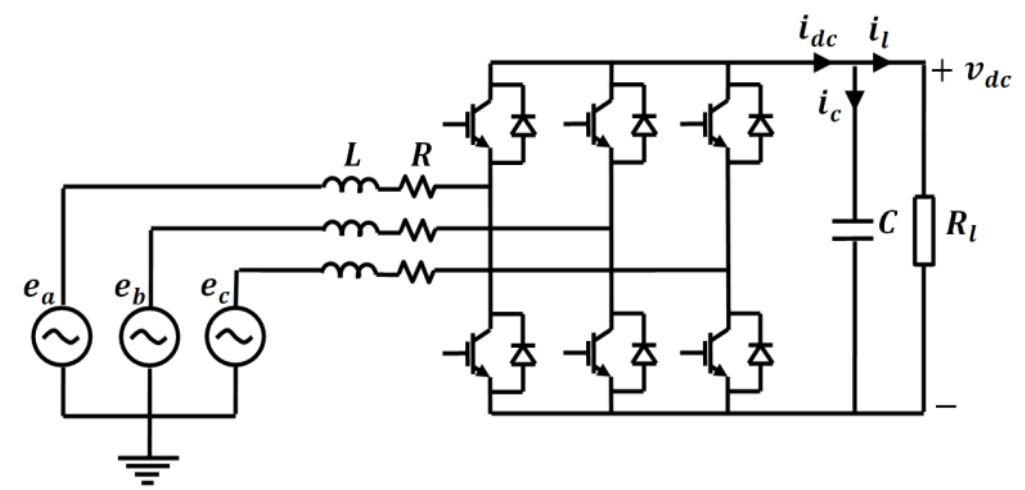

Figure 5.2.1: The three phase controlled rectifier used in the developed system. 


\subsubsection{Converter Description and Mathematical Modeling}

A fully controlled three phase rectifier was designed and implemented for coupling the DC network with the AC grid. A vector decoupling vector PWM control technique was used to control the output voltage of the rectifier while having the capability of controlling both the active and reactive power drawn from the grid independently. Vector decoupling PWM control of three phase rectifiers requires coordinated transformation to the d-q frame of reference in order to obtain the desired controllability. Feedback and feed-forward control techniques within the rectifiers are possible. However, they are complicated and require accurate mathematical modeling of the inverter. Hence, three PI controllers was utilized to assist us in building the control model although the mathematical model of the rectifier is very important, especially in order to have a successful decoupling of the vectors. The three phases PWM rectifier circuit used is shown in figure 5.2.1.

Taking line-line loop equations of the circuit, we can describe the system as in (5-

$1)$

$$
\left[\begin{array}{l}
e_{a} \\
e_{b} \\
e_{c}
\end{array}\right]=\left[\begin{array}{lll}
R & 0 & 0 \\
0 & R & 0 \\
0 & 0 & R
\end{array}\right]\left[\begin{array}{l}
i_{a} \\
i_{b} \\
i_{c}
\end{array}\right]+\left[\begin{array}{ccc}
L & 0 & 0 \\
0 & L & 0 \\
0 & 0 & L
\end{array}\right] p\left[\begin{array}{c}
i_{a} \\
i_{b} \\
i_{c}
\end{array}\right]+\left[\begin{array}{c}
v_{r a} \\
v_{r b} \\
v_{r c}
\end{array}\right]
$$

The DC output of the rectifier depends on the PWM signals driving the switches. The switching signals are designated $S_{a}, S_{b}$ and $S_{c}$. These switching signals control the relationship between the rectifier input voltages, i.e. $v_{r a}, v_{r b}$ and $v_{r \varepsilon}$ and the DC bus voltage $v_{d \varepsilon}$ as given by the set of equalities in (5-2), 


$$
v_{r a}=\frac{S_{a} v_{d c}}{2}, v_{r b}=\frac{S_{b} v_{d c}}{2}, v_{r c}=\frac{S_{c} v_{d c}}{2}
$$

Converting the system equations into rotating d-q references frame using Park's transformation, we obtain,

$$
\left[\begin{array}{c}
e_{q} \\
0
\end{array}\right]=\left[\begin{array}{cc}
R+L p & w L \\
-w L & R+L p
\end{array}\right]\left[\begin{array}{c}
i_{q} \\
i_{d}
\end{array}\right]+\left[\begin{array}{c}
v_{r q} \\
v_{r d}
\end{array}\right]
$$

Where,

$$
v_{r q}=\frac{S_{q} v_{d c}}{2}, v_{r d}=\frac{S_{d} v_{d c}}{2}
$$

As for the DC side, the equation governing the DC output of the rectifier is given by $(5-5)$,

$$
C \frac{d v_{d c}}{d t}=\frac{3 S_{q} i_{q}}{2}-\frac{v_{d c}}{R_{L}}
$$

Hence, the complete dynamic model of the system is given by (5-6),

$$
\left[\begin{array}{c}
\frac{d i_{q}}{d t} \\
\frac{d i_{d}}{d t} \\
\frac{d v_{d c}}{d t}
\end{array}\right]=\left[\begin{array}{ccc}
-\frac{R}{L} & w & -\frac{S_{q}}{L} \\
w & -\frac{R}{L} & -\frac{S_{d}}{L} \\
\frac{3 S_{q}}{2 C} & 0 & -\frac{1}{C R_{L}}
\end{array}\right]\left[\begin{array}{c}
i_{q} \\
i_{d} \\
v_{d c}
\end{array}\right]+\left[\begin{array}{ccc}
\frac{1}{L} & 0 & 0 \\
0 & 0 & 0 \\
0 & 0 & 0
\end{array}\right]\left[\begin{array}{c}
e_{q} \\
0 \\
0
\end{array}\right]
$$

The power balance equation of the system assuming that is lossless is given by $(5-7)$,

$$
\frac{3}{2} v_{r q} i_{q}=v_{d c} C \frac{d}{d t} v_{d c}+\frac{v_{d c}^{2}}{R_{L}}
$$




\subsubsection{Vector Decoupling Technique}

Two nested loops was utilized to realize DC voltage and input current control simultaneously. The outer loop is for controlling the DC bus voltage. In this loop, the developed smart controller is utilized and the inner loop current control is realized. PI controllers were tuned and utilized in the controller. We used the d-q transformation and PI controllers worked on three DC signals, which helped eliminate steady state errors.

Moreover, in order to enhance the performance of the current control loop, the decoupling term $(\mathrm{wL})$ was included while calculating the rectifier's input voltages. These voltages are the modulation signals for the PWM technique. The equations used in building the controller are given by (5-8) and (5-9),

$$
\begin{aligned}
& v_{r q}^{\text {cont }}=w L i_{d}+e_{q}+k_{p}\left(i_{q}^{\text {ref }}-i_{q}\right)+k_{i} \int\left(i_{q}^{r e f}-i_{q}\right) d t \\
& v_{r d}^{\text {cont }}=-w L i_{q}+k_{p}\left(i_{d}^{\text {ref }}-i_{d}\right)+k_{i} \int\left(i_{d}^{\text {ref }}-i_{d}\right) d t
\end{aligned}
$$

This vector decoupling control technique allows control of the active and reactive power drawn from the grid separately so it is able to work at the unity power factor if the reference value of id was set at zero as shown in the equations of active and reactive power in d-q frame of references given by (5-10) and (5-11), respectively. Figure 5.2.2.1 shows a block diagram of the controller used in this paper.

$$
\begin{aligned}
& P(t)=\frac{3}{2}\left(v_{r q} i_{q}-v_{r d} i_{d}\right) \\
& Q(t)=\frac{3}{2}\left(v_{r q} i_{d}-v_{r d} i_{q}\right)
\end{aligned}
$$




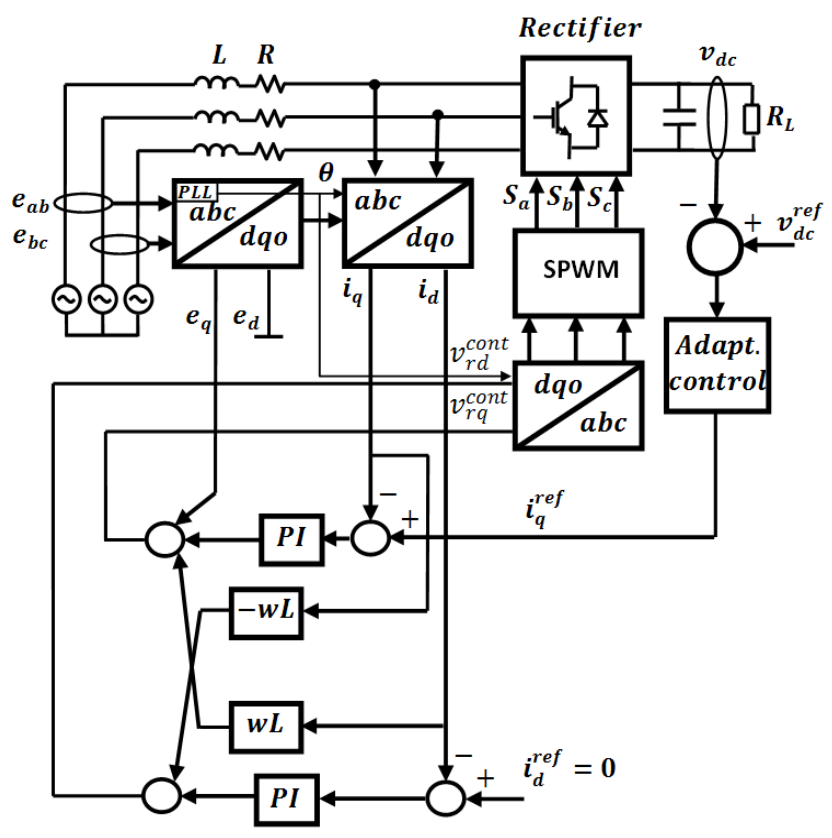

Figure 5.2.2.1: Vector decoupling control of the SPWM rectifier used in this paper.

\subsection{Adaptive Voltage Controller}

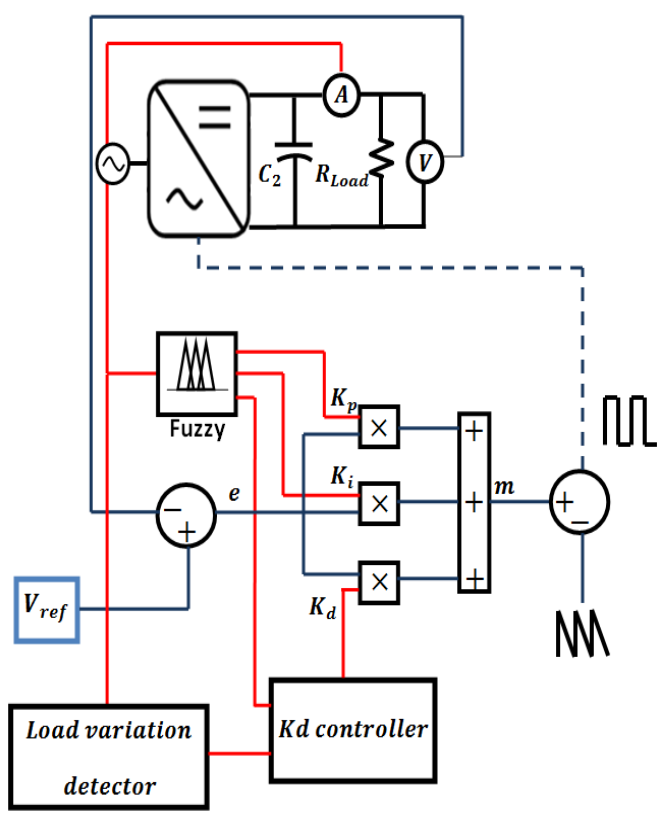

Figure 5.3.1: Block diagram of the developed adaptive controller used in the controlled rectifier under study in this paper. 
Proportional integral derivative (PID) or Proportional integral (PI) controllers are usually used to control the output DC voltage in such systems. However, they have to be tuned based on a certain defined operating range. Loading conditions have great effect on PI controllers and PI controllers are subjected to failure under dramatic load changes. This limits the PI controller's operating range. Moreover, transient and steady state response both get affected by changing the operating range. Thus, in this paper we use an adaptive-PID controller. This developed controller maximizes the stable operating range by ultimately tuning the PID parameters at various loading conditions. Then, a fuzzy logic approach is used to add a factor of intelligence to the controller such that it can autonomously move among different values of proportional gain $(\mathrm{Kp})$, derivative gain $(\mathrm{Kd})$ and integral gain $(\mathrm{Ki})$ based on the system conditions. This controller widens the converter's operating range and reduces the possibility of failure. Moreover, a technique to move between the PI and PID configurations of the controller such that the minimum overshoot and ripple are obtained, which makes the controller very applicable even for systems supplied with sensitive loads. A block diagram of the controller used in the developed system is shown Figure 5.3.1.

\subsection{Maximizing the Operating Range}

In order to maximize the operating range of the control system and make the controller capable of handling wide range of output currents. The PID controller parameters were tuned around different overlapped operating points. The tuning process aims at minimizing rise time, settling time, ripple, and steady state error of the output voltage of the rectifier and maximize the controller's stability corresponding to step 
changes in the load. This process yields values of $\mathrm{Kp}, \mathrm{Ki}, \mathrm{Kd}$ which are optimal for different output current ranges. An example of the results of the tuning process in the range from 0-4 Amps is given in Table 5.4.1.

Table 5.4.1: $\mathrm{Kp}, \mathrm{Ki}$ and $\mathrm{Kd}$ optimal values at different loading conditions

\begin{tabular}{c|ccc}
\hline Current range & $\mathrm{Kp}$ & $\mathrm{Ki}$ & $\mathrm{Kd}$ \\
\hline $0.00-0.80$ & 0.00200 & 0.2000 & 0.000000 \\
$0.80-1.36$ & 0.00940 & 0.6216 & $1.1765 \mathrm{e}-4$ \\
$1.36-1.76$ & 0.00830 & 0.6216 & $1.1913 \mathrm{e}-4$ \\
$1.76-2.24$ & 0.00320 & 0.6214 & $7.0000 \mathrm{e}-4$ \\
$2.24-3.00$ & 0.00270 & 0.5300 & $2.7420 \mathrm{e}-5$ \\
$3.00-4.00$ & 0.00128 & 0.4042 & $1.4527 \mathrm{e}-4$ \\
\hline
\end{tabular}

\subsection{Bi-directional Power Flow}

An important feature of grid-connected DC micro-grids or DC distribution systems is the ability to inject or extract power from the grid based on the generation and loading conditions. In order to do that, a controlled AC-DC/DC-AC which allows bidirectional power flow was designed. This controlled converter is responsible for controlling the amount of power that flows between the AC and the DC grids. Power flow from the AC to DC grid is very important to cover any deficiency in the demand in the DC grid due to normal or pulse loading

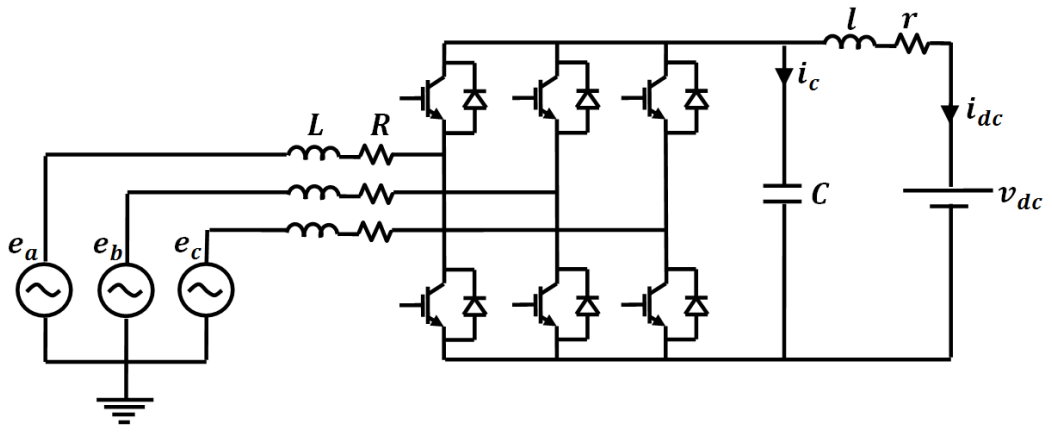

Figure 5.5.1: The three phase bi-directional AC-DC/DC-AC used in the developed system. 
. Power flow from the DC to AC grid is needed when there is an excess in power from renewable energy sources on the DC bus. The same vector decoupling control technique discussed in section II is utilized to allow unity power factor operation while controlling the amount of power bi-directionally flow. However, for this converter, the topology is slightly changed by replacing the $\mathrm{C}$-filter (C in figure 5.2.1) by an L-filter as shown in figure 5.5.1. Moreover, the DC voltage controller in figure 5.2.2.1 is replaced by a current controller as shown in figure 5.5.2. Based on the reference current of this controller $\left(i_{d c}^{\text {ref }}\right)$ the phase shift of the modulating signals of the power electronic switches is adjusted with respect to the grid voltage such that the desired amount of power flows in either direction. The current on the DC side is assumed positive if flowing from the Ac grid to the DC system and vice versa. Hence, if $\mathrm{idc}_{\mathrm{dc}}^{\text {ref }}$ is set to a positive value the bi-directional AC-DC/DC-AC converter will autonomously operate in the rectifier mode and the modulating signals will lag in the grid voltage. However, if it is set to a negative value the modulating signals will lead and the DC network will inject current to the $\mathrm{AC}$ grid. In both modes of operation, the vector decoupling technique used allows unity power factor operation by setting $\mathrm{i}_{\mathrm{d}}^{\text {ref }}$, which is responsible for the reactive power, to zero. 


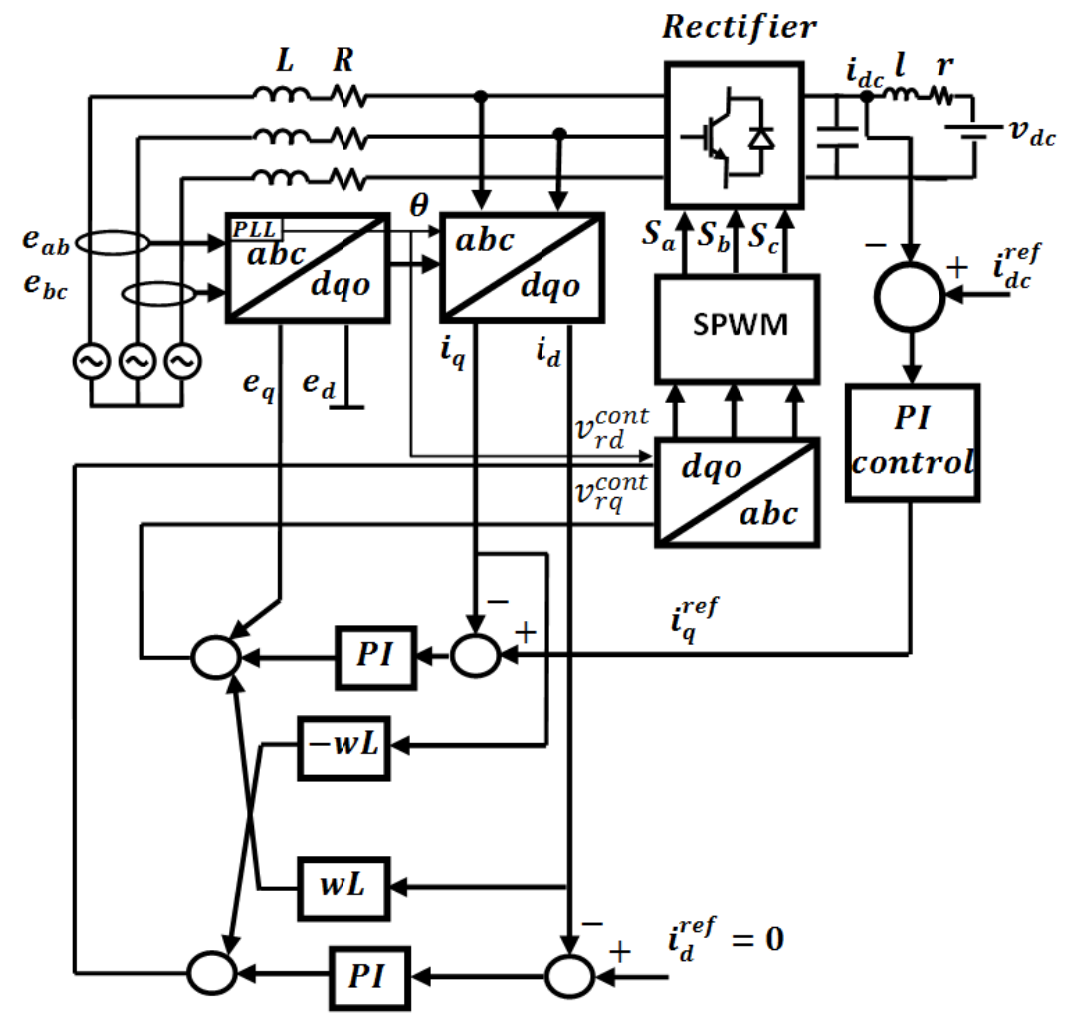

Figure 5.5.2: Vector decoupling control of the SPWM rectifier used in this paper.

\subsection{Results and Discussion}

The fully controlled bi-directional converter is operated at $8 \mathrm{KHz}$ switching frequency and sampling time $0.3 \mathrm{~ms}$, which allows the controller to detect and respond quickly to different load demands at either the AC or DC sides. The converter is designed to operate at a low THD and at unity power factor. A $24 \mathrm{mH}$ inductor with $0.9 \mathrm{ohm}$ losses is connected between the AC grid and the converter to filter harmonics associated with the fundamental current wave form. A $1200 \mu \mathrm{F}$ capacitor is placed at the converter's DC side. Simulation results that are verified by experimental results were taken for the converter under different operating conditions. The bi-directional was operated in the 
current controlled rectifier mode, current controlled inverter mode and has also been tested to instantaneously change its mode of operation.

Power sharing in the DC side is different from power sharing in the $\mathrm{AC}$ side. In case of sharing AC power, the voltage phase and amplitude is changed at one terminal of a reactive passive element and power can flow from one point to another. However, in DC network the only way to share continues current is by changing the DC voltage at one terminal of a resistor. Which leads to having a potential difference across its terminals and eventually DC power can flow. However, resistors are losses in the system. Therefore, the resistor that couples between the DC grid and the controlled bi-directional converter must have as small of a value as possible. The value of the resistor has a direct relation to the voltage drop across the resistor terminals which must be in a sensible range in order for the current control to be achieved properly. In this case a $24 \mathrm{mH}$ inductor with internal resistance of $0.9 \mathrm{ohms}$ is used to couple between the DC grid and the bidirectional converter. The inductor enhances the distortions in the DC current by a huge factor which allows smooth current sharing. In conclusion, an inductor that is properly designed is placed between the output terminal of the converter and the DC grid to allow a continuance of power sharing. 


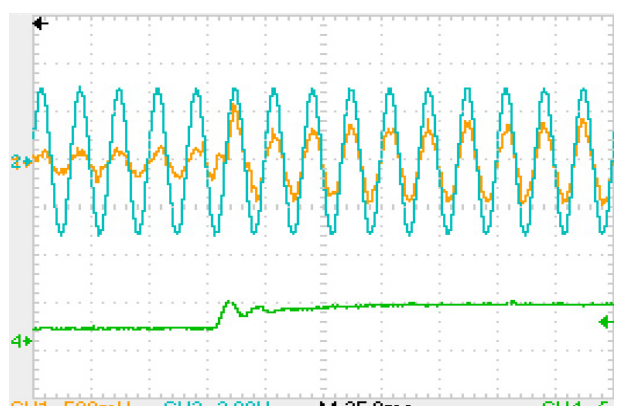

(a)
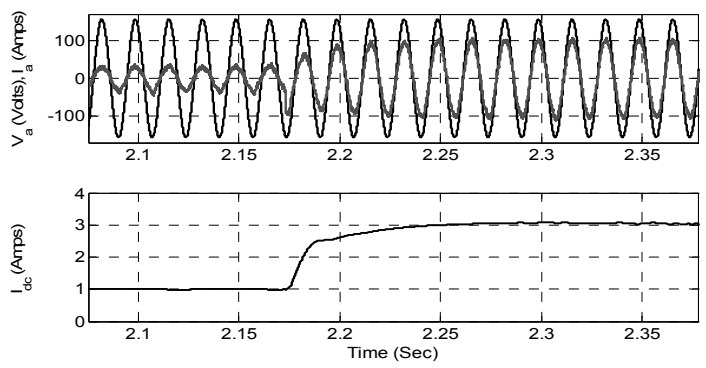

(b)

Figure 5.6.1: Controlled Bi-directional response to DC current reference change 1-3 Amps, (a) experimental results, (b) simulation results.

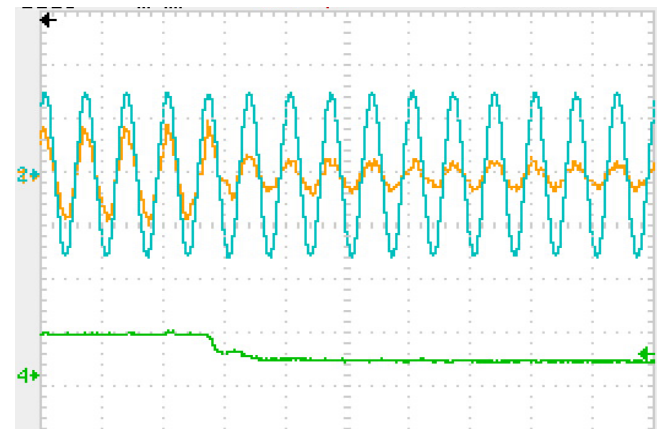

(a)
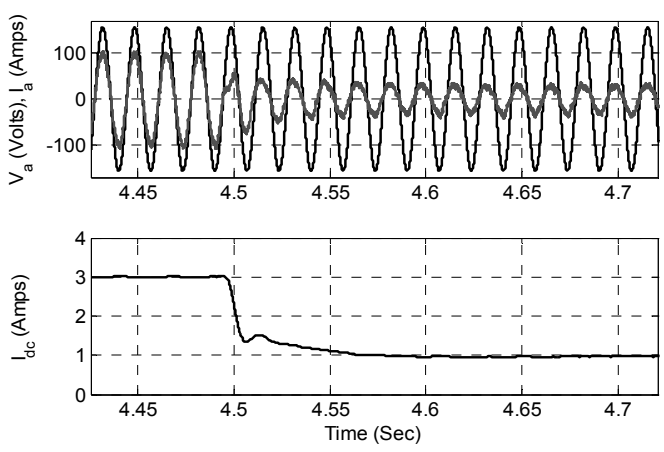

(b)

Figure 5.6.2: Controlled Bi-directional response to DC current reference change 3-1 Amps, (a) (a) experimental results, (b) simulation results.

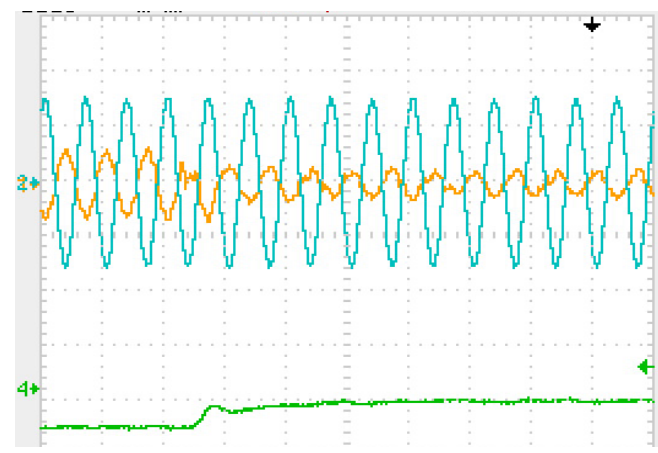

(a)
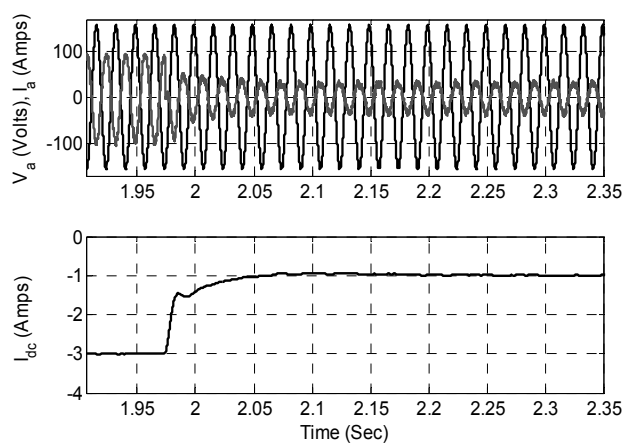

(b)

Figure 5.6.3: Controlled Bi-directional response to DC current reference change (-3)-(-1) Amps, (a) experimental results, (b) simulation results. 


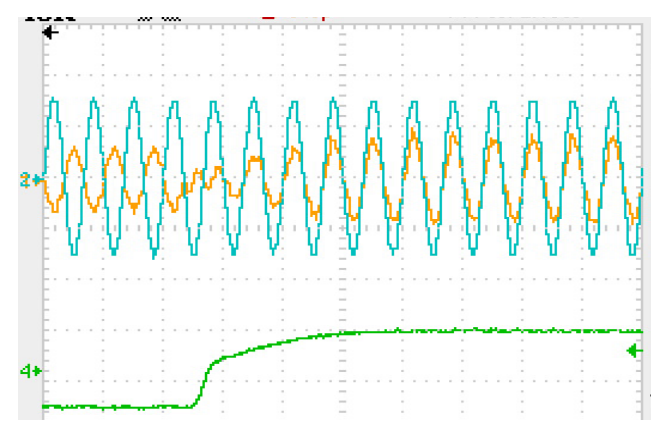

(a)
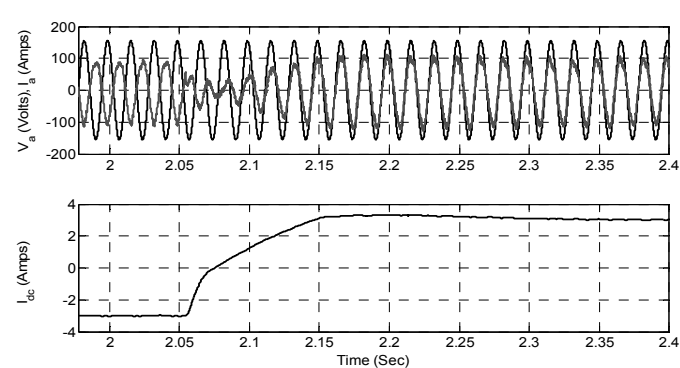

(b)

Figure 5.6.4: Controlled Bi-directional response to DC current reference change (-2)-(3) Amps, (a) simulation results, (b) experimental results.

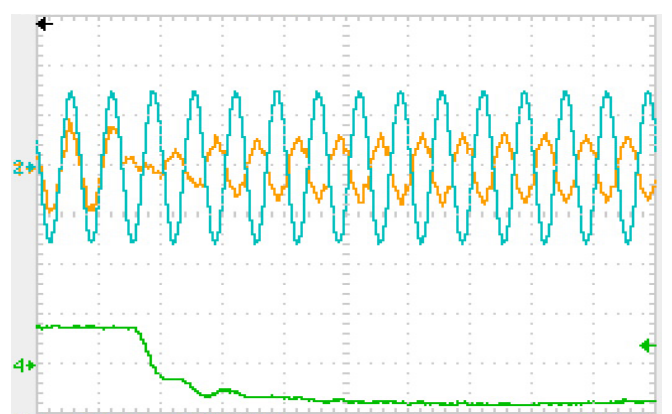

(a)
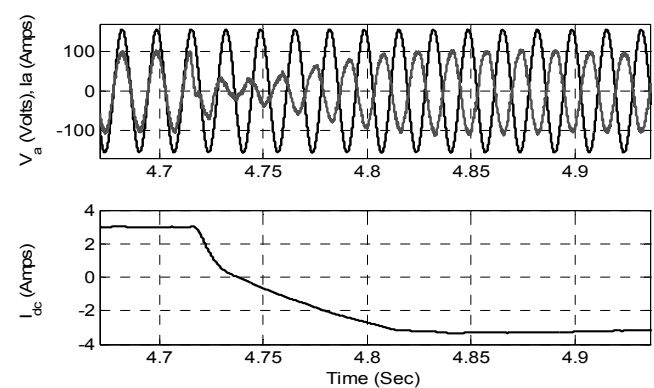

(b)

Figure 5.6.5: Controlled Bi-directional response to DC current reference change (3)-(-2) Amps, (a) simulation results, (b) experimental results.

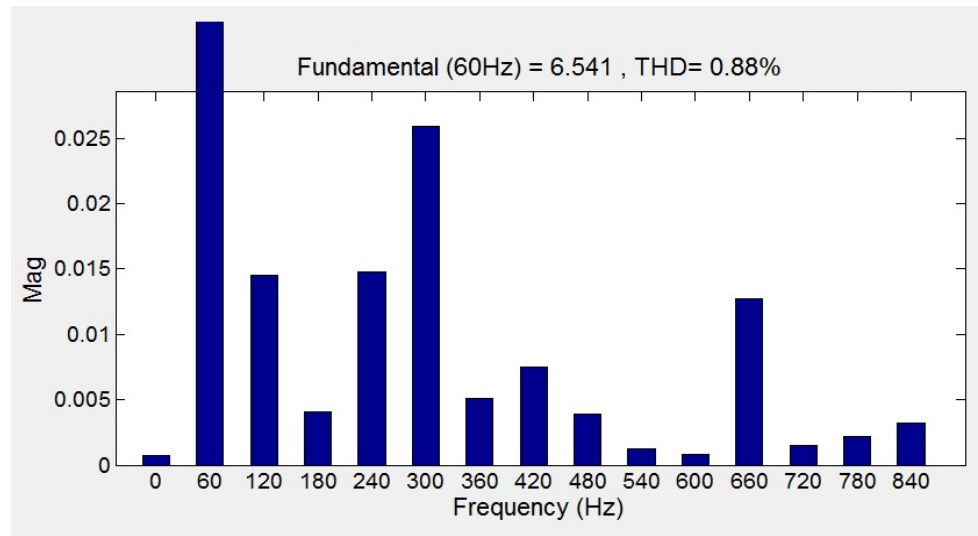

Figure 5.6.6: Harmonic analysis of the input current to the rectifier. 
Figure 5.6.1 shows the operation of the bi-direction converter at unity power factor. It is operated in the current controlled rectifier mode. The reference current is set to transfer $1 \mathrm{ADC}$ from the $\mathrm{AC}$ grid to the $\mathrm{DC}$ grid. Within 2 cycles the controller achieves to satisfy the reference current. Also in figure 5.6.2, the controller is tested to reduce the current been sucked from the $\mathrm{AC}$ grid from $3 \mathrm{~A}$ to $1 \mathrm{~A}$. The experimental results validate the simulation results. The bi-directional controller is also tested in the mode of controlled inverter. The controller is commanded to transfer $1 \mathrm{~A}$ to the grid and then at a later time the current reference is changed from $-1 \mathrm{~A}$ to -3 . As seen in figure 5.6.3 the controller quickly satisfied the reference value. Figure 5.6.3 shows the results of the converter when it is operated in the inverter mode and the reference are changed from -3 A to -1 A. The current is shifted $180^{\circ}$ from the voltage waveform, since it is injecting power to the grid. It can also be seen that the converter is operating at unity power factor in this mode.

One of the most important advantages of the bi-directional converter is its ability to instantaneously change from the current controlled inverter to a current control rectifier and vice versa by switching the current direction. Figure 5.6.4 shows the simulation and experimental results for the controlled rectifier when the current retrace is changed from $-2 \mathrm{~A}$ to $3 \mathrm{~A}$. The sign of the current indicates the direction of the current. $3 \mathrm{~A}$ indicates a $3 \mathrm{~A}$ is being taken from the $\mathrm{AC}$ grid to the $\mathrm{DC}$ grid and $-2 \mathrm{~A}$ represents a $2 \mathrm{~A}$ given to the $\mathrm{AC}$ from the $\mathrm{DC}$ grid. Moreover, Figure 5.6.5 shows the results for changing the reference current from $3 \mathrm{~A}$ to $-2 \mathrm{~A}$. in other words, the controller is commanded to switch from the controlled current rectifier mode to the controlled current inverter mode, 
i.e. current will flow from $\mathrm{DC}$ grid to the $\mathrm{AC}$ grid. It can be seen that the experimental results are a match for the simulation results.

Finally, Figure 5.6.6 shows the harmonic analysis of the current drawn from the grid. The total harmonic distortion (THD) of the current is $0.88 \%$, which is acceptable. 
CHAPTER 6

SMART DYNAMIC UNIT COMMITMENT SCHEME FOR AC DISTRIBUTION SYSTEMS INVOLVING HYBRID RENEWABLE ENERGY SOURCES

\subsection{Introduction}

In this chapter, an effective algorithm for optimizing distribution system operation in a smart grid, from cost and system stability points of view, was developed. The developed algorithm mainly aims at controlling the power available from different sources such that they satisfy the load demand with the least possible cost while giving the highest priority to renewable energy sources. Moreover, a smart battery charger was designed to control the batteries in such a way that allows them to discharge only when there is not a huge load predicted within the coming period. Therefore, they become available to act as a buffer for the predicted large load, they also increase the stability of the system, and reduce voltage dips. In addition, batteries are used to serve another purpose from an economic point of view, which is peak-shifting during the day in order to avoid the relatively high prices of grid power during peak periods. Since this algorithm is mainly dependent on forecasted data of the power available from different renewable energy sources as well as the load demand, full attention was paid to the forecasting process. Hence, a non-linear regression technique was applied to build accurate forecasting models for different sources as well as the load. These models help in monitoring and predicting the total power generation and demand online. Furthermore, a fuzzy controller was utilized to make use of the forecasted data of the coming peak 
period then decide dynamically the amount of power that should be taken out of the battery. Different case studies were investigated to verify the validity of the developed algorithm and define the system behavior under several conditions.

\subsection{System and Problem Description}

In order to examine the developed commitment scheme, a prototype system was used. The system under study is an AC distribution system that depends mainly on renewable energy sources to supply its local loads. However, the system includes a backup battery system that can support load deficiencies. In addition, the system is connected to the main grid, which also can supply the load in case the power available from different renewable energy sources is not enough. However, in this paper we try to make the system under study as self satisfied as possible. This means that we are minimizing the power drawn from the grid. The maximum peak load is assumed as 300 $\mathrm{kW}$. The PV system has a capacity of $100 \mathrm{~kW}$. On the other hand, the wind system has a capacity of $150 \mathrm{~kW}$.

\subsection{Data Forecasting}

A Mathematical models for PV, wind and load demand power was obtained based on previous actual data from data bases. The unit commitment problem of a prototype system containing PV, wind, battery system and loads was investigated in case the system is grid-connected. To add a factor of intelligent, a fuzzy controller was designed to control the amount of power that should be taken out of the battery system in case of 
power deficiency to cover the load demand, while maintaining high voltage stability of the system.

\subsubsection{Data Collection}

In order to solve the commitment problem involving renewable energy sources and coordinate the sources in an economic way, information about the total generation available out of renewable energy sources as well as the load demand should be known in advance. Hence, we count on real data forecasting of PV and wind output power as well as the demand. The data forecasting process was based on PV data collected over 15 years on an hourly basis for a unit in the state of Texas, wind data collected over four years on a 10 minute basis and load data over four years on an hourly basis for the same region. A non-linear regression modeling technique was employed to mathematically model the output power of each of the renewable sources and the load demand. Different model evaluation indices was used to validate the mathematical models obtained.

\subsubsection{Non-Linear Regression Modeling}

The non-linear regression model used in this paper has the ability to cope with the non-linearity of the data and form an accurate model. It is based on the idea of transformation of the data using a pre-defined set of non-linear functions in order to achieve linearity [32].

The non-linear model given in and designated as has the following form:

$$
Y_{n l m}=b_{0}+y_{1}+y_{2}+\ldots+y_{m}=b_{0}+\sum_{i=1}^{m} y_{i}, i=1,2, \ldots, m
$$


$y_{i}=a_{i 1} b_{i 1} f_{1}\left(x_{i}\right)+a_{i 2} b_{i 2} f_{2}\left(x_{i}\right)+\ldots+a_{i j} b_{i j} f_{j}\left(x_{i}\right)+\ldots+a_{i k} b_{i k} f_{k}\left(x_{i}\right)$

where:

$\mathrm{k} \quad$ is the total no. of non-linear functions.

$\mathrm{m} \quad$ is the total no. of variables to be included in the model.

$\mathrm{y}_{\mathrm{i}}, \quad$ is a non-linear model for each variable and is the summation of all terms resulting from transforming input xi through a pre-selected set of nonlinear functions.

aij, bij are constants to be determined, $\mathrm{j}=1,2, \ldots, \mathrm{k}$.

$f_{1}, f_{2}, . ., f_{k}$ are pre-selected set of non-linear functions that will be used for transformation of inputs. The set of non-linear functions may contain $x^{\alpha}, 1 / x, e^{-x} \& \ln (x)$

$\mathrm{x}_{\mathrm{i}} \quad$ is the numerical values for a given input to be used for deducing the model.

\subsubsection{Model Evaluation Indices}

Different model evaluation indices were implemented to measure the accuracy of the developed mathematical models. They are the mean absolute percentage error (MAPE) calculated by (3) and the coefficient of determination $R_{\tilde{\varepsilon}}^{2}$ computed by (4): 
$M A P E=\frac{\left\{\sum|\vec{d}-\vec{y}| \times 100 /|\vec{y}|\right\}}{n}$

$R_{d}^{2}=\frac{\left.\sum \overrightarrow{(d}-\vec{y}\right)^{2}}{\sum\left(\vec{y}-y_{a v g}\right)^{2}}$

Where, $\vec{d}$ and $\vec{y}$ are the vectors of real and predicted data, respectively.

The value of $R_{d}^{2}$ for a model is ranging from 0 to 1 and it implies that $R_{d}^{2}$ of the sample variation is attributable to or explained by one or more of the variables as long as it approaches unity. The better regression fits the data the closer the value of $R_{d}^{2}$ is to one.

\subsubsection{Mathematical Modeling Results}

Mathematical models for PV and wind systems output power in addition to the load demand were deduced. These mathematical models are given by (6-5), (6-6) and (67), respectively.

$$
\begin{aligned}
& P_{P V}=-962.8+5915 H^{0.4}+797.6 D^{0.8}+114.5 H^{0.7} D^{0.8} \\
& P_{\text {Wind }}=62.2-106 H^{0.8}+82 D^{0.4}+4.2(100 / H) D^{0.7}+17.3 H^{0.4} D^{0.7}-0.2 H^{0.8} D^{0.4} \\
& P_{\text {Load }}=32.5-45.6 H^{0.4}+102 D^{0.8}+7.24 D^{0.7}(100 / H)-3.1 H^{0.4} D^{0.4}
\end{aligned}
$$

Where, $H$ and $D$ are the hour and month, respectively.

The PV mathematical model was trained using the sets of data of fourteen previous years. However, the model was tested using the data of the most recent year, which has not been included during the training process. Figure 6.3.4.1 shows the mathematical modeling results of the PV data versus the actual data. We can see that the 
modeling results are successfully tracking the actual ones along the whole year. The $M A P E$ of this model is 4.65 , which is a reasonable value taking into consideration that we are minimizing the inputs to the model (variables of the non-linear functions) to only time bases. However, if we were to take other inputs related to environmental variations corresponding to sun radiations, we would definitely obtain a more detailed model as these inputs are much more correlated to the output power of the PV than just time. Moreover, the value of $R_{d}^{2}$ is 0.951 , which means that the transformed inputs used are representative to the output power of the PV system. In this paper, we try to count on only time to predict the output power. Non-linear regression is helpful in this case as it transforms sets of inputs into other forms that are more correlated to the desired output.

The wind data was categorized into two groups; data of the first two years available was used as training data and data of the most recent year was used as testing data. Figure 6.3.4.2 shows the mathematical modeling results versus the actual data results of the wind. We can also see that the model is successfully representing the actual data. The MAPE is $6.1 \%$, such a small value proves the accuracy of the model. Moreover, the value of $R_{d}^{2}$ is 0.941 , which is again acceptable.

The load data for four consecutive years was used to model the load duration curve and they was categorized as follows, data of three years as training data whereas data of another year as testing data. Figure 6.3.4.3 shows the results of the obtained load demand model. Actual and modeling data are close to each other, which validates the model obtained. Moreover, values of the $M A P E$ and $R_{d}^{2}$ are $6.45 \%$ and 0.934 , respectively. The value of $M A P E$ is relatively small. Whereas, the value of $R_{d}^{2}$ is close to 
one. These two facts support our conclusion that the mathematical model is well representing the actual data.

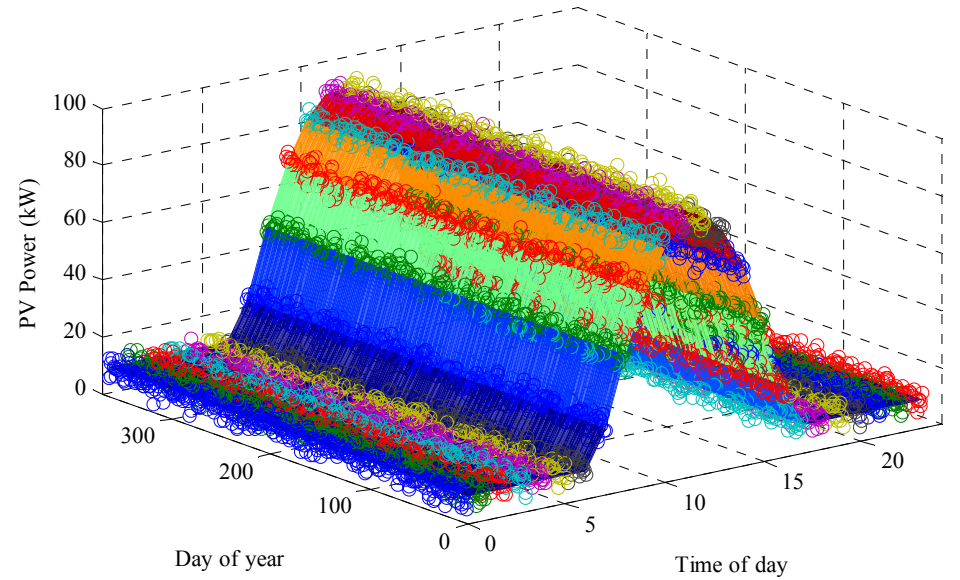

Figure 6.3.4.1: PV actual versus modelling data for one year

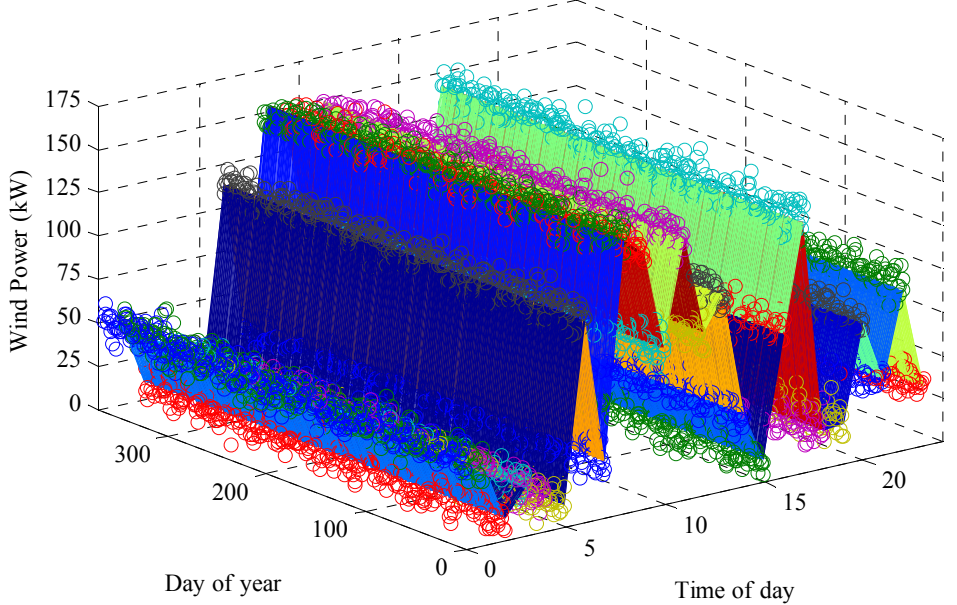

Figure 6.3.4.2: Wind actual versus modelling data for one month 


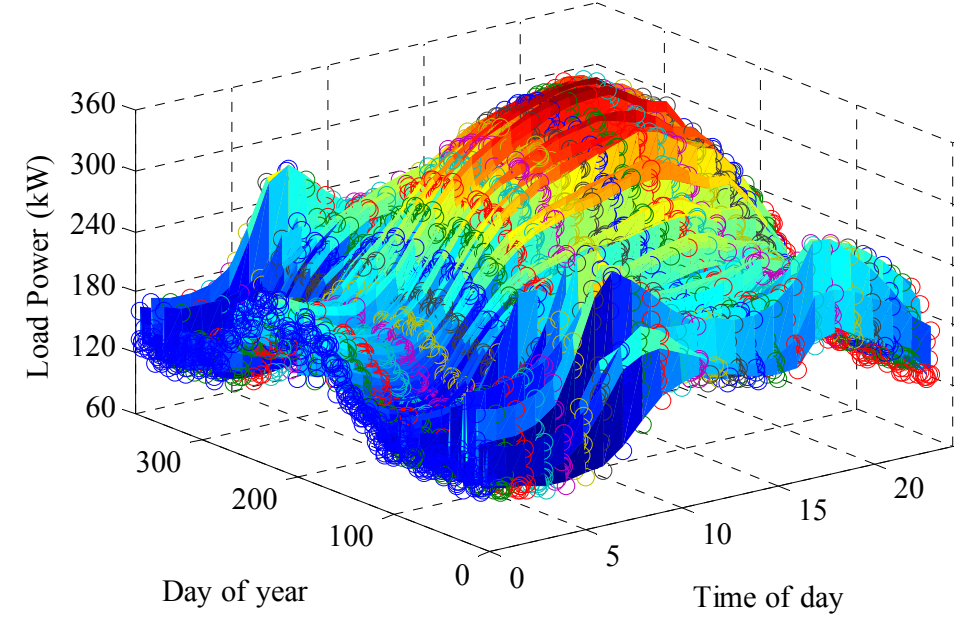

Figure 6.3.4.3: Load demand actual versus modeling data for one year

\subsection{Unit Commitment Problem}

The main objective of the unit commitment problem solved in this paper is to minimize the power drawn from the grid, to keep the battery's SOC above $60 \%$ and to be prepared as a buffer for sudden large loads, and to use the energy stored in the batteries to shift peaks and, consequently, save money.

Hence, intuitively we commit both the PV and the wind systems to supply all the power available at them. This means that both of them are working in the maximum power point tracking mood. These types of systems generally have two different scenarios;

Firstly, if the power available from renewable energy sources exceeds the load demand, the power is injected back to the grid or used to charge the batteries.

Secondly, if the load demand is larger than the power available from renewable energy sources, we have power deficiency as given by (6-8).

$p_{d}=p_{\text {load }}-\left(p_{P V}+P_{\text {wind }}\right)$ 
Where, $P_{d}$ is the power deficiency. Generally, we have two different sources to supply this deficiency in power. That is either by using the power stored in the battery system or using the grid. In this case, as we previously stated the objective here is to make the system as self-dependent as possible. Hence, the priority is given to the batteries to supply the deficiencies. However, if it is predicted to have a big peak load within the coming few hours the priority is given to have the batteries ready with a relatively high state of charge (SOC) by the time of occurrence of that peak load. The purpose of this is to maintain high voltage stability of the system while minimizing the cost.

Moreover, a special care was given to whether it is a peak or an off-peak hour as the cost of energy is different in both cases. Managing the power corresponding differently corresponding to peak and off-peak hours reduces the total annual cost. The commitment problem is run continuously. This means that the futuristic load and total supply powers are predicted and based on these values in addition to the time at which the coming peak load is taking place and the current SOC of the batteries. The percentage of power that will be taken from each of the grid and the batteries will be decided. The mathematical models derived are used to forecast the peak load and the hour of its occurrence as well as the renewable energy power. In addition, in one of the cases they will used to calculate the energy that will be required during the coming peak hours by integrating the area under the power curve. Moreover, a fuzzy system is used to solve a part of this commitment problem as fuzzy systems have the abilities to solve such kinds of complicated problems. 
The mathematical models derived were used to predict the peak load and generation available at the time it occurs. At peak load, the partial derivative of the curve with respect to hours tends to go to zero. Hence the hour at which the peak load will take place at a given day can be calculated as in (6-9)

$\frac{\partial P_{\text {load }}}{\partial H} \|_{D=D_{1}}=0$

Where, D1 is the day in which we are calculating. Solution of (6-9) yields the hour H1, which is the hour at which the coming peak load is taking place. Substituting in (6-5), (6-6) and (6-7) with the value of H1, we get values of the load demand, PV and wind output power. These values are Pload1, PPV1 and Pwind1, respectively. The energy during the coming peak hours, used in the energy management algorithm developed in this paper, is predicted as follows:

$E=\int_{H_{\min }}^{H_{\max }} P_{\text {load }} \bullet d H$

Where, $\mathrm{H}_{\min }$ and $\mathrm{H}_{\max }$ are the starting and end hour of the coming peak period.

Since, customers can save an average of 6\%-7\% annually over the Basic Plan by shifting some energy use to off-peak hours. This was taken into consideration in order to have the economic operation of the system.

The available sources are,

- $\quad \mathrm{PV}$ and Wind (P_PV 『+P》_Wind)

- Battery during the discharging mode (P_(d,batt))

- Utility Grid $\left(\mathrm{P}_{\mathrm{u}}\right)$

Loads are, 
- Normal loads $\left(\mathrm{P}_{\text {load }}\right)$

- Battery during the charging mode $\left(\mathrm{P}_{\mathrm{d}, \mathrm{batt}}\right)$

The developed algorithm has three inputs; the difference between the renewable power $\left(\mathrm{P}_{\mathrm{PV}}+\mathrm{P}_{\text {wind }}\right)$ and the load demand, if the current time is within peak hours or not, SOC of the battery, predicted renewable power at the hour of the coming week and the hour at which it occurs.

There are two possible cases discussed in section 6.4.1 and section 6.4.2.

\subsubsection{Case 1}

In case 1 , there is a surplus in power $\mathrm{P}_{\mathrm{PV}}+\mathrm{P}_{\text {Wind }}-\mathrm{Pl}_{\text {oad }} \geq 0$

1. If $\mathrm{H}$ lies within the Off-peak hours, since the electric energy price is expected to be lower than its value within the peak hours, priority is given to charge the battery. However, the portion of the surplus power $\left(\mathrm{P}_{\text {surplus }}\right)$ that charges the battery system $\left(\mathrm{P}_{\mathrm{c}, \text { batt }}\right)$ follows the developed pattern shown in figure 6.4.1.1 whereas the rest is injected to the grid.

2. If $\mathrm{H}$ lies within the peak hours, since the electric energy price is relatively high, priority is given to sell power to the grid then charge the battery system. Hence, the power assigned to charge the battery follows this developed pattern shown in figure 6.4.1.2. 


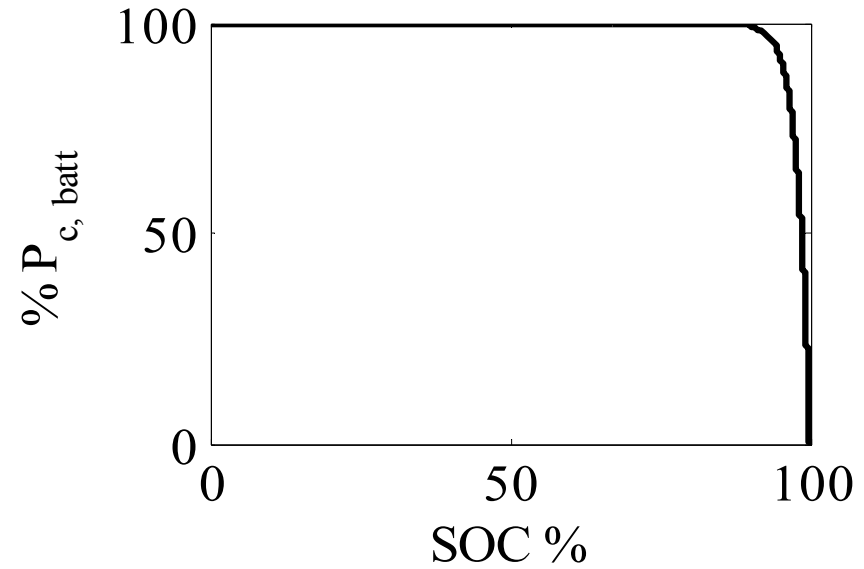

Figure 6.4.1.1: Battery power as a function of its SOC when there is an excess in power within the Off-peak period.

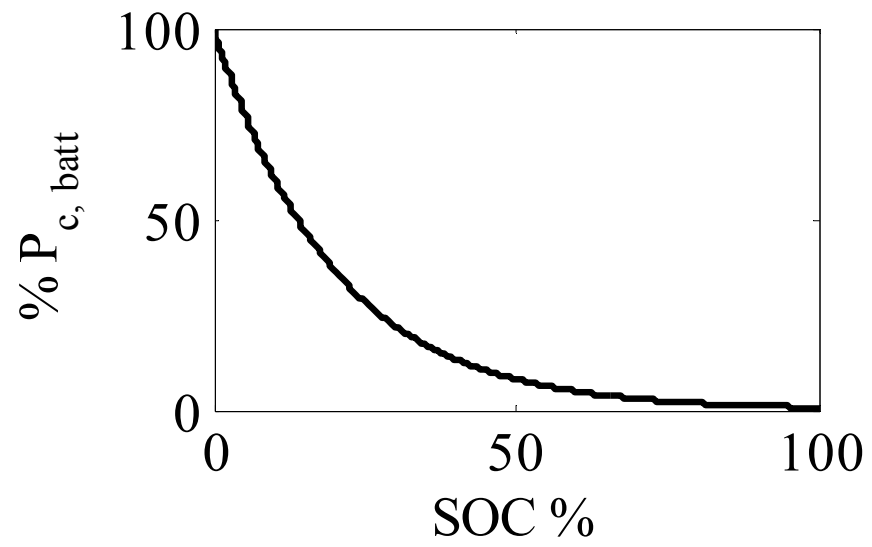

Figure 6.4.1.2: Battery power as a function of its SOC when there is an excess in power within the peak period.

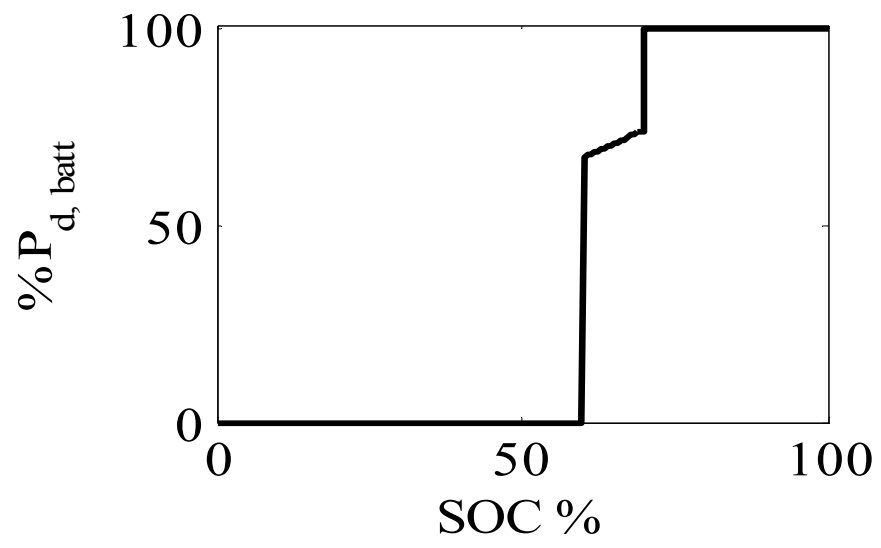

Figure 6.4.1.3: Battery power as a function of its SOC when there is a deficiency in power within the peak period. 


\subsubsection{Case 2}

In Case 2, there is a deficiency in power $\mathrm{P}_{\text {load }}-\mathrm{P}_{\text {Wind }} \geq 0$, if the SOC is less than $60 \%$, we disconnect the battery to charge it when there is a surplus in power. Whereas, if the SOC is greater than $60 \%$, the algorithm goes on with the following conditions,

1. If $\mathrm{H}$ lies within the peak hours, priority is given to the power stored in the battery system to supply the loads to help satisfying $P_{\text {def }}$, the rest of load demand is satisfied from the grid. The portion of the deficiency power $\left(\mathrm{P}_{\text {deficiency }}\right)$ that discharges from the battery system $\left(\mathrm{P}_{\mathrm{d}, \text { batt }}\right)$ is implemented mathematically using the exponential curve shown in figure 6.4.1.3.

2. If $\mathrm{H}$ lies within the Off-peak hours, $\mathrm{P}_{\mathrm{def}}$ is covered partially by the battery system according to a fuzzy system that was developed. This fuzzy system was based on the forecasted data of the expected next peak period and the energy needed within it. The developed fuzzy system will be explained explicitly in section 6.5 .

\subsection{Fuzzy Systems}

Fuzzy is a powerful control method that can be applied on different systems. It is based on the experience of the user about the system behaviour rather than modelling the system under control mathematically like in linear control theory. This makes fuzzy control a powerful control technique especially with non-linear systems in which it is difficult to derive an accurate approximated mathematical model of the system and expect its behaviour. Fuzzy control is a rule-based control technique that is approached by linguistic fuzzy rules, which describe the output desired out of the system under 
different operating conditions. Fuzzy rules are in the form of if-then rules that the proficient user should design such that they cover all the conditions the system is expected to go through.

In this model, Fuzzy was used only in the case when the instantaneous load demanded is higher than the instantaneous available power from renewable energy sources and the system is not in at the peak period. At this state, the battery will be operated at the discharge mode. Hence, Fuzzy determines the amount of power to be drawn from the battery while taking into consideration the time left for the coming peak period and the ration between the current energy available in the battery to the total energy needed during that peak period (R). It is worthy to remind here that the SOC of the battery is also playing a significant role as explained earlier section 6.4 .

Designing a fuzzy logic controller is achieved through three basic steps; fuzzification, inference Mechanism and defuzzification. The Sugeno type fuzzy system was used in this paper.

In fuzzification, time left for the coming peak period and the current SOC of the batteries are the inputs to the control system which are mapped into a certain linguistic values. The output of the fuzzy is a percentage that determines the percentage of load to be satisfied by the batteries. Three Fuzzy variables; two inputs and an output, was involved in this paper as shown in figure 6.5.1. Each variable has some membership functions. For the first input, which is the time left for the coming peak period, three Fuzzy subsets are used; small (S), medium (M) and big (B). Whereas, for the second input, which is the ratio between the current energy available in the battery to the total energy needed during that peak period, four subsets was used; very small (VS), small (S), 
medium (M) and big (B). On the other hand, the output is represented by six Fuzzy subsets; small (S), small big (SB), medium (M), medium big (MB), big (B) and big big (BB). These membership functions are used to map the input variable into fuzzy set. Operation of the membership functions on the input variable yields the extent to which that variable is a member of a particular rule.

The process of converting control variables into linguistics rules is called fuzzification. However, in inference Engine and Rule base step, the output of fuzzy controller is managed through putting certain linguistic rules. These control rules are constructed based on given conditions (inputs) such that the fuzzy controller decides the proper control action.

Finally, in defuzzification, as the output of the fuzzy controller is in the form of fuzzy set, it has to be transformed from linguistic form into a number that can be used to control the system. The rules that was used here are given in Table 6.5.1.

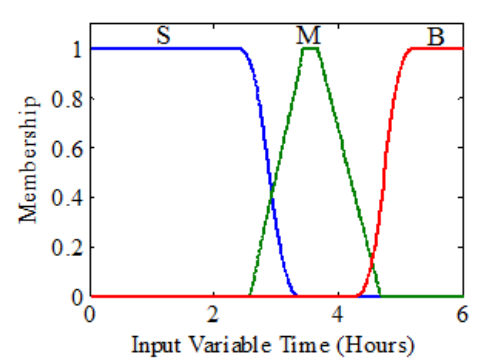

(a)

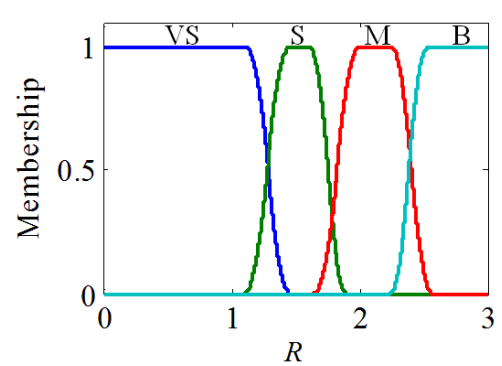

(b)

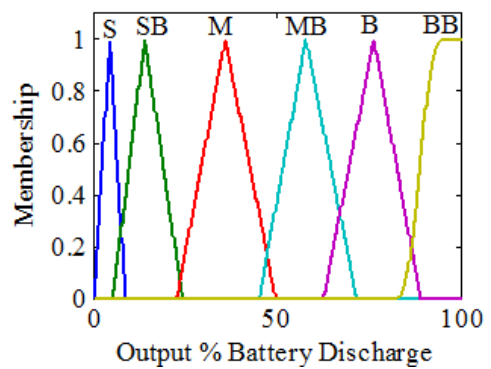

(c)

Figure 6.5.1: Membership functions of different variables of the fuzzy controller: (a) and (b) show the membership functions of the two inputs to the Fuzzy system. Whereas, (c) shows the membership functions of the output variable. 
Table 6.5.1: Fuzzy Rules

\begin{tabular}{|c|c|c|c|}
\hline$R^{\text {Hour }}$ & $\mathrm{B}$ & $\mathrm{M}$ & $\mathrm{S}$ \\
\hline$B$ & $\mathrm{BB}$ & $\mathrm{B}$ & $\mathrm{MB}$ \\
\hline$M$ & $\mathrm{MB}$ & $\mathrm{M}$ & $\mathrm{SB}$ \\
\hline$S$ & $\mathrm{SB}$ & $\mathrm{S}$ & $\mathrm{S}$ \\
\hline $\mathrm{VS}$ & $\mathrm{S}$ & $\mathrm{S}$ & $\mathrm{S}$ \\
\hline
\end{tabular}

The complete developed energy management algorithm is summarized in the flow chart given in figure 6.5.2.

\subsection{Results and discussion}

A simulated environment based on the forecasted data was built to prove the validity of the developed method for estimating the amount of power to be supplied by the battery array each day. A dynamic operation of power flow in a one day-period is shown in figure 6.5.2. The amount of power supplied by the battery array is controlled every day of the year and it is a function of the PV power forecasted data and the wind power forecasted data. The amount of power generated by wind and PV are added and subtracted from the load demand at every time instant. There are four conditions that can be encountered: 


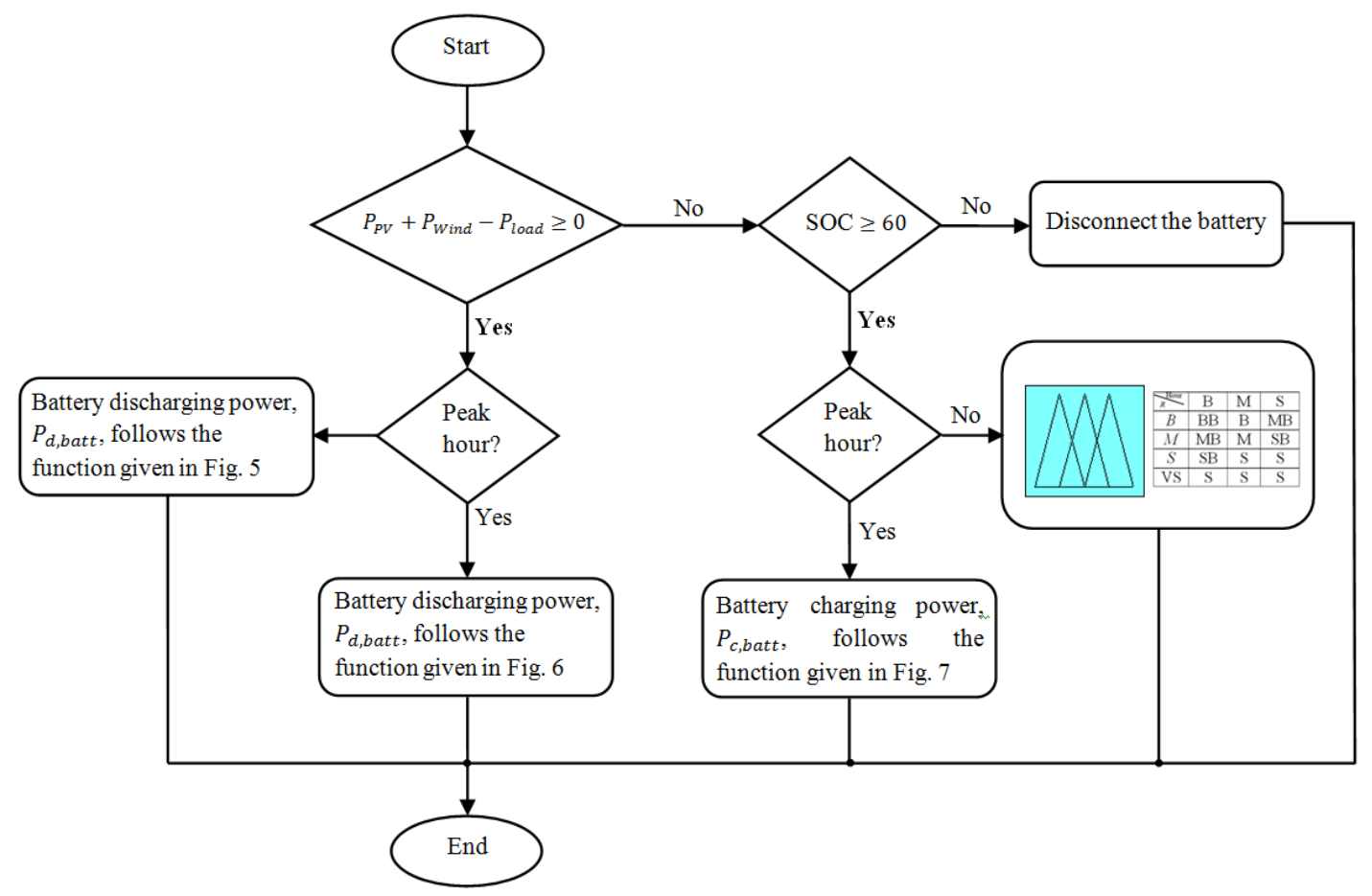

Figure 6.5.2: A flow-chart of the developed energy management algorithm.

1. Load demand is higher than the available renewable energy $P_{\text {load }} \geq P_{P V}+P_{\text {Wind }}$ not during peak period

2. Load demand is higher than available renewable energy $P_{\text {load }} \geq P_{P V}+P_{\text {Wind }}$ during peak hour

3. Renewable energy is higher than load demand during peak hour $P_{\text {load }} \geq P_{P V}+P_{\text {Wind }}$

4. Renewable energy is higher than load demand not during peak hour $P_{\text {load }} \geq P_{P V}+P_{\text {Wind }}$ 


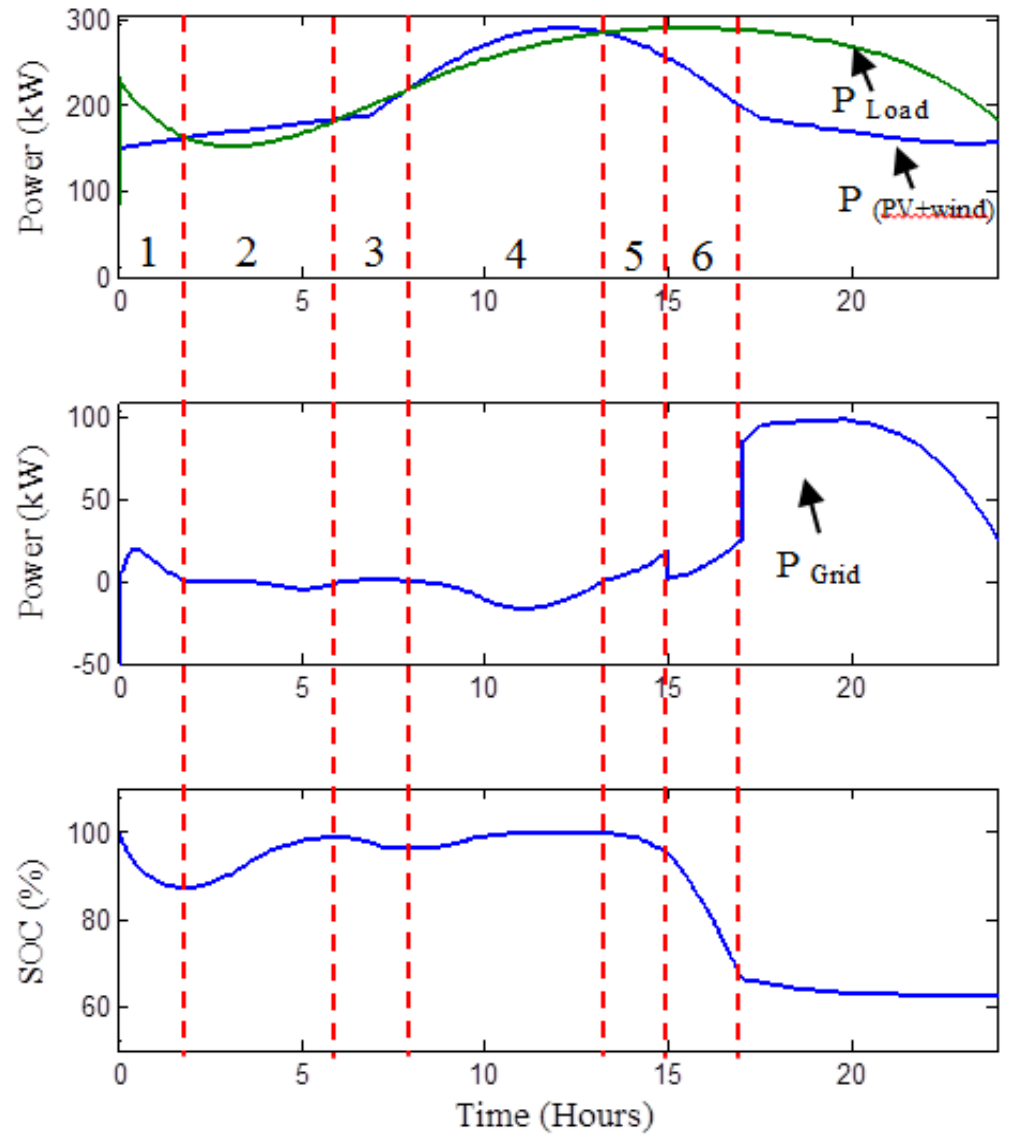

Figure 6.6.1: Case study 1, dynamic operation of the developed algorithm in a one-day period

Figure 6.6.1 is divided into 6 sections to illustrate the operation of the battery at the different 4 possibilities stated above. Section 1, section 3 and section 5 of the figure represent the same state when there is a deficiency in renewable power not during the peak hour. Hence, fuzzy is used to determine the percentage of power the battery will share with the grid in order to minimize the power taken from the grid and at the same time make sure the battery has enough energy for the coming peak period. To illustrate the use of forecasting, the SOC in section 3 and section 5 have a smaller slope than in section 1 , since it is near the peak hour, the battery will discharge slower. Section 2 
represents the state when renewable sources are satisfying loads and having excess energy that can be either sold to the grid or used to charge the battery. In this case, since this period does not fall in the peak period, it would be more beneficial to utilize the excess energy from renewable to charge the battery array. When the battery is charged to $100 \%$, the extra energy available is sold to the grid. During peak hour the battery has to satisfy a big portion of the load or sell its energy to the grid. Section 6 represents the peak hour. It can be observed from the SOC of the battery in that section, the slope is large and the battery is used as the main source to satisfy the loads during this period. During peak hour the battery SOC is reduced from $97 \%$ to $64 \%$. Therefore, the battery was successful in satisfying a big portion of the load during the peak hour. 


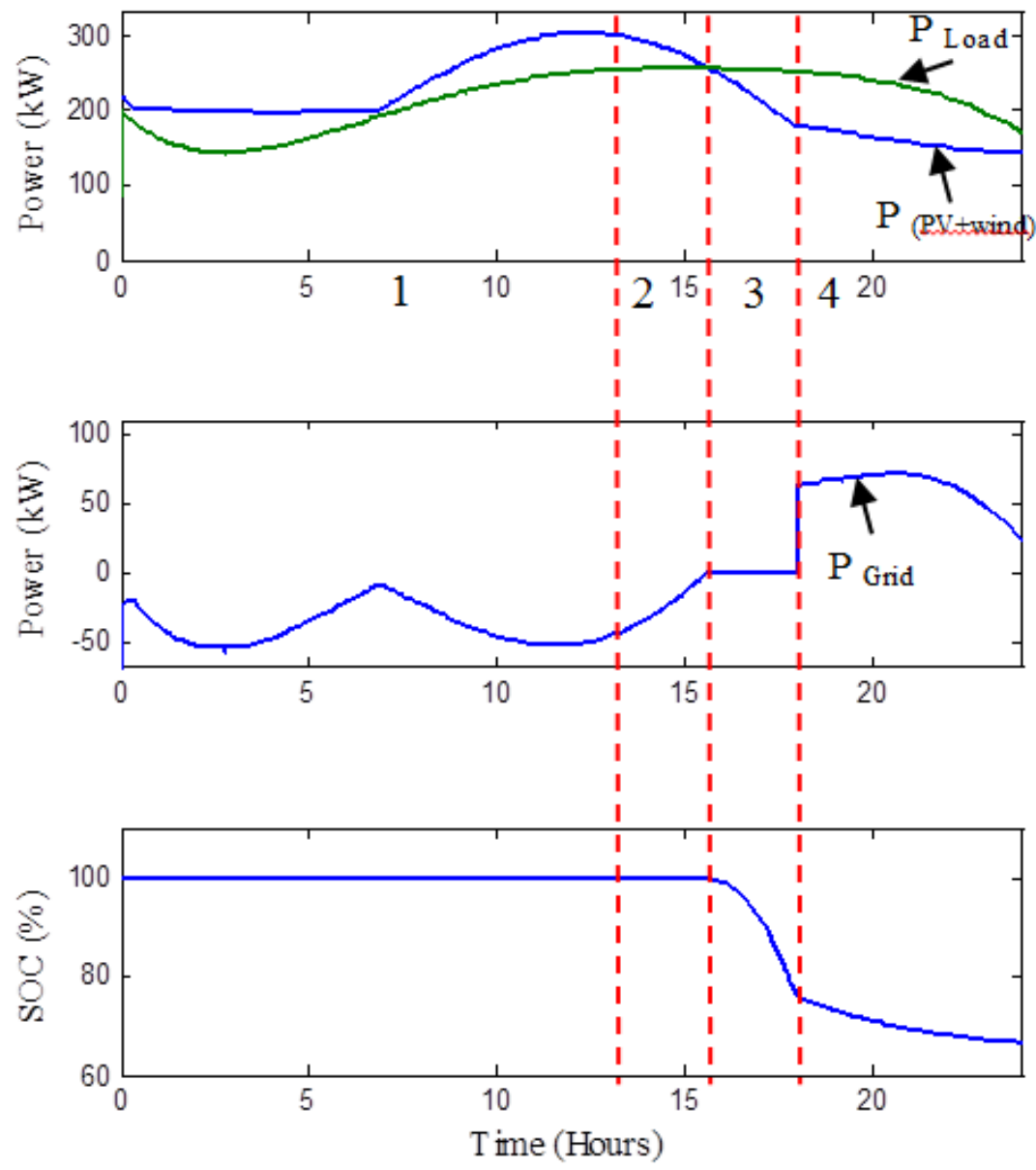

Figure 6.6.2: Case study 2, dynamic operation of the developed algorithm in a one-day period

Power flow operation of another day is shown in figure 6.6.2. Renewable power and load demand are different from the previous case. The graph is divided into 4 sections to illustrate the battery controller operation. The battery SOC is used to demonstrate the charge/ discharge operations.

Section 1 represents an Off-peak period and a surplus in power. The battery is assumed to have a $100 \%$ initial SOC and $P_{\text {load }} \geq P_{P V}+P_{\text {Wind }}$ Hence, the battery will not be discharged in section 1 since there is a surplus in power during this period. The surplus power from renewable energy sources will be directly injected to the grid. 
Section 4 represents the condition where $P_{\text {load }} \geq P_{P V}+P_{\text {Wind }}$ during the Off-peak period. The time left for the coming peak period is considered big according to the fuzzy membership function in Fig. 8.a. Based on the ratio between the energy available in the battery, calculated by the SOC\%, to the energy needed during the coming peak period, the battery is dynamically classified from very small power availability to big availability according to the fuzzy membership function in figure 6.5.1.b. Then, based on the fuzzy rules in Table 6.5.1, the battery will share some percentage of the load demand.

On the other hand, the peak period is treated differently. When there is a surplus in power, as in section 2, the energy is directly fed to the grid in case the battery has an SOC higher than $60 \%$. During this peak period, one of the main objectives is to minimize the power utilization from the grid. Therefore, the battery will satisfy the deficiency in power within its limits. Section 3, represents the condition where $P_{\text {load }} \geq P_{P V}+P_{\text {Wind }}$ during peak period. Priority is given to the battery to satisfy the load rather than the grid while considering the SOC of the battery. The battery will discharge to satisfy the load according to Figure 6.4.1.3. It can be seen that during the peak period the grid was not used to satisfy the load demand and the system is able to sell the surplus energy to the grid while satisfying its constraints. 


\section{CHAPTER 7}

\section{CONCLUSION}

The application of DC-DC boost converters as an interface between fuel cells and the DC bus in a DC zonal electric distribution system (DC ZEDS) have been investigated. Investigating the performance of the conventional DC-DC boost converter, it has been found that it yields a pulsating output current, which is not convenient for ship board applications. Hence, a modification has been applied to it in order to enhance its performance. The developed converter's performance has been compared to that of a conventional boost converter.

A novel smart-PID controller for optimal control of DC-DC boost converter used as voltage controller in PV systems was developed. This controller maximizes the stable operating range by using genetic algorithms (GA) to tune the PID parameters ultimately at various loading conditions. Then, a fuzzy logic approach is used to add a factor of intelligence to the controller such that it can move among different values of proportional gain $(\mathrm{Kp})$, derivative gain $(\mathrm{Kd})$ and integral gain $(\mathrm{Ki})$ based on the system conditions. This controller allows optimal control of boost converter at any loading condition with no need to retune parameters or possibility of failure. It also allows significant mitigation of large step changes by controlling the effect of the derivative part of the PID controller. Both simulation and experimental results prove the effectiveness and the validity of the controller.

A DC distribution system has been designed and implemented. Different aspects related to such design have like, DC bus voltage control grid connectivity have been 
addressed. The system under study is dependent mainly on sustainable energy sources. A smart controller that allows a quite stable wide range of loading has been designed and implemented to replace conventional PI and other controllers. Results show the validity of this controller and its importance, especially in the case of transients. A vector decoupling controlled SPWM rectifier has been designed and implemented to connect the DC system to the grid. Results show very good response for the rectifier during steady state and transient operation. Vector decoupling controlled SPWM bi-directional ACDC/DC-AC converter has been designed and implemented to allow power sharing between the $\mathrm{AC}$ and $\mathrm{DC}$ grids.

A unit commitment scheme for an $\mathrm{AC}$ distribution system involving sustainable energy sources has been designed. The commitment scheme aims at minimizing the cost of the power served to the loads and depending mainly on renewable energy sources. In case of deficiency in the power, a fuzzy system has been developed to control the sharing of the power between the grid and the battery system. A prototype system has been simulated to validate the applicability of the developed scheme. Results show accurate performance of the commitment scheme developed. 


\section{CHAPTER 8}

\section{RECOMMENDATIONS FOR FUTURE WORK}

The converters developed in this thesis have a maximum power capability of 5 $\mathrm{kW}$ and operate at relatively low frequencies. In case of designing a higher power converter, it is advised to seek topologies that have low power losses and operate at higher frequencies. Semiconductor switches are the main contributor for losses in a converter. In case of a buck converter, the switch will suffer high voltage stress as it turns ON and OFF. Switching losses are divided into three components; turn ON losses, turn OFF losses and conduction losses. The turn ON and turn OFF losses depend on the gate circuit design and the voltage across the terminals of the IGBT. If the gate circuit is designed to have a slow turn ON, then the gate to emitter voltage of the IGBT will charge slower causing the IGBT to have a longer transition time to enter saturation mode where it acts as almost a short circuit. During this transition time, the IGBT is in the active mode where it acts as a variable resistor that is changing its resistance from several mega ohms to almost zero ohms; imitating switch behaviour. The opposite will happen as the IGBT closes. The gate to emitter voltage of the IGBT will drop causing the IGBT to be open circuit, attain a high resistance across its terminals. Therefore, if the gate circuit is designed to have a low turn OFF time, then the IGBT will take longer time to exit the saturation mode and enter the active mode where its resistance is increased to act as open circuit. The IGBT turn OFF by discharging the voltage across its terminals and turns ON by charging the voltage across its terminal. Hence, the voltage across the terminals of the 
IGBT and the turn ON/OFF durations will determine the amount of power losses during these two transitions.

Designing a converter can easily get very complicated since the operation of the converter is not the only concern. Electromagnetic compatibility (EMC) is another design factor that cannot be ignored. Now EMC is regulated through standards. This makes the design of the converter very challenging especially if the converter is operated at high frequency, in the range of $100 \mathrm{kHz}$ and above. The sub-harmonic associated with the fundamental frequency will have a significant impact on the EMC performance. Voltage ringing associated with IGBTs switching and diodes yield very high voltage noise at high frequencies. Therefore, from EMC point of view, the slower the switch turns ON and OFF, the lower $\mathrm{dV} / \mathrm{dt}$ across its terminals, the lower noise and ringing. However, slowing down switch turn ON/OFF time increases the losses. Resonant converters such as the zero voltage switching (ZVS) full bridge converter can be used to either step up or step down voltage. These converters has multiple advantages over the conventional single switch converters or the hard switched full bridge converters. It can achieve high efficiency, since it switches at zero voltage. Hence, its switches theoretically have zero turn ON/OFF losses. At high power and high frequency operations, such topology is required since the turn ON and turn OFF losses of a semiconductor could be significant. It also reduces the stress on switches allowing less cooling and smaller heat sink. 


\section{REFERENCES}

[1] J. Carr, J. Balda and H. Manooth, "A Survey of Systems to Integrate Distributed Energy Resources and Energy Storage on the Utility Grid," in IEEE 2008 Energy 2030 Conf., 2008, Georgia, USA.

[2] H. Puttgen, P. MacGregor, F. Lambert, "Distributed Generation: Semantic Hype or the Dawn of a New Era," IEEE Power and Energy Magazine, vol. 1, no. 1, pp. 22-29, Jan-Feb 2003.

[3] R. Lawrence, S. Middlekauff, "Distributed Generation: The New Guy on the Block," in IEEE Industry Applications Society 50th Annual Petroleum and Chemical Industry Conf., pp. 223-228, Sept. 2003.

[4] K. Drenten, "Landmark AEP-sponsored Galapagos wind project starts operation," AEP Now, American Electric Power's Monthly Employee Magazine, October 18 th 2007.

[5] S. Barsali, M. Ceraolo, P.Pelacchi, and D. Poli, "Control techniques of dispersed generators to improve the continuity of electricity supply," in IEEE PES Winter Meeting, New York, NY, USA, pp. 789-794, Jan. 2002.

[6] Y. Li, and C. Kao "An Accurate Power Control Strategy for Power-Electronics interfaced Distributed Generation Units Operating in a Low-Voltage Multibus Microgrid," IEEE Trans. on Power Electronics, vol. 24, no. 12, pp. 2977-2988, Dec. 2009. J. Hammerstrom, "AC Versus DC Distribution Systems --- Did We Get Right?," IEEE Power Engineering Society General Meeting, 2007, pp. 1-5

[7] K. Engelen, E. L. Shun, P. Vermeyen, L. Pardon, R. D'hulst, J. Driesen and R. Belmans, "The Feasibilty of Small-Scale Residential DC Distribution Systems" IEEE Industrial Electronics Conf., IECON, 2006, pp. 2618-2623

[8] Nilsson and A. Sannino, "Efficiency analysis of low- and mediumvoltage dc distribution systems," IEEE PES General Meeting, 2004.

[9] Salomonsson and A. Sannino, "Low-Voltage DC distribution system for commercial power systems with sensitive electronic loads," IEEE Trans. on power delivery, vol. 22, no. 3, pp. 1620-1627, July 2007

[10] D. Salomonsson, L. Soder and A. Sannino, "Protection of low -voltage DC microgrids," IEEE Trans. on power delivery, vol. 24, no. 3, pp. 1045-1053, July 2009

[11] M. E. Baran and N. R. Mahajan, "DC Distribution for industrial systems: opportunities and challenges," IEEE Trans. on industrial applications, vol. 39, no. 
6, pp. 1596-1601, November/December 2003

[12] Sannino, G. Postiglione and M. H. J. Bollen, "Feasibility of a DC network for commercial facilities," IEEE Trans. on industry applications, vol. 39, no. 5, pp. 1499-1507, September/October 2003

[13] M. Brenna, E. Tironi and G. Ubezio, "Proposal of a local dc distribution network with distributed energy resources," in Proc. of 11th International Conference on Harmonics and Quality of Power, pp. 397-402, 2004.

[14] P. Karlsson and J. Svensson, "DC bus voltage control for a distributed power system," IEEE Trans. Power Electronics, vol. 18, no. 6, pp.1405-1412, November 2003.

[15] P. Mattavelli, L. Rossetto, G. Spiazzi and P. Tenti, "General-purpose fuzzy controller for DC-DC converters," IEEE Transaction on Power Electronics, vol. 12, no. 1, pp. 79-86, 1997.

[16] M. H. Rashid, Power Electronics Handbook, California: ACADEMIC PRESS, 2001.

[17] J. G. Ciezki and R. W. Ashton, "Selection and stability issues associated with a navy shipboard DC zonal electric distribution system," IEEE Trans. on Power Delivery, vol. 15, no. 2, pp. 695-669, Apr. 2000.

[18] J. Mahdavi, A. Emadi and H. A. Toliyat, "Application of State Space Averaging Method to Sliding Mode Control of PWM DC/DC Converters," in Proc. of IEEE Industry Applications Society Annual Meeting, pp. 820-827, Louisiana, Oct. 5-9, 1997.

[19] T. Khatib, A. Mohamed and N. Amin, "A new controller scheme for photovoltaics power generation systems," European Journal of Scientific Research, vol. 33, no. 3, pp. 515-524, 2009.

[20] J. Santos, F. Antunes, A. Chehab and C. Cruz, "A maximum power point tracker for PV systems using a high performance boost converter," Solar Energy, vol. 80, pp. 772-778, 2006.

[21] C. Elmas, O. Deperlioglu, H. Sayan, "Adaptive fuzzy logic controller for DC-DC converters,” Expert Systems with Applications, vol. 36, pp. 1540-1548, 2009.

[22] M. Villalva, J. Gazoli and E. Filho, "Comprehensive approach to modeling and simulation of photovoltaic arrays," IEEE Transaction on Power Electronics, vol. 24, no. 5, 2009. 
[23] A. H. F. Dias and J. A. de Vasconcelos, "Multiobjective Genetic Algorithms Applied to Solve Optimization Problems," IEEE Transactions on Magnetics, vol. 38, no. 2, pp. 1133-1136, 2002.

[24] R. Gutman, "Application of line loadability concepts to operating studies", IEEE Transactions on Power Systems, Volume 3, Issue 4, Nov. 1988 Page(s):1426 1433

[25] R.P. Klump, T.J. Overbye, "Assessment of transmission system loadability", IEEE Transactions on Power Systems, Volume 12, Issue 1, Feb. 1997 Page(s): $416-423$

[26] B. Venkatesh, R. Ranjan, H.B.Gooi, "Optimal reconfiguration of radial distribution systems to maximize loadability", IEEE Transactions on Power Systems, Volume 19, Issue 1, Feb. 2004 Page(s):260 - 266

[27] R. Gutman, P.P. Marchenko, R.D. Dunlop, "Analytical Development of Loadability Characteristics for EHV and UHV Transmission Lines", IEEE Transactions on Power Apparatus and Systems, Volume PAS-98, Issue 2, March 1979 Page(s):606 - 617

[28] P.C. Krause, O. Wasynczuk, S.D. Sudhoff, "Analysis of electric machinery and drive systems", IEEE Press, Wiley-Interscience, Second edition, 2002

[29] N. Mohan, T.M. Undeland, W.P. Robbins, "Power electronics: converters, applications, and design", John Wiley \& sons, Third edition, 2002

[30] IEEE Recommended Practices and Requirements for Harmonic Control in Electric Power Systems, IEEE Std 519-1992.

[31] "BP 175I solar module data sheet", BP Solar USA (www.bp.com)

[32] Nilsson and A. Sannino, "Efficiency analysis of low- and medium voltage dc distribution systems," IEEE PES General Meeting, 2004.

[33] Y. M. Atwa, E. F. El-Saadany, M. A. Salama and R. Seethapathy, "Optimal Renewable Resources Mix for Distribution System Energy Loss Minimization," IEEE Trans. on Power Systems, vol. 25, pp. 360-370, Feb. 2010.

[34] M. Lisierre, T. Sauter and J. Y Hung, "Future Energy Systems: Integrating Renewable Energy Sources into the Smart Power Grid Through Industrial Electronics," in IEEE Industrial Electronics Magazine, vol. 4, pp. 18-37, March 2010

[35] S. C. Smith, P. K. Sen, B. Koroposki and K. Malmedal, "Renewable energy and 
energy storage systems in rural electrical power systems: Issues, challenges and application guidelines," in Proc. Rural Electric Power Conference (REPC), May 2010, pp. B4-B4.7.

[36] M. A. Wahab, M. M. Hamada and A. Mohamed (El-Tallawy) "Artificial Neural Network and Non-linear Models for Prediction of Transformer Oil Residual Operating Time," Electr. Power System Research (EPSR), vol. 81, pp. 219-227, Jan. 2011 
VITA

\section{MOHAMED ELSHAER}

1989

2007-2008

2008

2006-2010

2008-2011
Born, Alexandria, Egypt

Assistant Engineer at Hamilton Sundstrand, Miramar, Florida.

Undergraduate research scholar at the Office of Naval Research, Philadelphia, Pennsylvania.

Bachelor of Engineering in Electrical Engineering, Florida International University

Undergraduate research scholar and then a graduate Research Assistant at the Energy Systems Research laboratory, Department of Electrical and Computer Engineering, Florida International University, Miami, Florida

\section{PUBLICATIONS}

1. M. Elshaer, A. Mohamed, and O. Mohammed, "Grid Connected DC Distribution System for Efficient Integration of Sustainable Energy Sources," presented at the Power Systems Conference and Exposition (PSCE), 2011 IEEE/PES, Phoenix, Arizona, USA 20-23 May 2011.

2. M. Elshaer, A. Mohamed and O. Mohammed, "Smart Optimal Control of DC-DC Boost Converter in PV Systems," presented at the Transmission and Distribution Conference and Exposition: Latin America (T\&D-LA), 2010 IEEE/PES, vol., no., pp.403-410, 8-10 Nov. 2010.

3. M. Elshaer, A. Mohamed and O. Mohammed, "Integration of Sustainable Energy Sources into DC Zonal Electric Distribution Systems," presented at Power and Energy Society General Meeting, 2011 IEEE/PESGM, Detroit, Michigan, USA.

4. Mohamed A. Elshaer, Ahmed A. Mohamed and Osama A. Mohammed, "Smart Operation for AC Distribution Infrastructure Involving Hybrid Renewable Energy Sources," presented at the $18^{\text {th }}$ World Congress, Milano, Italy, Aug. 28-Sept.2.

5. A. Mohamed, Mohamed. Elshaer and Osama Mohammed, "Bi-Directional AC-DC/DCAC converter for Power Sharing of Hybrid AC/DC Systems," presented at the power and 
Energy Society General Meeting, 2011 IEEE/PESGM, Detroit, Michigan, USA 24-29 July 2011.

6. A. Mohamed, M. Elshaer and O. Mohammed, "Reactive Power Compensation Control for Stand-Alone Synchronous Generator-Based Wind Energy Conversion Systems," presented in the Industrial Electronic Society Conf., IECON, Phoenix, AZ, USA, Nov. 7$10,2010$.

7. A. Mohamed, M. Elshaer, O. Mohammed, "High-quality integration of fuel cells energy into electric grids," in Proc. Of 4th International Symposium on Resilient Control Systems, ISRCS 2011, Boise, Idaho, USA, Pages 89-84, IEEE Xplore DOI 10.1109/ISRCS.2011.6016095, Aug 9-11, 2011.

8. A. Mohamed, M. Elshaer and O. A. Mohammed, "Protection of Bi-Directional ACDC/DC-AC converter in Hybrid AC/DC Microgrids ," IEEE SoutheastCon 2012, Orlando, Florida, USA, March 15-18, 2012.

9. Ali KashefiKaviani, Mohamed Elshaer, Osama Mohammed, "Enhancing loading limitations in PV systems," presented at the Industrial Electronic Conf., IECON 2010, Phoenix, AZ, 7-10 Nov., 2010.

10. Amin, Mahmoud; Elshaer, Mohamed; Mohammed, Osama, "DC Bus Voltage Control for PV Sources in a DC Distribution System Infrastructure," PESGM 2010 conference, IEEE, Minneapolis, USA, vol., no., 25-29 Jul. 2010.

11. Elshaer, M.; Mohamed, A.; Mohammed, O.A. "Smart optimal control of DC-DC boost converter for intelligent PV systems," Intelligent System Application to Power Systems (ISAP), 2011 16th International Conference on , pp.1-6, 25-28 Sept. 2011 ID: 10.1109/ISAP.2011.6082252, Crete, Greece. 